\title{
Cristiane Ortigosa
}

\section{Doppler venoso fetal na insuficiência placentária: relação com o pH no nascimento}

Tese apresentada à Faculdade de Medicina da Universidade de São Paulo para obtenção do título de Doutor em Ciências

Programa de: Obstetrícia e Ginecologia

Orientadora:

Prof ${ }^{a}$. Dr ${ }^{a}$. Roseli Mieko Yamamoto Nomura 
Dados Internacionais de Catalogação na Publicação (CIP)

Preparada pela Biblioteca da

Faculdade de Medicina da Universidade de São Paulo

Creprodução autorizada pelo autor

\section{Ortigosa, Cristiane}

Doppler venoso fetal na insuficiência placentária : relação com o pH no nascimento / Cristiane Ortigosa. -- São Paulo, 2012.

Tese(doutorado)--Faculdade de Medicina da Universidade de São Paulo.

Programa de Obstetrícia e Ginecologia.

Orientadora: Roseli Mieko Yamamoto Nomura.

Descritores: 1.Ultrassonografia doppler 2.Insuficiência placentária 3.Hipoxia fetal 4.Circulação hepática 5.Veias umbilicais

USP/FM/DBD-069/12 
Dedicatória 
Aos meus pais, Antônio e Cristina, exemplos de luta, humildade e honestidade, por todo amor, dedicação e apoio. 
Agradecimentos 
À Profa . Dra. Roseli M. Y. Nomura, pela confiança em mim depositada, pela competência, apoio e disponibilidade constantes na orientação desta tese e pela amizade sincera de sempre, o meu agradecimento e a minha enorme admiração.

Ao Prof. Dr. Marcelo Zugaib, digníssimo Professor Titular de Obstetrícia do Departamento de Obstetrícia e Ginecologia da Faculdade de Medicina da Universidade de São Paulo, pelo estímulo à minha formação profissional e por todas as oportunidades concedidas, a minha renovada e eterna gratidão. 
Ao Giovane, mestre da paciência. Sempre compreensivo e carinhoso. Sem ele, tudo seria mais difícil

À minha irmã Andréia, minha afilhada Lavínia, minha amiga Isabel e a todos os meus familiares, por me apoiarem mesmo de longe, e pela compreensão nos momentos de ausência.

Aos maravilhosos amigos Marcelo Graziano, Thatianne C. Trindade, Antônio Amorim Filho, Raquel G. Ribeiro, Karen Abrão, Renata Lopes Ribeiro, Sâmia Albuquerque, dra Maricy Tacla e Andréia Sapienza, obrigada pelo carinho e lealdade.

Às colegas da Pós-Graduação, Tatiana Liao, Verbênia, Cristina Giglioti, Letícia Paiva, Priscila Beirigo, amigas queridas, que colaboraram de diversas maneiras neste trabalho.

Ao Prof. Dr. Seizo, Prof. Dr. Adolfo Liao, dra Iracema Peron, dr Marco Aurélio Galletta e dr Silvio Martinelli, pela valiosa apreciação desta pesquisa quando apresentada para Qualificação.

A todos os docentes e assistentes da Clinica Obstétrica, pelo apoio e incentivo na realização deste estudo e pelo ótimo convívio durante todos estes anos.

A todos colaboradores da Clínica Obstétrica, pela disponibilidade e ajuda prestimosas.

Aos residentes, internos e toda a equipe de enfermagem da Enfermaria e Ambulatório, pela amizade e estímulo.

A todas as gestantes e seus recém-nascidos, razão e motivação deste estudo, minha profunda gratidão. 
Esta dissertação ou tese está de acordo com as seguintes normas, em vigor no momento desta publicação:

Referências: adaptado de International Committee of Medical Journals Editors (Vancouver).

Universidade de São Paulo. Faculdade de Medicina. Divisão de Biblioteca e Documentação. Guia de apresentação de dissertações, teses e monografias. Elaborado por Anneliese Carneiro da Cunha, Maria Julia de A. L. Freddi, Maria F. Crestana, Marinalva de Souza Aragão, Suely Campos Cardoso, Valéria Vilhena. 3a ed. São Paulo: Divisão de Biblioteca e Documentação; 2011.

Abreviaturas dos títulos dos periódicos de acordo com List of Journals Indexed in Index Medicus. 


\section{SUMÁRIO}

\section{LISTA DE ABREVIATURAS E SIGLAS}

LISTA DE TABELAS

LISTA DE FIGURAS E GRÁFICOS

\section{Resumo}

\section{SUMMARY}

1. INTRODUÇÃO

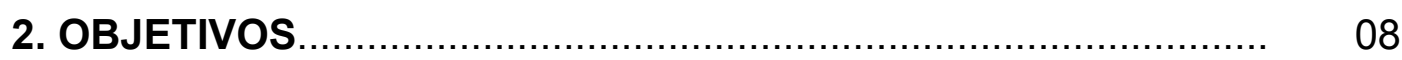

3. REVISÃO DA LITERATURA ................................................. 10

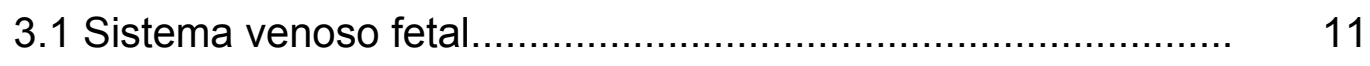

3.2 Estudos em animais............................................................. 20

3.3 Estudos em humanos.............................................................. 22

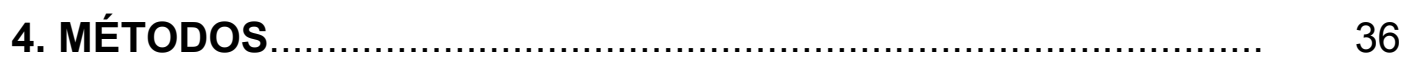

4.1 Critérios de inclusão........................................................... 37

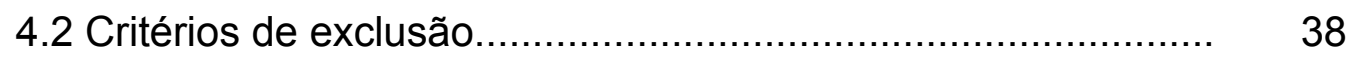

4.3 Coleta de dados.............................................................. 38

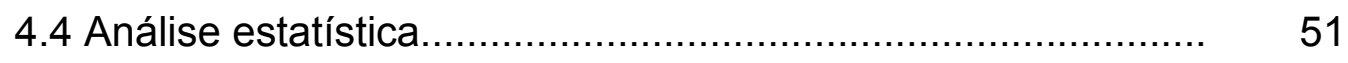

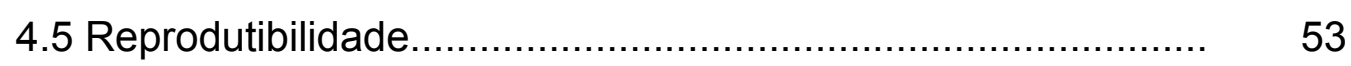

4.6 Caracterização da população............................................... 55

5. RESULTADOS

5.1 Análise geral dos testes de vitalidade fetal............................ 59

5.2 Correlação entre a dopplervelocimetria venosa e o pH no

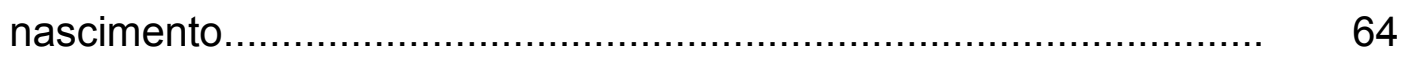

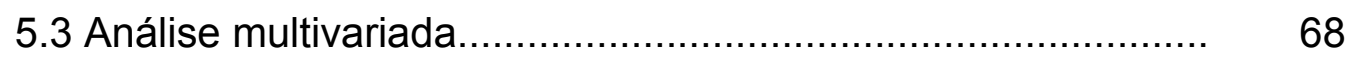

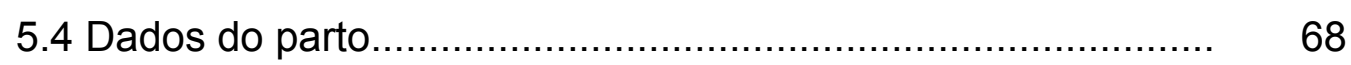

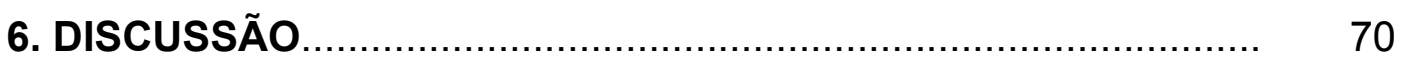

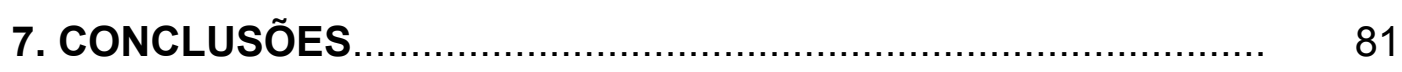

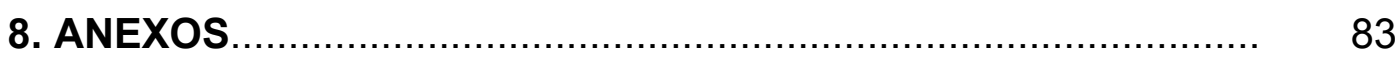

9. REFERÊNCIAS BIBLIOGRAFICAS ...................................... 91 


\section{LISTA DE ABREVIATURAS E SIGLAS}

ACM: artéria cerebral média

AU: artéria umbilical (s)

bpm: batimentos por minuto

CAPPesq: Comissão de Análise de Projeto de Pesquisa

D: diâmetro

DP: desvio padrão

DV: ducto venoso

DR: diástole reversa das artérias umbilicais

DZ: diástole zero das artérias umbilicais

et al.: e outros

FCF: frequência cardíaca fetal

h: coeficiente para o perfil da velocidade do sangue

HCFMUSP: Hospital das Clínicas da Faculdade de Medicina da Universidade de São Paulo

IC: intervalo de confiância

IG: idade(s) gestacional(is)

ILA: índice de líquido amniótico

IP: índice de pulsatilidade

IPV: índice de pulsatilidade para veias

$\mathrm{P}$ : percentil

PBF: perfil biofísico fetal

Q: volume de fluxo sanguíneo

Q/Kg: volume de fluxo sanguíneo por $\mathrm{Kg}$ de peso fetal

$\mathrm{n}$ : número

RCF: restrição do crescimento fetal

RCP: relação cérebro-placentária

rho: coeficiente de Spearman

$\mathrm{RN}$ : recém-nascido(s)

TAMxV: "time-averaged maximum velocity"

VCl: veia cava inferior

VP: veia portal principal

VPE: veia portal esquerda

VU: veia umbilical 


\section{LISTA DE TABELAS}

Tabela 1- $\quad$ Medidas de concordância intraexaminador para diâmetro e 54 TAMxV das VPE e VU em fetos com insuficiência placentária - HCFMUSP - 2010/2011

Tabela 2- Medidas de concordância interexaminadores para $\mathbf{5 5}$ diâmetro e TAMxV das VPE e VU em fetos com insuficiência placentária - HCFMUSP - 2010/2011

Tabela 3- Caracterização das gestantes incluídas no Grupo I (26 casos) e Grupo II (32 casos) quanto à idade materna, cor, nuliparidade, presença de doenças de base- HCFMUSP 2010/2011

Tabela 4- Distribuição dos casos de acordo com os resultados da cardiotocografia, perfil biofísico fetal e índice de líquido amniótico nos grupos analisados - HCFMUSP 2010/2011

Tabela 5- Distribuição dos casos de acordo com os resultados da dopplervelocimetria de artéria umbilical e artéria cerebral média fetal nos grupos analisados - HCFMUSP 2010/2011

Tabela 6- Distribuição dos casos de acordo com os resultados da dopplervelocimetria do ducto venoso fetal nos grupos analisados - HCFMUSP 2010/2011

Tabela 7- Distribuição dos casos de acordo com os resultados da dopplervelocimetria da veia portal esquerda fetal nos grupos analisados - HCFMUSP 2010/2011

Tabela 8- Distribuição dos casos de acordo com os resultados da dopplervelocimetria da veia umbilical fetal nos grupos analisados - HCFMUSP 2010/2011

Tabela 9- Rank correlations entre $\mathrm{o} \mathrm{pH}$ no nascimento e os parâmetros do Doppler venoso em gestações com insuficiência placentária - HCFMUSP 2010/2011

Tabela 10- Variáveis independentes identificadas no modelo de regressão logística múltipla com eliminação retrógrada de fatores associados com a acidemia - HCFMUSP 2010/2011

Tabela 11- Dados do parto, resultados perinatais e $\mathrm{pH}$ no nascimento nos grupos analisados - HCFMUSP 2010/2011 


\section{LISTA DE FIGURAS E GRÁFICOS}

Figura 1- Anatomia da veia umbilical (VU) e suas ramificações em 13 ducto venoso (DV) e veia portal esquerda (VPE)

Figura 2- $\quad$ Dopplervelocimetria da artéria umbilical em alça livre do $\mathbf{4 2}$ cordão umbilical próximo à inserção placentária

Figura 3- Dopplervelocimetria da artéria cerebral média em sua 43 porção inicial com ângulo de insonação inferior a 20 graus

Figura 4- Dopplervelocimetria do Ducto Venoso em sua porção 44 inicial, em corte transverso do abdome fetal

Figura 5- Imagem ultrassonográfica do abdome fetal com (B) e sem (A) mapeamento colorido de fluxo. VPE: veia portal esquerda; VU: veia umbilical; DV: ducto venoso; EST: estômago

Figura 6- Dopplervelocimetria da veia portal esquerda no abdome 46 fetal com medidas de velocidade $(A)$ e do diâmetro dos vasos (B). VPE: veia portal esquerda; VU: veia umbilical.

Figura 7- $\quad$ Dopplervelocimetria da veia umbilical no abdome fetal com $\mathbf{4 8}$ medidas de velocidade $(A)$ e do diâmetro do vaso (B). VU: Veia umbilical

Gráfico 1- Correlação entre os valores do $\mathrm{pH}$ no nascimento e o 65 escore-zeta do índice de pulsatilidade para veias do ducto venoso - HCFMUSP 2010/2011

Gráfico 2- Correlação entre os valores do $\mathrm{pH}$ no nascimento e o 66 escore-zeta da TAMxV da veia portal esquerda HCFMUSP 2010/2011

Gráfico 3- Correlação entre os valores do $\mathrm{pH}$ no nascimento e $0 \quad \mathbf{6 7}$ Fluxo/peso na VPE - HCFMUSP 2010/2011

Gráfico 4- Correlação entre os valores do $\mathrm{pH}$ no nascimento e $0 \quad 67$ Fluxo/peso na VU - HCFMUSP 2010/2011 


\section{RESUMO}

Ortigosa C. Doppler venoso fetal na insuficiência placentária: relação com o pH no nascimento [tese]. São Paulo: "Faculdade de Medicina, Universidade de São Paulo"; 2012.

OBJETIVO: O presente estudo, realizado em gestantes de alto risco com diagnóstico de insuficiência placentária, tem como objetivo avaliar o fluxo sanguíneo fetal na veia portal esquerda (VPE), veia umbilical (VU) e ducto venoso (DV), e estabelecer quais parâmetros associam-se com a acidemia fetal no nascimento. MÉTODO: Pesquisa prospectiva envolvendo 58 gestantes, classificadas segundo a presença ou ausência do diagnóstico de acidemia no nascimento, de acordo com o pH no sangue da artéria umbilical, constituindo-se de: Grupo I: 26 casos (acidemia- $\mathrm{pH}<7,20$ ) e Grupo II: 32 casos ( $\mathrm{pH}$ normal- $\mathrm{pH} \geq 7,20$ ). Foram excluídos da pesquisa os casos com diagnóstico pós-natal de anomalia do $\mathrm{RN}$ e aqueles em que não se obteve a mensuração do $\mathrm{pH}$ no nascimento. As seguintes variáveis dopplervelocimétricas da VPE e VU foram comparadas entre os grupos: escore-zeta da TAMxV (time averaged maximum velocity) (cm/s), Q/Kg (fluxo sanguíneo por $\mathrm{Kg}$ de peso fetal) $(\mathrm{ml} / \mathrm{min} / \mathrm{kg}$ ) e presença de pulsatilidade; e o escore-zeta do índice de pulsatilidade para veias (IPV) do DV. RESULTADOS: O escore-zeta da TAMxV (rho=0,392, $\mathrm{P}=0,002)$ e o $\mathrm{Q} / \mathrm{Kg}$ da VPE (rho=0,274, P=0,037), o escore-zeta do IPV do DV (rho=-0,377, $P=0,004$ ) e o $Q / K g$ da VU (rho=0,261, $P=0,048$ ) apresentaram correlação significativa com o pH no nascimento. Realizando-se a análise de regressão logística multivariada, as variáveis independentes que restaram no modelo final para a ocorrência de acidemia no nascimento $(\mathrm{pH}<7,20)$ foram: escore-zeta da TAMxV da VPE (OR=0,41; IC95\% 0,25 a $0,71 ; P=0,001)$ e fluxo reverso na VPE (OR=0,004; IC95\% 0,00 a 0,15; $P=0,003)$, ambas demonstrando efeito protetor para acidemia. Com o presente modelo, constatou-se que $74,1 \%$ dos casos são corretamente classificados para acidemia no nascimento. CONCLUSÕES: pela análise do Doppler venoso fetal na insuficiência placentária constatou-se que a acidemia no nascimento $(\mathrm{pH}<7,20)$ está associada de forma independente com o fluxo reverso na VPE e com o escore-zeta da TAMxV da VPE, ambos demonstrando efeito protetor com redução do risco para a acidemia.

\section{Descritores: 1.Ultrassonografia Doppler 2.Insuficiência Placentária 3.Hipoxia fetal 4.Circulação Hepática 5.Veias Umbilicais}




\section{SUMMARY}

Ortigosa C. Fetal venous Doppler in pregnancies with placental dysfunction: correlation with pH at birth [thesis]. São Paulo: "Faculdade de Medicina, Universidade de São Paulo"; 2012.

OBJECTIVE: This study, conducted in high-risk pregnancies with placental insufficiency, aims to avaliate blood flow in the fetal left portal vein (LPV), umbilical vein (UV) and ductus venosus (DV), and establish which parameters are associated with acidemia at birth. METHOD: A prospective research involving 58 pregnant women, classified according to the presence or absence of the diagnosis of fetal acidosis at birth, according to $\mathrm{pH}$ in the blood of the umbilical artery, consisting of: Group I: 26 cases (acidemia, $\mathrm{pH}<7,20$ ) and Group II: 32 cases (normal $\mathrm{pH}, \mathrm{pH} \geq 7,20$ ). Exclusion criteria were patients who had postnatal diagnosis of abnormality of the newborn and those in which the $\mathrm{pH}$ measurement was not obtained at birth. The following Doppler variables of LPV and UV were compared between the groups: TAMxV (Time Averaged Maximum Velocity) (cm/s) zeta-score, $\mathrm{Q} / \mathrm{kg}$ (blood flow per $\mathrm{kg}$ of fetal weight) $(\mathrm{ml} / \mathrm{min} / \mathrm{kg})$ and presence of pulsatility; and DV pulsality index for veins (PIV) zetascore. RESULTS: LPV TAMxV zeta-score (rho=0.392, $P=0.002)$ and $Q / k g(r h o=0.274$, $\mathrm{P}=0.037$ ), DV PIV zeta-score (rho=-0.377, $\mathrm{P}=0.004$ ) and UV $\mathrm{Q} / \mathrm{kg}$ (rho=0.261, $\mathrm{P}=0.048$ ) showed significant correlation with $\mathrm{pH}$ at birth. Performing the multivariate logistic regression analysis, the independent variables that remained in the final model were: TAMxV of LPV zeta-score (OR=0.41; IC95\% 0.25 a $0.71 ; P=0.001)$ and reverse flow in LPV (OR=0.004; IC95\% 0.00 a $0.15 ; \mathrm{P}=0.003)$, both showing a protective effect to reduce the risk of acidemia. With this model, it was found that $74,1 \%$ of cases are correctly classified to birth acidemia. CONCLUSION: by analysis of fetal venous Doppler in placental insufficiency we found that acidemia at birth $(\mathrm{pH}<7.20)$ is independently associated with reverse flow in the LPV and LPV TAMxV z-score, both showing a protective effect with reduced risk for the event.

Descriptors: 1. Ultrasonography, Doppler 2.Placental Insufficiency 3. Fetal Hypoxia 4. Liver Circulation 5. Umbilical Veins 


\section{Introdução}


Diante da insuficiência placentária, é difícil a escolha do momento ideal do parto em fetos prematuros. A demora na resolução da gestação pode causar danos fetais e o parto precoce pode trazer complicações neonatais devido à prematuridade grave.

A restrição do crescimento fetal (RCF) causada pela disfunção placentária está associada a mudanças próprias nos padrões de fluxos arteriais e venosos das circulações fetal e fetoplacentária (1, 2). Para a vigilância do bem estar fetal, a dopplervelocimetria estuda o fluxo sanguíneo dos vasos fetais à procura dessas mudanças, que inicialmente refletem a adaptação do organismo fetal, e que, nas situações de maior gravidade, estão associadas a distúrbios metabólicos do concepto. As alterações dos exames de Doppler arterial, principalmente da artéria umbilical (AU) e da artéria cerebral média (ACM), são características de estágios precoces do comprometimento da função placentária, e frequentemente acompanham a fase de hipoxemia fetal $(3,4)$. A deterioração da circulação venosa, achado mais tardio, está comumente associada à ocorrência de hipoxia e acidemia fetais $(5,6)$. 
Os dados atuais sugerem que a avaliação da circulação venosa fetal pelo Doppler é bom método de vigilância do bem estar fetal $(6,8-10)$, e pode ajudar na tomada de decisões sobre o momento da resolução da gestação (11-13), reduzindo riscos de morbidade e mortalidade.

$\mathrm{Na}$ circulação fetal, a veia umbilical (VU) conduz o sangue rico em nutrientes e oxigênio, proveniente da placenta, para o organismo fetal. Ao adentrar no território hepático, a VU emite ramos para o lobo hepático esquerdo e, depois, emite uma intercomunicação vascular denominada ducto venoso (DV), que conecta a VU com a veia cava inferior ( $\mathrm{VCl})$. No território hepático ainda, após a saída do DV, a VU passa a ser denominada seio portal, ou de acordo com alguns autores, é chamada de veia portal esquerda (VPE) $(7,14,15)$.

A divisão do fluxo de sangue oriundo da VU, entre a VPE e o DV, pode ser indicador da estabilidade hemodinâmica fetal, pois o DV é a intercomunicação que direciona o sangue bem oxigenado e rico em nutrientes, via forame oval, diretamente ao miocárdio e cérebro fetais.

Estudos em ovelhas demonstram que a hipoxemia promove redução no fluxo sanguíneo umbilical destinado ao fígado. Aspecto semelhante é relatado em estudos em humanos, pela verificação da dilatação do DV (16). O custo deste aumento no fluxo ductal recai sobre a perfusão hepática. Essas mudanças hemodinâmicas levam a grande aumento na porcentagem de desvio em direção ao DV nas situações de insuficiência placentária, para manter o adequado suprimento de oxigênio aos chamados órgãos nobres. Essa diminuição do fluxo ao fígado é observada principalmente no lobo 
direito (17-19), pois o lobo esquerdo do fígado recebe sangue diretamente de ramos da VU, ramos esses que emergem antes do DV. Essa redistribuição do sangue oxigenado capacita o feto a sobreviver por um período de tempo considerável, especialmente em gestações precoces, antes da $30^{\mathrm{a}}$ semana. Não se pode excluir que os aumentos da resistência e viscosidade do sangue também possam influenciar na distribuição do fluxo sanguíneo entre fígado e DV, em adição à dilatação ductal $(20,21)$.

A insuficiência placentária cursa, com frequência, com redução no fluxo sanguíneo na VU de acordo com o peso fetal estimado, podendo surgir pulsações $(22,23)$. O débito cardíaco fetal é responsável pela distribuição do fluxo sanguíneo para a placenta, e no comprometimento deste território com aumento da sua resistência, a fração do débito cardíaco fetal destinado para a placenta, que é normalmente de um terço na maior parte da segunda metade da gravidez, e de um quinto próximo ao termo, se reduz, provocando a recirculação do sangue no corpo fetal. A redução do fluxo sanguíneo na VU parece ser evento precoce, podendo persistir por várias semanas antes do parto (24).

Ademais, em fetos com insuficiência placentária, verifica-se que o desvio de fluxo da VU para o DV aumenta para $39 \%$ comparado com o desvio de $25 \%$ no grupo controle, reduzindo o fluxo sanguíneo para o fígado fetal (25). Nas situações de maior gravidade, descreve-se, inclusive, fluxo retrógrado na VPE, havendo o aporte de sangue pouco oxigenado proveniente da veia portal principal em direção ao DV $(26,27)$. 
Além da evidente redução na circunferência abdominal, alterações na coagulação, hipoglicemia, baixa síntese protéica no fígado e mudanças em níveis séricos de lipídios são frequentemente observados em recém-nascidos (RN) com RCF grave, o que pode ser consequência da diminuição na perfusão hepática $(28,29)$.

Dois estudos mostram lesão hepática não relacionada a processos infecciosos em RN com RCF, que pode refletir as consequências da isquemia hepática grave no feto $(30,31)$. Além disso, se apenas em fetos com insuficiência placentária grave podemos ver fluxo reverso do sangue na VPE, uma pequena redução do fluxo na perfusão do fígado advindo da VU pode ocorrer em fetos com menor grau de disfunção placentária, que poderia levar a diminuição no volume hepático, com crescimento assimétrico e alterações no metabolismo a curto e longo prazos.

A diminuição na velocidade do fluxo no sistema venoso pode representar redução do retorno venoso. Estudos em animais mostram que um dos maiores determinantes do fluxo venoso umbilical é a resistência na circulação fetoplacentária (32). Na insuficiência placentária grave há aumento da resistência na circulação placentária, demonstrado pelo aumento do índice de pulsatilidade (IP) nas AU (1).

Na hipoxia fetal, a vasoconstricção arterial periférica pode resultar em aumento na pós-carga ventricular e na pressão diastólica final ventricular. Em consequência, durante a contração atrial no final da diástole, pode haver fluxo reverso de sangue no sistema venoso. Variações na pressão venosa umbilical afetam os dois caminhos de forma diferente. A redução na pressão 
venosa reduz a perfusão hepática mais do que o fluxo no DV, e essa redução implica aumento na resistência viscosa na vasculatura portal, resultando em aumento ainda maior no desvio.

A direção do fluxo na VPE pode refletir a presença de retorno venoso comprometido, demandando aumento compensatório de sangue vindo da veia portal para manter a pressão portal e umbilical, o que resulta na cessação do fluxo venoso umbilical para a VPE. Em estágio avançado de comprometimento, o fluxo reverso provoca retorno de sangue proveniente da veia portal principal ao DV (33).

A extração de oxigênio pelo fígado é modesta (10 a 15\% de redução na saturação de oxigênio) (34), o que significa que o sangue proveniente das veias hepáticas média e esquerda são importantes contribuintes de sangue oxigenado (35).

Em estágios finais, ocorre a diminuição da função cardíaca, levando à falência na acomodação da pré-carga cardíaca. Diferentemente do sistema arterial, as ondas de velocidade do fluxo venoso precordial têm um fluxo complexo trifásico, que refletem as mudanças de pressão no átrio direito durante o ciclo cardíaco.

Estudos da velocidade do sangue nas $\mathrm{VU}$ e $\mathrm{VCl}$ têm demonstrado existir padrão característico durante a falência cardíaca fetal. Assim, a velocidade do sangue venoso no feto deve ser capaz de ajudar na vigilância da função cardíaca fetal em gestações de alto risco. Se o suprimento de oxigênio para o miocárdio alcança seu limite, a pressão venosa central 
aumenta. Isso pode ser refletido na velocidade sanguínea na $\mathrm{VCI}$, nas veias hepáticas e no DV. Até agora, existem poucas publicações que se focam nas mudanças específicas da velocidade venosa antes do óbito fetal $(36,37)$.

Embora a vigilância com o Doppler venoso tenha sido cada vez mais incorporada ao manejo de gestações com RCF, não existe um consenso uniforme se um simples parâmetro venoso pode predizer com acurácia o estado ácido-básico no nascimento. O papel da circulação hepática fetal pelo Doppler venoso no período pré-natal é tópico cujo conhecimento ainda encontra-se pouco estabelecido, principalmente no que diz respeito às modificações do fluxo sanguíneo em situações de insuficiência placentária. Não existem publicações sobre as alterações no fluxo da VPE em casos de insuficiência placentária, nem sobre o significado de suas alterações metabólicas no concepto. Justifica-se a presente proposta pela necessidade de maior entendimento sobre a circulação hepática fetal e a importância de se conhecer e descrever as alterações no fluxo da VPE, juntamente com a VU nos fetos de risco para a hipoxia fetal e sua relação com acidemia no nascimento. 
Objetivos 
Objetivos 9

O presente estudo, realizado em gestantes de alto risco em situações de insuficiência placentária, tem como objetivos:

1) Estudar o Doppler venoso fetal (DV, VPE e VU);

2) Estabelecer quais parâmetros associam-se com a acidemia fetal no nascimento. 
Revisão de Literatura 
Desde a década de 1980, exames de ultrassom com dopplervelocimetria estudam o sistema venoso fetal em humanos, nas gestações normais e patológicas, enquanto pesquisas experimentais em animais tentam elucidar com acurácia a anatomia e a hemodinâmica venosa fetal.

\subsection{Sistema venoso fetal}

A investigação ultrassonográfica do sistema venoso fetal tem se desenvolvido rapidamente desde sua introdução nos anos 1980 (38, 39). A elucidação da anatomia venosa normal, sua avaliação e manejo nos casos com RCF são ainda objetos de pesquisas.

Para o reconhecimento dos sonogramas normais e anormais do sistema venoso fetal, o conhecimento de sua anatomia e fisiologia é vital para se obter melhores informações e orientar as decisões, e dessa forma providenciar aconselhamento pré-natal apropriado quando algum problema é detectado.

A principal função do sistema venoso fetal é trazer sangue rico em oxigênio e nutrientes provenientes da placenta em direção ao coração fetal. Para facilitar esse fluxo sanguíneo, a resistência placentária baixa e o 
funcionamento cardíaco adequado devem trabalhar em sinergia. Um gradiente de pressão é criado entre os átrios e ventrículos, que reduz a précarga no sistema circulatório venoso e ajuda o fluxo sanguíneo seguir em direção ao coração. Esse gradiente de pressão é ainda mais acentuado pela estenose fisiológica do DV. Neste ponto, a velocidade do sangue sobe de 15 a $17 \mathrm{~cm} / \mathrm{s}$ no segmento intra-hepático da VU, para 65 a $75 \mathrm{~cm} / \mathrm{s}$ no $\mathrm{DV}$, causando aumento no gradiente de pressão umbilico-caval $(40,41)$.

Fluxo contínuo de sangue está presente na porção intra-hepática da VU e na veia porta e suas divisões. No feto normal, não há mudança de velocidade neste nível durante o ciclo cardíaco. Isso acontece provavelmente porque, sob condições normais, as pulsações na $\mathrm{VCl}$, que refletem o ciclo cardíaco fetal, não são transmitidas ao sistema porta ou para a VU. Isso acontece devido ao fígado e ao DV, com seu esfíncter, funcionar como uma barreira que evita a transmissão da pulsatilidade (42-44).

Do sangue que vai para o fígado, aproximadamente $75 \%$ abastece o lobo esquerdo, e $25 \%$ o direito. Desta forma, o sangue trazido pela VU representa $50 \%$ do suprimento sanguíneo para o lobo direito, enquanto o restante é trazido pela veia porta. Então, como já dito anteriormente, o fígado fetal é dividido em dois lobos fisiologicamente distintos, o esquerdo, suprido por sangue rico em oxigênio e nutrientes, e o direito, que recebe suprimento misto de sangue.

Além desses determinantes da dinâmica do fluxo sanguíneo, as regulações neural e endócrina do leito vascular hepático também têm seu papel (45). A vasculatura do sistema porta apresenta uma constrição mais 
pronunciada em resposta a estímulos adrenérgicos comparados ao DV (46). Assim, ela apresenta uma distribuição extremamente sensível às regulações ativa e passiva $(47,48)$.

\subsubsection{Veia umbilical}

No feto, o sangue rico em oxigênio e nutrientes proveniente da placenta é transportado por meio da VU para o organismo fetal. Ao adentrar o território hepático, a VU emite ramos para o fígado, e, depois, emite uma intercomunicação vascular denominada ducto venoso (DV), que conecta a VU com a VCI. Após a saída do DV, o segmento intra-abdominal da VU segue através do ligamento falciforme para se tornar a VPE ou seio portal. A VPE se estende até a bifurcação da veia portal principal com a veia portal direita (Figura1).

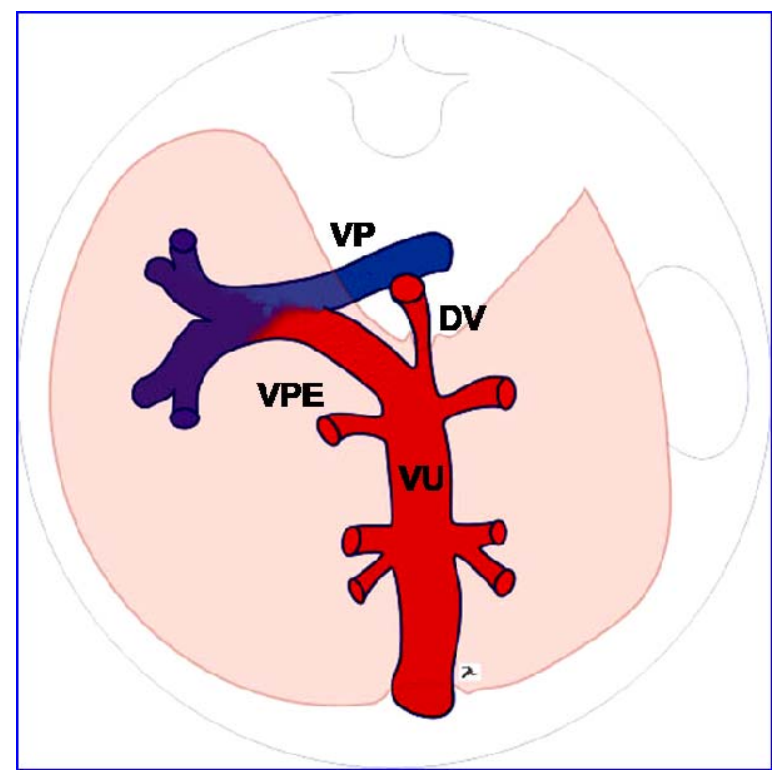

\section{Figura 1:}

Anatomia da veia umbilical (VU) e suas ramificações em ducto venoso (DV) e veia portal esquerda (VPE)(7)

VPD: veia portal direita

VP: veia porta

Em vermelho: sangue ricamente oxigenado proveniente da placenta

Em azul: sangue pobremente oxigenado

O padrão de fluxo ao Doppler na VU deve ser avaliado na sua porção intra-abdominal. Um fluxo contínuo está presente na porção intra-hepática da VU e na veia portal e suas divisões (49). 
Estudos in útero em humanos mostram que o fluxo na VU aumenta com o avançar da gestação, de 33-54 ml/minuto com 20-23 semanas, para 221-320 $\mathrm{ml} /$ minuto com 36-38 semanas. Entretanto, quando o fluxo de sangue é calculado por unidade de peso fetal, o fluxo venoso umbilical diminui de 117-125 ml/minuto/kg com 20-23 semanas, para 63-104 $\mathrm{ml} / \mathrm{minuto} / \mathrm{kg}$ com 36-38 semanas de gestação $(47,50)$.

Embora o fluxo contínuo reflita funcionamento normal do gradiente de pressão na VU, a presença de pulsações pode ser considerado normal até 15 semanas de gestação, antes que a baixa resistência vascular placentária seja estabelecida pela segunda onda de invasão trofoblástica (51).

A presença de pulsações na VU após o primeiro trimestre é sinal indicativo de falência cardíaca fetal e iminência de asfixia. Elas ocorrem por diferentes mecanismos: o DV possui um mecanismo de esfíncter na sua origem. Há especulações de que a imaturidade deste mecanismo de esfíncter na gestação inicial e a perda do seu controle nos fetos gravemente comprometidos por hipoxia crônica possam permitir a transmissão retrógada da pulsação para o sistema venoso umbilical. Assim, na gestação inicial e nos fetos seriamente comprometidos, pode existir fluxo reverso no DV (44).

Pulsações na VU são consideradas como último reflexo do aumento da pressão venosa central, observadas em estágios tardios do comprometimento fetal. Apresentam relação significante com o estado ácidobásico fetal. Entretanto, as pulsações na VU podem ter várias causas, incluindo oligohidrâmnio, alterações na pós-carga placentária, mudanças no diâmetro do DV e presença de movimentos respiratórios fetais. 


\subsubsection{Ducto venoso}

O DV é uma estrutura em forma de trompete com 1 a $2 \mathrm{~mm}$ de diâmetro, aproximadamente um terço do diâmetro da VU (52). Alguns pesquisadores citam a presença de um esfíncter que regularia o fluxo de sangue através do DV, e que um mecanismo dependente da concentração de oxigênio controlaria a atividade desse esfíncter. Entretanto, Mavrides et al. (2001), em seus estudos de histologia, demonstram que essa zona de estreitamento consiste em uma estrutura com várias camadas de elastina, sem a formação clássica de esfíncter. O restante do DV é composto de uma camada única de elastina muscular e células endoteliais (53).

A complexa hemodinâmica ductal, pelo seu formato único e sua não usual ramificação da $\mathrm{VU}$, tem sido pesquisada por vários estudos experimentais, que incluem estudos anatômicos e de sofisticadas simulações em computador. Esses estudos têm validado fórmulas que calculam o fluxo de sangue através do DV por meio do Doppler (54).

O DV conecta a porção intra-hepática da $\mathrm{VU}$ à $\mathrm{VCl}$, direcionando o sangue ao átrio direito e, então, através do forâmen oval, o sangue passa ao átrio esquerdo, permitindo que fração significativa de sangue umbilical rico em oxigênio e nutrientes atinja o miocárdio e cérebro fetais $(17,41,55)$. Portanto, do ponto de vista funcional, esse vaso tem importante papel na regulação da circulação do sangue oxigenado proveniente da placenta. Em fetos normais, $45 \%$ (20 semanas) e 20 a 30\% (próximo ao termo) do sangue da VU é direcionado pelo DV para o lado esquerdo do coração $(35,47)$. Os 
outros 70 a $80 \%$ fluem para o fígado, principalmente em direção ao lado direito do coração e, em seguida, via ducto arterioso, são direcionados para a aorta descendente. A redução da porcentagem de fluxo que se dirige ao DV no feto no termo ocorre pelo aumento proporcionalmente maior do fluxo da VU quando comparado ao aumento do fluxo observado no DV, conforme avança a gravidez (56).

No feto comprometido, existem inúmeros estudos demonstrando o maior desvio de sangue para o DV, do que em fetos sem comprometimento (57). Nos fetos com RCF, mais de $70 \%$ do fluxo da VU é desviado para o DV para manter um alto suprimento de oxigênio para órgãos essenciais, e a perfusão hepática é reduzida a 30\%, como demonstrado em estudos realizados com fetos animais e humanos $(16,58-61)$.

Estudos animais têm mostrado um aumento do desvio ao DV durante hipoxia fetal, o que sugere a dilatação ductal como componente da resposta ao sofrimento fetal (62). Informações sobre o fluxo sanguíneo no DV e suas mudanças no fluxo e porcentagem de sangue da VU desviado pelo DV são importantes para o entendimento da circulação fetal e dos ajustes que ocorrem na insuficiência placentária.

\subsubsection{Sistema portal}

Durante o desenvolvimento do fígado fetal, dois sistemas venosos opostos se desenvolvem: o aferente e o eferente. O aferente (VU, VPE e DV) e o eferente (veias hepáticas) formam dois sistemas posicionados nas porções caudal e cranial do fígado, respectivamente $(53,63)$. 
A veia portal principal entra no fígado no porta hepatis, ou fissura hepática, posteriormente à artéria hepática e ducto hepático comum. Esta fissura divide o fígado em seus lobos direito e esquerdo. O local da conexão da veia portal principal à VPE representa o ponto anatômico de divisão entre seus lobos direito e esquerdo, e está situado à direita e inferiormente à origem do DV.

No feto, a circulação destinada ao território hepático direito é dependente da oferta proveniente da VU e da veia portal principal. O fluxo sanguíneo proveniente da VU responde por 75 a $79 \%$ do suprimento do fígado, e o restante (21 a 25\%), é proveniente da veia portal principal (17).

A circulação hepática não é uniforme entre os seus lobos, que assim, diferem não apenas na sua coloração, mas também quanto à microarquitetura, nível de hematopoiese e conteúdo de ferro. Grande parte do suprimento sanguíneo da porção esquerda do fígado fetal é proveniente da VU. Apenas $6 \%$ do suprimento é proveniente da artéria hepática e $1 \%$ da veia portal principal, de tal forma que a maior parte do fígado fetal esquerdo recebe sangue rico em nutrientes e oxigênio provindos da placenta (64).

A porção direita do fígado fetal, por sua vez, recebe aporte sanguíneo proveniente da mistura do fluxo da veia portal principal, VPE e da artéria hepática, com menor suprimento de oxigênio e nutrientes. A veia portal principal supre exclusivamente o lobo direito do fígado. O sangue proveniente da veia portal principal contribui com cerca de $50 \%$ do fluxo destinado ao lobo direito. Isso constitui apenas $20 \%$ de todo suprimento venoso ao fígado, o restante vindo da VU e do principal tronco da VPE. 
O grande volume e concentração de oxigênio que é destinado ao lado esquerdo do fígado, comparado com o lado direito, faz com que aquele seja muito maior que este durante a vida fetal. Quando a VU e o DV se atrofiam, após o nascimento, esta situação se reverte, e o lobo direito torna-se maior que o esquerdo.

A VPE é considerado território "divisor de águas" (watershed) da circulação venosa fetal. Essa denominação se justifica por ser um local da circulação fetal que pode ter seu fluxo modificado de acordo com o estado hemodinâmico fetal. É o ponto de encontro entre os sistemas umbilical, com sangue proveniente da placenta, e portal, com fluxo proveniente do território intestinal e esplênico. Em situações normais, na segunda metade da gestação, o sangue flui, nessa veia, na direção da veia portal direita, garantindo o aporte de oxigênio e nutrientes para o desenvolvimento do fígado direito fetal $(27,33)$.

Essa particularidade da VPE, que intermedeia a circulação do tronco portal principal propriamente dito com o DV, faz com que o fluxo em seu interior se comporte de forma diversa de acordo com a magnitude da centralização da circulação fetal.

O sistema eferente do fígado está situado superiormente ao aferente, e consiste de três veias hepáticas principais: direita, esquerda e média. As veias hepáticas são facilmente encontradas ao Doppler, mas não são muito estudadas (65). Se comparadas com o DV e com a VCl, as veias hepáticas apresentam pequeno aumento no pico de velocidade e decréscimo nos índices de resistência com o avançar da idade gestacional (IG). Isso as 
tornam menos apropriadas para o monitoramento do bem estar fetal. Suas ondas são semelhantes às da $\mathrm{VCl}$, apresentando onda "a" reversa característica. Os sinais de comprometimento cardíaco observados nas veias hepáticas são semelhares aos que aparecem no DV e na VCI (65).

\subsubsection{Veia cava inferior}

A $\mathrm{VCl}$ é geralmente examinada no abdome fetal, caudalmente à entrada do DV, para evitar interferência dos vasos vizinhos na sua avaliação. Os valores de fluxo normal da VCI são bem estabelecidos. É normal observar a onda "a" negativa por causa de suas baixas velocidades (66-69).

O estudo da $\mathrm{VCl}$ tem tido sua importância reconhecida na última década nos casos com sofrimento fetal, principalmente no sentido de oferecer um método para se estimar a função cardíaca fetal $(70,71)$. Estudos da velocidade do sangue na $\mathrm{VCl}$ demonstram padrão característico durante a falência cardíaca fetal em fetos comprometidos com insuficiência placentária e hipoxemia grave (55).

O fluxo de sangue na veia cava torácica é caracterizado por um sistema duplo de fornecimento. Ele é composto de um fluxo de alta velocidade proveniente do DV, que flui pela porção esquerda dorsal da $\mathrm{VCl}$, e direciona-se pela cristia dividens em direção ao forame oval, e pelo fluxo de baixa velocidade proveniente da $\mathrm{VCl}$, que corre pela porção direita ventral da veia cava, e é dirigida em direção à valva tricúspide. O resultado final é um 
suprimento preferencial de sangue de alta qualidade para os órgãos "nobres", ou seja, para o cérebro e coração $(18,35,40,41)$.

\subsection{Estudos em animais}

Estudos em animais demonstram as adaptações hemodinâmicas venosas e arteriais provocadas pela hipoxia fetal. (72). Pelo grande valor e importância destes dados, o fluxo venoso fetal tem sido estudado em modelos animais com técnicas invasivas, que não podem ser reproduzidas em humanos, com o intuito de esclarecer os mecanismos fisiopatológicos da adaptação fetal à hipoxia.

Estudos pioneiros sobre a hemodinâmica venosa fetal são descritos por Edelstone et al., em 1978 (64). Esses pesquisadores usam microesferas radiomarcadas em 24 fetos de cordeiros, introduzidas na circulação fetal por meio de catéteres na aorta, $\mathrm{VCl}$, artéria carótida e VU. Demonstram que o fígado recebe grande fluxo de sangue, primariamente proveniente da VU (73\%), e em menor proporção da veia porta (18\%) e artéria hepática (9\%). O fluxo da veia porta é quase exclusivamente direcionado ao lobo direito do fígado.

Os efeitos da hipoxemia sobre o fluxo na VU são motivos de controvérsia. Em estudos com microesferas radiomarcadas, Morrow et al. (1990) (22) mostram, em fetos de cordeiros, pequena redução no fluxo sanguíneo na VU, de $184+/-28 \mathrm{ml} / \mathrm{min} / \mathrm{kg}$ para $175+/-21 \mathrm{ml} / \mathrm{min} / \mathrm{kg}$, medidos uma hora após a hipoxia. Arbeille et al. (1995) (73) demonstram 
diminuição de $10 \%$ no fluxo da VU após um minuto de compressão da aorta materna de cordeiros. Rudolph (1983) (17) e Vanhuisseling et al. (1991) (74) não encontram alterações no fluxo da VU durante a hipoxia fetal.

Essas diferenças são explicadas em parte, pelas diferentes intensidades ou na durações da hipoxia, pois o fluxo na VU tende a aumentar na reação inicial à hipoxemia, e aparentemente se reduz nos estágios finais da hipoxia. A bradicardia nos estágios finais da hipoxia fetal parece ser indicador confiável da hipoxia, tal como a gasometria arterial, predizendo resultados perinatais adversos (6).

Tchirikov et al. (2002) (75) realizam estudo em que colocam um stent no DV para promover o aumento de fluxo no DV em um dos fetos de gestação gemelar em nove ovelhas prenhas. Em outro grupo, com 17 ovelhas com prenhez gemelar, o DV de um dos fetos tem seu fluxo bloqueado por embolização por aproximadamente uma semana. Com a oclusão do DV (grupo embolização), há maior perfusão de sangue no fígado, o que aumenta em seis vezes a proliferação celular desse órgão e aumenta em duas vezes a proliferação do músculo cardíaco, músculos esqueléticos e rins, enquanto que nenhuma diferença é constatada na placenta. Com a diminuição do suprimento sanguíneo do fígado (grupo stent), há diminuição da proliferação celular no fígado, músculo e rins, e nenhuma diferença é relatada na placenta. Assim, os autores sugerem que a perfusão sanguínea hepática pode regular o crescimento fetal. Em estudo prévio, Tchirikov et al. (2001) (76) já haviam mostrado aumento significativo da proliferação celular 
em órgãos fetais após aumento da perfusão de sangue do fígado pela obstrução do DV.

\subsection{Estudos em humanos}

Em humanos, os primeiros estudos de dopplervelocimetria da circulação fetal são limitados apenas ao sistema arterial, e mostram a redistribuição na circulação arterial com a hipoxia fetal, revelando aumento da velocidade e diminuição da resistência ao fluxo nos vasos cerebrais. Apenas posteriormente, o sistema venoso fetal torna-se objeto de estudo com o Doppler in vivo em humanos. A primeira medida do fluxo sanguíneo na $\mathrm{VU}$, in útero, é publicada em 1979, por Gill et al. (77).

Durante as últimas décadas, muitos estudos em humanos têm focado o fluxo venoso fetal, obtidos de forma não invasiva por meio da dopplervelocimetria. No passado, os métodos utilizando o Doppler eram considerados de alta complexidade e requeriam equipamentos de maior custo, geralmente não disponíveis para prática clínica habitual. Atualmente, com a introdução de novas tecnologias, as limitações se reduziram, e o uso na rotina clínica tem sido cada vez mais universal.

Diversas abordagens para a avaliação do fluxo venoso estão atualmente em uso. Intervalos de referência, padrões de fluxo considerados normais e estudos de reprodutibilidade para os índices do Doppler venoso são obtidos por diversos autores. 


\subsubsection{Fluxo no sistema venoso fetal}

Em 1999, Barbera et al. (78), realizam estudo com o objetivo de determinar a relação entre o aumento no fluxo sanguíneo na $V U$ e o crescimento das medidas corporais de fetos humanos em gestações normais. Além disso, calculam a relação entre o aumento do diâmetro da VU e o aumento da velocidade no fluxo sanguíneo umbilical. Validam o estudo com um modelo em ovinos e estabelecem novas referências para valores de fluxo na $\mathrm{VU}$, em relação às circunferências cefálica e abdominal. $\mathrm{O}$ crescimento do diâmetro da VU é responsável pela maior parte do aumento no fluxo da VU. Esses resultados são concordantes com os encontrados por Gerson et al. (1987) (79), que previamente haviam demonstrado redução linear não significante do fluxo por kg de peso fetal durante a gestação. Gill et al. (1979) (77), e Sutton (80) também observam decréscimo gradual do fluxo de sangue na VU, até o termo, fato não observado no estudo de Kiserud et al. (2000) (47).

Lees et al. (1999) (81) realizam estudo semelhante ao de Barbera et al. (1999) (78) com moderna tecnologia de Doppler para a época. Ambos concordam que a quantificação do fluxo de sangue na VU tem boas acurácia e reprodutibilidade. No entanto, o estudo do fluxo sanguíneo no feto humano é complicado pela dificuldade e impraticabilicade em se obter medidas de fluxos e pressões. Modelos matemáticos têm sido usados para melhor entendimento da hemodinâmica em vários tratos da vasculatura fetal (82-85), bem como do sistema cardiovascular fetal completo (82, 86-88). Esses 
modelos têm diversos graus de detalhamento, de acordo com diferentes objetivos e métodos utilizados.

Baseando-se em observações clinicas, Penatti et al. (2003) (89), utilizam modelo matemático, e demonstram que o fluxo através do DV e VU aumenta com a IG (de aproximadamente 25 a $75 \mathrm{ml} / \mathrm{min}$ para aproximadamente 45 a $370 \mathrm{ml} / \mathrm{min}$, de 20 para 40 semanas de gestação), enquanto a proporção do fluxo desviado para o DV diminui (de 50\% para $20 \%$ neste mesmo período gestacional). Os resultados desse modelo matemático podem ser integrados às medidas do fluxo pelo Doppler tradicional para a obtenção de interpretação mais consistente dos padrões de fluxo.

Em estudo envolvendo 91 gestantes de baixo risco e fetos com peso adequado para idade gestacional na $36^{a}$ semana de gestação, Haugen et al. (2004) (14), estimam o fluxo na VU e veia porta nos lobos direito e esquerdo do fígado. Concluem que o suprimento venoso para o lobo esquerdo é proveniente, principalmente, da VU, e para o lobo direito, $50 \%$ da VU e os outros $50 \%$ da veia porta. Estudos em fetos de cordeiro demonstram que o lobo esquerdo do fígado fetal recebe sangue quase exclusivamente da VU. Edelstone et al. (1978) (64) calculam que a contribuição para o fluxo sanguíneo para o lobo esquerdo do fígado seria de $6 \%$ da artéria hepática e apenas $1 \%$ da veia portal principal. O lobo direito recebe uma mistura de sangue da VU, veia portal principal e artéria hepática. Em estudo de Bellotti et al. (2000) (57), é medida a distribuição do sangue da VU para o fígado fetal humano, durante a segunda metade da gestação, usando o Doppler. Esse 
estudo mostra a distribuição constante ao lobo esquerdo de, aproximadamente, $40 \%$ do fluxo da VU durante a gestação, e aumento na porcentagem do fluxo para o lado direito de $20 \%$ com 20 semanas para $45 \%$ no termo. $\mathrm{Na} 36^{\mathrm{a}}$ semana de gestação, a distribuição entre os dois lobos é quase igual à reportada por Bellotti et al. (2000) (90). Esses resultados são pouco diferentes dos de Haugen et al. (2004) (14), em que maior proporção do fluxo sanguíneo da VU se dirige para o lobo esquerdo do que para o direito. Haugen et al., em 2004 (14) comentam no seu trabalho as causas possíveis da superestimação do fluxo da VU para o fígado no trabalho de Bellotti et al., em 2000 (57).

Em 2005, Acharya et al. (91) constroem nova tabela com valores de referência para medidas seriadas do fluxo na VU, baseados em 511 exames longitudinais entre 19 e 42 semanas de gestação, em 130 gestantes de baixo risco.

Kessler et al., em 2007 (7, 92), recrutam 160 gestantes em situação de normalidade materna e fetal e realizam estudo longitudinal da velocidade de fluxo na VPE, incluindo cinco exames de Doppler com intervalos mensais, durante a segunda metade da gestação, a fim de estabelecer valores de referência para as velocidades pelo índice "time-averaged maximum velocity" (TAMxV). Baseados nos 554 exames de Doppler realizados, chegam aos seguintes valores: a TAMxV aumenta de $10,6 \mathrm{~cm} / \mathrm{s}$ para $14,2 \mathrm{~cm} / \mathrm{s}$, entre $21^{\mathrm{a}} \mathrm{e}$ $31^{\text {a }}$ semanas de gestação, se mantém estável até a $37^{a}$ semana, e então diminui até o termo. Obtém assim, os valores de referência para esse parâmetro na segunda metade da gravidez, em gestações de baixo risco. 
Nesse mesmo trabalho, esses autores encontram fluxo reverso na VPE em 2/160 fetos próximos ao parto ou durante movimentação respiratória sem sinais de comprometimento placentário ou comprometimento fetal hemodinâmico, ao contrário do estudo de Haugen et al. (2004) (93), no qual o fluxo era normal nos 91 fetos estudados com 36 semanas de gestação. Esse achado também está em discordância com estudos como os de Kilavuz et al. (2003) (27), Kiserud et al. (1999) (94) e Bellotti et al. (2000) (57), nos quais o fluxo reverso na VPE só ocorre em casos de comprometimento hemodinâmico fetal. Aproximadamente $70 \%$ dos casos apresentam fluxo sanguíneo pulsátil na VPE, achado semelhante ao de Vansplunder et al. (1994) (26). Havia sido previamente apresentado que na circulação de fetos comprometidos o padrão pulsátil na VPE é uma imagem inversa do DV. Esse estudo de Kessler et al. (2007) (95) indica que a transmissão do pulso do DV para a VPE pode, em alguns casos, acontecer em fetos não comprometidos, discordando dos estudos citados acima.

Ainda em 2007, Link et al. (96), realizam estudo com objetivo de determinar a relação entre o fluxo na $V U$ e o peso fetal em diferentes períodos no terceiro trimestre e assim, indiretamente avaliar o suprimento fetal de oxigênio próximo ao termo. Mostram que o fluxo na VU aumenta nas últimas semanas de gestação. Entretanto, quando comparado ao peso fetal, o fluxo na VU se reduz no final da gestação. A diminuição na relação fluxo VU/peso fetal reflete a redução na capacidade de transporte de oxigênio para o feto no final da gestação. Essa observação de velocidade constante de fluxo sanguíneo na VU e aumento no diâmetro da VU é concordante com outros estudos. 
Medindo o fluxo através da ultrassonografia nas $\mathrm{VU}$, veia portal principal, VPE e DV em 160 gestantes de baixo risco, Kessler et al., em 2008 (97), demonstram haver aumento da contribuição da veia portal na circulação hepática com o avançar da gestação. Com o avançar da IG, o fluxo total sanguíneo para o fígado diminuiu, a contribuição da veia porta aumenta e da VU diminui, enquanto a distribuição entre lobos esquerdo e direito mantém-se igual (60\% e $40 \%$, respectivamente). Quanto maior o fluxo da VU para o fígado, maiores os pesos ao nascimento e o índice ponderal neonatal. Interpretaram também esse aumento na contribuição da portal na circulação com um aumento na importância da circulação esplâcnica no final da gravidez como uma aproximação gradual para a circulação pós-natal.

\subsubsection{Fluxo venoso fetal na insuficiência placentária}

O fluxo da VU reflete o segmento placentário da circulação fetal e é crucial para o crescimento intrauterino. No final dos anos 1970, a velocidade de fluxo medida pelo Doppler combinada com a medida do diâmetro foi introduzida para avaliar o fluxo sanguíneo na VU (77). Recentemente, o método tem sido refinado para providenciar mais informações fisiológicas detalhadas e desenvolver uma nova ferramenta clínica $(47,78,98)$. A redução no fluxo sanguíneo na VU ocorre semanas antes que a RCF seja detectável pela biometria fetal convencional (38) e previamente a alterações significantes nos índices dopplervelocimétricos da $\mathrm{AU}$, sugerindo que a redução no fluxo fetoplacentário representa evento precoce na patogênese 
da RCF. Assim, as medidas do fluxo da VU podem ser úteis na vigilância de fetos sob risco de insuficiência placentária $(9,99)$.

A redução no fluxo da $\mathrm{VU}$ nos fetos com RCF é demonstrada por Laurin et al. (1987) (100), que utilizam tecnologia disponível para aquela época. Nesse trabalho, os fetos normais são comparados com fetos restritos em diferentes gravidades de acordo com o percentil do peso ao nascimento. Laurin et al. (1987) (100) também concordam com os achados de Ferrazzi et al. (2001) (98) de que o fluxo na VU teria melhor acurácia diagnóstica que IP da AU para predizer peso no nascimento, modo de parto, índices de Apgar e $\mathrm{pH}$ no nascimento. Concluem assim, que as mudanças na velocidade da VU podem representar vantagem diagnóstica na detecção de resultados perinatais adversos, por ser evento precoce na patogênese da RCF, levando à deprivação de nutrientes e oxigênio ao feto, e comprometendo seu potencial de crescimento. Evidência semelhante foi encontrada em estudo prospectivo realizado em 2000, por Ferrazzi et al. (101), que realizam exame de dopplervelocimetria em 37 fetos com RCF com objetivo de determinar se o fluxo na VU por peso fetal estaria reduzido. Encontram que, ajustado pelo peso, o fluxo na VU de fetos com RCF está sim reduzido se comparado aos adequados para a IG.

No ano seguinte, Rigano et al. (2001) (99), mostram que a redução no fluxo sanguíneo da VU é achado inicial nos fetos com RCF e pode persistir por muitas semanas até o parto. Essa redução no fluxo sanguíneo é devido à diminuição da velocidade sanguínea na VU. Esse estudo envolveu 21 fetos 
com RCF e alteração na dopplervelocimetria na $A U$, realizando neles ultrassonografias seriadas entre 23 e 36 semanas de gestação.

Hofstaetter et al. (2002) (102), investigando os sinais de descompensação cardíaca no Doppler venoso fetal para tentar predizer óbito em fetos gravemente comprometidos, realizam estudo prospectivo envolvendo 154 fetos com RCF, 37 destes com diástole reversa (DR) da AU. Encontram correlação significante entre a velocidade do sangue na VU e a resistência vascular placentária. $\mathrm{Na}$ veia hepática direita constatam diminuição significante no pico sistólico e na velocidade final da diástole, e aumento da velocidade máxima durante a contração arterial, além da presença de pulsatilidade. No DV verificam decréscimo de todas as velocidades e aumento da pulsatilidade. A veia hepática parece ser melhor preditora da mortalidade fetal que o DV. Mudanças na velocidade diastólica do sangue venoso e pulsação na VU são os parâmetros mais intimamente relacionados à mortalidade perinatal.

Boito et al. (2002) (50) mostram que as medidas no diâmetro da VU e sua TAMxV resultam em cálculo de fluxo de volume aceitável e reprodutível, que aumenta cerca de sete vezes entre a $20^{a}$ e $36^{a}$ semanas de gestação nos fetos normais. Nos fetos com RCF, o fluxo de volume é significantemente reduzido. Se calculado por peso fetal, os valores reduzem-se em $63,6 \%$ dos 33 casos avaliados. Concluem que as medidas de área e TAMxV da VU são reprodutíveis. Assim, o cálculo de volume de fluxo é aceitável para a prática clínica. Esse estudo concorda com estudos prévios que demonstram concordância excelente entre o Doppler e medidas invasivas de fluxo em 
humanos e animais (103-105). Considerando-se as medidas obtidas nesse trabalho na segunda metade de gravidez, observa-se diminuição significante no fluxo de sangue na VU relacionado ao peso fetal. Esses dados estão em desacordo com os obtidos por Sutton (1990) (80), e Barbera et al. (1990) (78), que encontram redução não significante no fluxo relacionado ao peso. Entretanto, Lingman et al. (1986) (106) também encontram redução significante. Esses propõem que a redução esteja associada ao aumento tanto no fluxo visceral quanto de extremidades, enquanto a gestação progride. Essa redistribuição do fluxo sanguíneo também é encontrada em outras espécies, e pode ser devido à discordância de crescimento entre placenta e do corpo fetal durante o terceiro trimestre da gestação.

Ainda em 2002, Di Naro et al. (9), realizam estudo longitudinal do fluxo sanguíneo na VU e suas mudanças em fetos normais e com RCF com Doppler da AU normal. Demonstram que o fluxo na VU normalizado para parâmetros biométricos é menor nos fetos com RCF do que em fetos saudáveis, mesmo na ausência de alterações de Doppler na AU. Esses achados concordam com os resultados de Ferrazzi et al. (2001) (98), mas estão em desacordo com autores que não encontram redução significante no fluxo de sangue na VU em casos de fetos com RCF mas com IP da AU normal. Lees et al. (1999) (81) demonstram que o parâmetro mais importante para o aumento no fluxo sanguíneo na $\mathrm{VU}$ em fetos normais seria o diâmetro da VU. Nesse, a área da VU é significantemente menor nos fetos com RCF do que nos com crescimento normal. Como Weissman et al. (1994) (107) já demonstram previamente, o tamanho da VU não muda significantemente durante o terceiro trimestre da gestação, então a redução do fluxo sanguíneo 
na VU nos fetos com RCF pode ser, em parte, explicado por variações em outros dois parâmetros: velocidade de fluxo e viscosidade sanguínea. Embora a velocidade de fluxo seja medida de difícil obtenção, parece que nos fetos com RCF há uma menor velocidade de fluxo na VU do que nos fetos saudáveis (81). Assim, esse estudo concorda com Ferrazzi et al. (2001) (98) e Jouppila et al. (1984) (21), que encontram nos fetos com RCF velocidade média de fluxo sanguíneo na $\mathrm{VU}$ menor do que nos fetos adequados para IG. Tanto Di Naro et al. (1999) (9) quanto Sutton et al. (1990) (80) concordam que o cálculo do fluxo de sangue na VU produz um índice melhor da perfusão placentária do que a velocidade da $\mathrm{AU}$.

Estudando o fluxo na VPE em 28 gestantes com alteração no fluxo da AU, Kilavuz et al. (2003) (27) encontram a VPE não pulsátil e com fluxo na direção normal em nove casos, pulsátil e reversa em 10 casos e reversa em nove casos. O fluxo reverso correlaciona-se significantemente com o aumento do índice de resistência nas AU. Sendo assim, nos casos extremos, o fluxo reverso na VPE direciona ainda mais sangue pelo DV, que nestes casos já está recebendo maior aporte sanguíneo proveniente da VU. No entanto, ao contrario do desejado, esse sangue é pouco oxigenado e pobre em nutrientes.

\subsubsection{Pulsações no sistema venoso fetal na insuficiência placentária}

Kiserud (2003) (33) estudam fetos com RCF, hidropsia não imune e teratoma sacrococcígeo e sugerem que a onda na VPE seria uma imagem 
inversa à do DV. Nesse artigo, o autor frisa que, ao contrário do que ocorre na VU e no DV, na VPE a onda de pulso corre na mesma direção em que o sangue flui. Por conseguinte, a onda de pulso impõe um incremento de velocidade durante a onda "a", não uma redução, que está em consonância com o conceito de intensidade da onda aplicado em artérias.

Em 2004, Baschat et al. (6) realizam estudo prospectivo utilizando o Doppler em fetos com RCF e alterações na AU. Em 122 fetos, os índices do DV (onda "a" reversa) e da VU (presença de pulsações) e os índices da VCI foram bons parâmetros para a predição do estado ácido-básico no nascimento. A combinação dos exames venosos apresentam melhor acurácia de predição da acidemia fetal $(\mathrm{pH}<7,20)$ do que o exame isolado de qualquer vaso. Concluem que o exame dos três vasos deve ser encorajado para melhor precisão nas decisões dos casos.

Testando a hipótese de que o fluxo na veia portal principal compensaria o fluxo diminuído da VU para o fígado fetal, em casos de RCF, Kessler et al., em 2009 (108), realizam estudo transversal em 31 fetos com RCF (peso estimado <p5) pelo Doppler da VU, DV, VPE e veia portal principal. Verificam que, comparados com fetos normais, na RCF o fluxo sanguíneo hepático absoluto encontra-se reduzido, fato esse relacionado com a gravidade do comprometimento placentário, e afetando igualmente ambos os lobos hepáticos. A veia portal principal repõe parcialmente o fluxo umbilical para o lobo direito, que em casos graves não recebe nenhum aporte sanguíneo proveniente da VU. Esse fato resulta na hipoxemia hepática, pois o sangue portal é menos oxigenado do que o da VU. 
Tchirikov et al. (2009) (109) estudam a combinação do IP da AU e valores de fluxo da VU para predizer o prognóstico perinatal com sucesso.

Lingman \& Marsal (1986) (106) mostram que fetos com sinais de hipoxia apresentam fluxo pulsátil na VU. O fenômeno foi mais tarde identificado como fator de pior prognóstico para fetos com hidropsia (70). A pulsação na VU é um achado normal em fetos com menos de 13 semanas de IG (51), e é visto ocasionalmente no final da gestação, particularmente em porções mais profundas da VU no abdome fetal (26). Esse fenômeno ocorre mais frequentemente em fetos com anemia (110). Entretanto, o mecanismo fisiopatológico dessas ondas, o modo de propagação no sistema venoso e o aumento da amplitude em alguns fetos, é ainda pouco entendido. $\mathrm{O}$ aumento da força da contração atrial é um dos fatores documentados para aumento da amplitude de pressão e aumento correspondente na pulsatilidade sanguínea (111-114). Aumento na pós-carga e o stress hipóxico podem levar a esse tipo de aumento na contração, mediado pelo aumento no nível adrenérgico.

A junção entre o DV e a VU é geralmente considerada como uma unidade unidirecional de sangue no sentido do coração, mas do ponto de vista da dinâmica de fluidos, pode também atuar como uma linha de transmissão de ondas na direção contrária. Assim, as pulsações seriam parcialmente refletidas e parcialmente transmitidas quando houvesse mudança na impedância através desta junção $(94,115)$.

Outros determinantes são a rigidez da parede do vaso e a pressão intravascular $(42,113,115)$. O aumento na pressão intravascular e transmural no sistema venoso diminuem a complacência, aumentam a 
velocidade da onda, e promovem o transporte das pulsações adiante para a periferia. Isso pode desempenhar papel importante, particularmente na presença de insuficiência cardíaca congestiva.

\subsubsection{Estudos de reprodutibilidade/acurácia}

A acurácia das medidas de fluxo na VU tem sido amplamente discutida na literatura. Em 1987, Rasmussen relata que o fluxo de sangue na VU por $\mathrm{kg}$ de peso fetal, determinado pelo Doppler em tempo real, tem coeficiente de variância médio de 6,8\% (116). Em 1996, Schmidt et al. (18) comparam o fluxo de sangue na VU em ovinos medidos pelo Doppler, com o fluxo obtido pelo uso de microesferas marcadas com radionuclídeos e transdutores de fluxo eletromagnético. Nesse estudo, os dados se correlacionam com pequena superestimação do fluxo pelo Doppler. Entretanto, esse estudo foi realizado por laparotomia, com anestesia epidural, que pode alterar as pressões sanguíneas e os fluxos sanguíneos regionais em ovinos.

Vansplunder et al., em 1994 (26), testam a reprodutibilidade e a variação inter e intraobservador da medida da velocidade de fluxo na VU em suas porções intra e extra-abdominal, e da VPE em 23 gestantes baixo risco entre 34 e 38 semanas de gestação. Os três exames demonstram reprodutibilidade limitada por grandes variações inter e intraobservador. Pulsações acontecem nos três locais examinados, e precisam assim ser interpretadas com cautela no final da gestação. Destes exames, a VPE é a que apresenta melhor reprodutibilidade. 
Barbera et al. (1999) (78) mostram coeficientes de variação intra e interobservador para o diâmetro da VU, velocidade média e fluxo sanguíneo variando de 2,9, 7,9 e 12,7\%, que correspondem a variabilidade moderada. Lees et al. (1999) (81) encontram boa concordância interobservador tanto para velocidade quanto para diâmetro, em amostra de sete fetos.

Figueras et al., em 2008 (117), testam a acurácia e reprodutibilidade da dopplervelocimetria na medida do fluxo venoso na VU. Relatam que este exame tem boa acurácia e reprodutibilidade, mas os autores frisam que, para se estabelecer o valor clínico da medida do fluxo sanguíneo na VU, novos estudos são necessários. Nesse mesmo ano, Fernandez et al. (2008) (118) concordam com Figueras et al. (2008) (117) de que o estudo da dopplervelocimetria mostrou ser exame com boa acurácia, com poucas diferenças intra e interobservador, sendo, portanto, confiável o suficiente para seu uso clinico.

Com as novas gerações de aparelhos de ultrassom, é possível produzir medidas de fluxo venoso com maior precisão, e também fornecer imagens com maior acurácia com transdutores de alta frequência, identificação de vasos pelo Doppler colorido, foco ajustável, maior capacidade de magnificação da imagem, melhor processamento posterior das imagens, função de memória para recuperar as melhores ondas e maior resolução dos marcadores utilizados (119). 


\section{Métodos}


Esta pesquisa prospectiva foi realizada na Clínica Obstétrica do Hospital das Clínicas da Faculdade de Medicina da Universidade de São Paulo (HCFMUSP) no período compreendido entre 09/07/2008 e 14/12/2011.

O projeto de pesquisa e o termo de consentimento livre e esclarecido foram aprovados pela Comissão de ética em Pesquisa do HCFMUSP CAPPesq (Comissão de Análise de Projetos de Pesquisa), protocolado sob o número 376/08 (Anexo 1).

\subsection{Critérios de inclusão}

Foram incluídas no estudo as gestantes que apresentavam os seguintes critérios:

1. IG maior que 24 semanas;

2. Feto único e vivo;

3. Membranas íntegras;

4. Insuficiência placentária caracterizada pela dopplervelocimetria de AU anormal (IP>p95);

5. Ausência de anomalias fetais ou infecções congênitas;

6. Gestantes que consentiram em participar da pesquisa. 


\subsection{Critérios de exclusão}

Foram excluídos da pesquisa os casos que apresentaram diagnóstico pós-natal de anomalia do RN e aquelas em que não se obteve a mensuração do $\mathrm{pH}$ no nascimento.

\subsection{Coleta de dados}

As gestantes internadas na Clínica Obstétrica que preencheram os critérios de inclusão foram convidadas a participar do estudo. Após esclarecimento dos objetivos da pesquisa e dos exames a que seriam submetidas, foi solicitado o consentimento da paciente pelo termo anexo ao projeto (Anexo 2).

Os exames foram realizados na ocasião em que a paciente era submetida à avaliação da vitalidade fetal. Todas as gestantes com diagnóstico de insuficiência placentária internadas na Clínica Obstétrica são agendadas para essa avaliação, em frequência que pode variar de exames diários ou até a cada três dias.

Para a avaliação da vitalidade fetal foram realizados exames de cardiotocografia, perfil biofísico fetal (PBF) e dopplervelocimetria (AU, ACM e DV). Após a realização desses exames de rotina, procedeu-se com os exames de dopplervelocimetria do território venoso fetal (VPE e VU). As avaliações da VPE e VU não foram consideradas na orientação da conduta assistencial dos casos, tendo sido realizadas apenas para os fins da presente 
pesquisa, tendo acrescentado ao período de realização do exame cerca de 10 a 20 minutos.

\subsubsection{Avaliação da vitalidade fetal}

\subsubsection{Cardiotocografia anteparto}

Esse exame foi realizado com cardiotocógrafo da marca Hewllet Packard (Series 50-A). Utilizando-se cintas elásticas colocadas ao redor do abdome materno, foram colocados transdutores para captação dos batimentos cardíacos fetais e das contrações uterinas, ambos ligados ao aparelho que registra estes parâmetros em papel, na velocidade de $1 \mathrm{~cm} / \mathrm{min}$. Foram analisados traçados com duração mínima de 10 minutos para interpretação dos parâmetros cardiotocográficos.

Caracterizou-se como normal o traçado cardiotocográfico com presença de acelerações da frequência cardíaca fetal (FCF), de pelo menos 10 batimentos por minuto (bpm) para gestações com menos de 32 semanas completas, e de, pelo menos 15 bpm para as com mais de 32 semanas; com FCF basal entre 110 e 160 bpm, variabilidade normal da FCF (6 a 25 bpm) e ausência de desacelerações.

A cardiotocografia suspeita caracterizou-se pela ausência de acelerações transitórias da FCF, acompanhada ou não de redução da variabilidade, e ausência de desacelerações.

Considerou-se como anormal a cardiotocografia com variabilidade indetectável ou ausente, ausência de acelerações transitórias da FCF, acompanhada ou não de desacelerações. 


\subsubsection{Perfil biofísico fetal}

O PBF foi realizado pela avaliação das atividades biofísicas que incluem: FCF, movimentos respiratórios fetais, movimentos corpóreos fetais, tônus fetal e índice de líquido amniótico (ILA). A análise da FCF foi realizada pela cardiotocografia. As demais atividades biofísicas foram avaliadas pela ultrassonografia, durante período máximo de observação de 30 minutos. Os movimentos respiratórios foram tomados como normais quando o feto apresentou, no mínimo, um episódio com duração mínima de 30 segundos. Os movimentos corpóreos foram classificados como normais quando se verificou pelo menos um movimento amplo ou três movimentos discretos do feto. O tônus foi considerado normal quando houve ocorrência de movimentação corpórea fetal satisfatória ou pela presença de movimentos de abertura e fechamento das mãos.

A avaliação semiquantitativa do volume de líquido amniótico foi efetuada pela mensuração do ILA utilizando-se de ultrassonografia (120). A posição do transdutor deve ser perpendicular ao plano coronal da gestante. $\mathrm{O}$ abdome materno é dividido em quatro quadrantes e o maior bolsão de líquido amniótico foi identificado em cada quadrante. A medida do ILA consiste na soma das medidas em centímetros do diâmetro vertical do maior bolsão de líquido amniótico de cada quadrante do abdome materno. O ILA foi classificado como normal quando superior a 5,0 cm. 
Cada parâmetro do PBF recebeu pontuação 2 à qualificação normal e 0 à anormal. Pela somatória dos pontos obteve-se o valor do PBF.

\subsubsection{Dopplervelocimetria}

A dopplervelocimetria foi realizada utilizando-se de aparelho de ultrassonografia (Envisor, Phillips, Andover, MA, EUA) equipado com mapeamento colorido de fluxo, com transdutor convexo de $3,5 \mathrm{MHz}$, filtro de $50 \mathrm{~Hz}$ e volume amostral de 2 a $3 \mathrm{~mm}$. O ângulo de insonação foi sempre o menor possível, com angulação próxima a $0^{\circ}$.

A posição adotada pela paciente durante a realização do exame foi o decúbito horizontal com discreta elevação do dorso e lateralização do abdome materno para a esquerda, com o objetivo de diminuir a compressão da $\mathrm{VCl}$ da mãe, evitando-se assim a hipotensão materna.

Todas as medidas de Doppler foram obtidas em período de inatividade fetal, isto é, na ausência de movimentos corpóreos ou respiratórios fetais.

\subsubsection{Execução dos exames dopplervelocimétricos}

\subsubsection{Artéria Umbilical}

De acordo com o método adotado no Setor de Vitalidade Fetal da Clínica Obstétrica, a dopplervelocimetria das AU foi realizada insonando-se o cordão umbilical próximo ao local de sua inserção na placenta. A obtenção do sonograma foi realizada em, pelo menos, três momentos diferentes durante a realização do exame, ativando-se o dispositivo de Doppler até a obtenção de 
ondas uniformes. Para obtenção dos índices dopplervelocimétricos foi utilizada a demarcação manual de um ciclo cardíaco e o equipamento realizou o cálculo do IP. Foi caracterizado como anormal o valor do IP da AU acima do percentil 95 para a IG (121). A ausência de fluxo diastólico final na dopplervelocimetria da $\mathrm{AU}$, confirmada em pelo menos três sonogramas, caracterizou o diagnóstico de diástole zero (DZ). A ocorrência de fluxo diastólico reverso foi denominada de diástole reversa (DR).

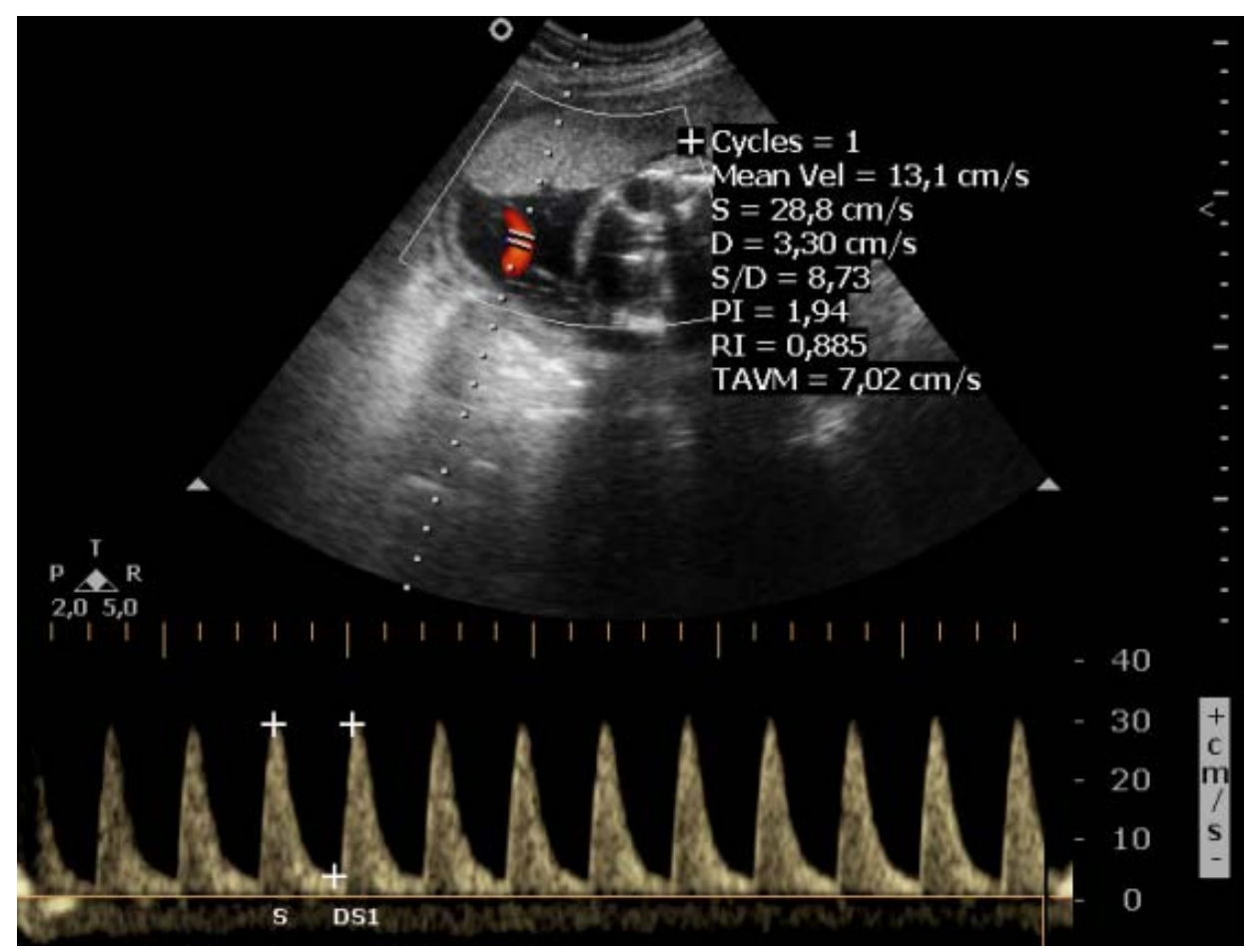

Figura 2: Dopplervelocimetria da artéria umbilical em alça livre do cordão umbilical próximo à inserção placentária

\subsubsection{Artéria cerebral média}

A avaliação dopplervelocimétrica da ACM foi realizada na porção inicial desse vaso, próximo ao polígono de Willis. Para a obtenção do sonograma, realizou-se corte transversal do cérebro fetal, na altura dos 
tálamos, e, em seguida, o transdutor foi deslocado caudalmente em direção da base do crânio, visualizando-se as asas do osso esfenóide. A ACM foi identificada com o dispositivo de mapeamento colorido de fluxo e foi realizada a insonação preferencialmente na janela anterior (têmporo-occipital) para obtenção de, pelo menos, três sonogramas em momentos diferentes do exame. O ângulo de insonação foi mantido menor do que 20 graus, e obtidas ondas uniformes para a mensuração do IP. Evitou-se a compressão excessiva do abdome materno na realização desse exame.

Foi calculada a relação cerebroplacentária $(\mathrm{RCP})$, pela divisão do IP da $\mathrm{ACM}$ pelo IP da $\mathrm{AU}$, caracterizando como anormal quando abaixo do percentil 5 para a IG correspondente $(121,122)$.

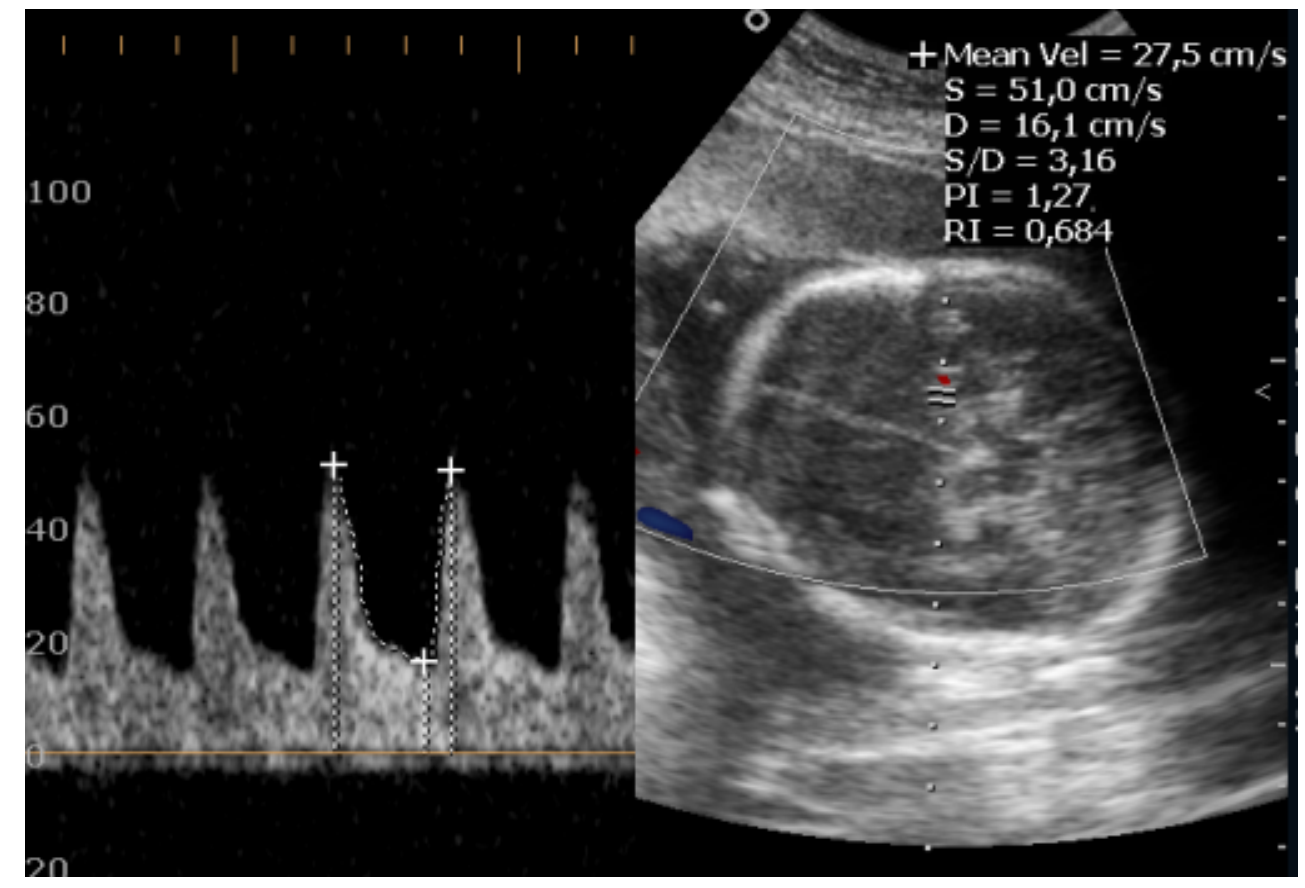

Figura 3: Dopplervelocimetria da artéria cerebral média em sua porção inicial com ângulo de insonação inferior a 20 graus 


\subsubsection{Ducto venoso}

Identificou-se o DV efetuando-se corte ultrassonográfico transverso do abdome fetal, na altura da inserção do cordão umbilical. Identificou-se a porção intra-abdominal da VU com mapeamento colorido de fluxo, e a sua bifurcação em VPE e DV. O sonograma característico foi obtido na porção inicial do ducto, onde ocorre turbilhonamento do sangue, provocando efeito de mistura de cores (efeito aliasing).

Após a obtenção de ondas uniformes, foi calculado o índice de pulsatilidade para veias (IPV), a partir do contorno manual da onda, e o resultado foi caracterizado como anormal quando apresentou valores superiores ao percentil 95 da curva de normalidade para a IG correspondente (123).

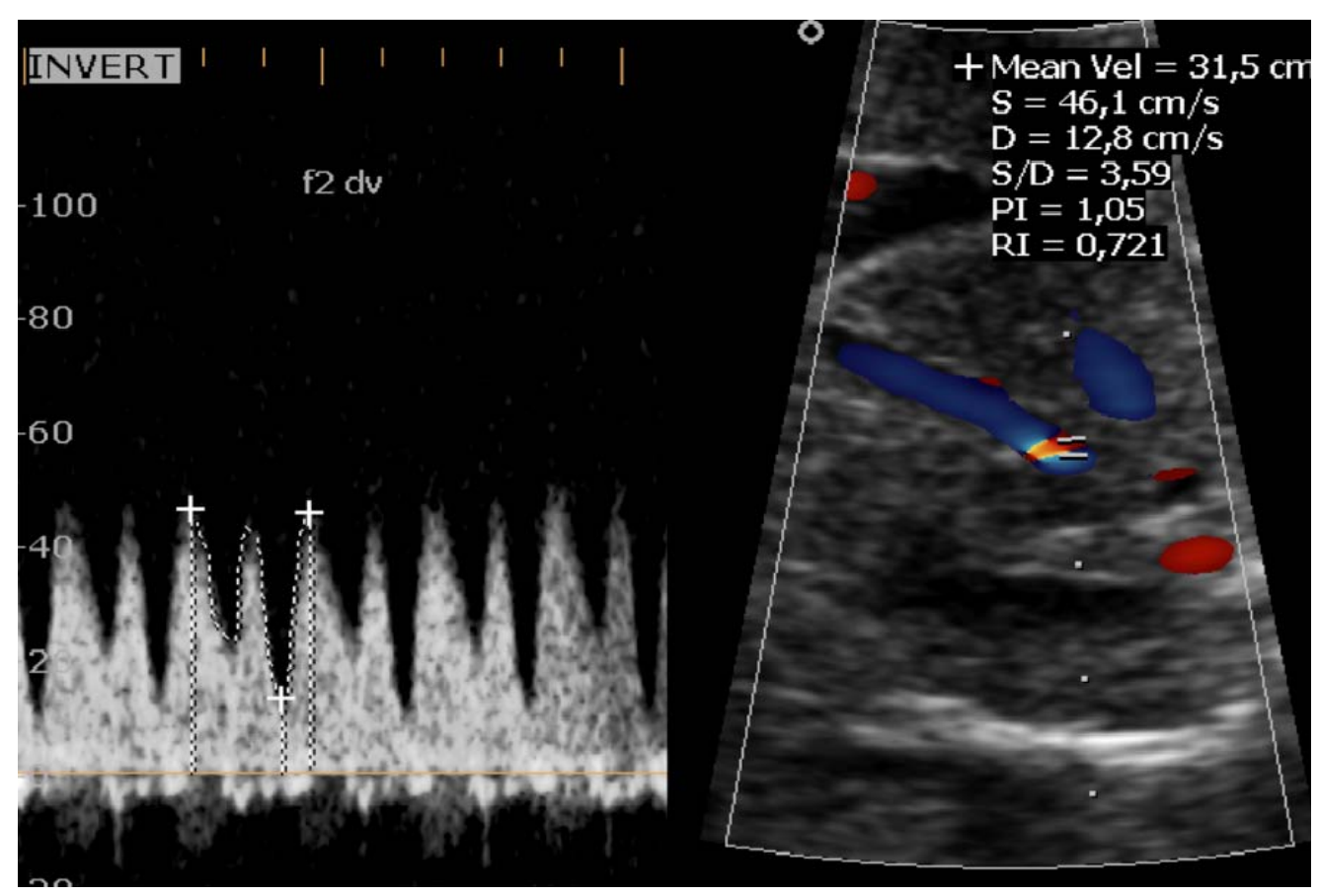

Figura 4: Dopplervelocimetria do Ducto Venoso em sua porção inicial, em corte transverso do abdome fetal 


\subsubsection{Veia portal esquerda}

A VU fetal, na sua porção intra-abdominal foi identificada com o auxílio do mapeamento colorido de fluxo, iniciando-se a insonação no plano transverso do abdome fetal, no corte onde habitualmente é medida a circunferência abdominal. Realizando-se discreta angulação acompanhando o trajeto da VU intra-hepática, identifica-se a bifurcação do vaso em VPE e DV.

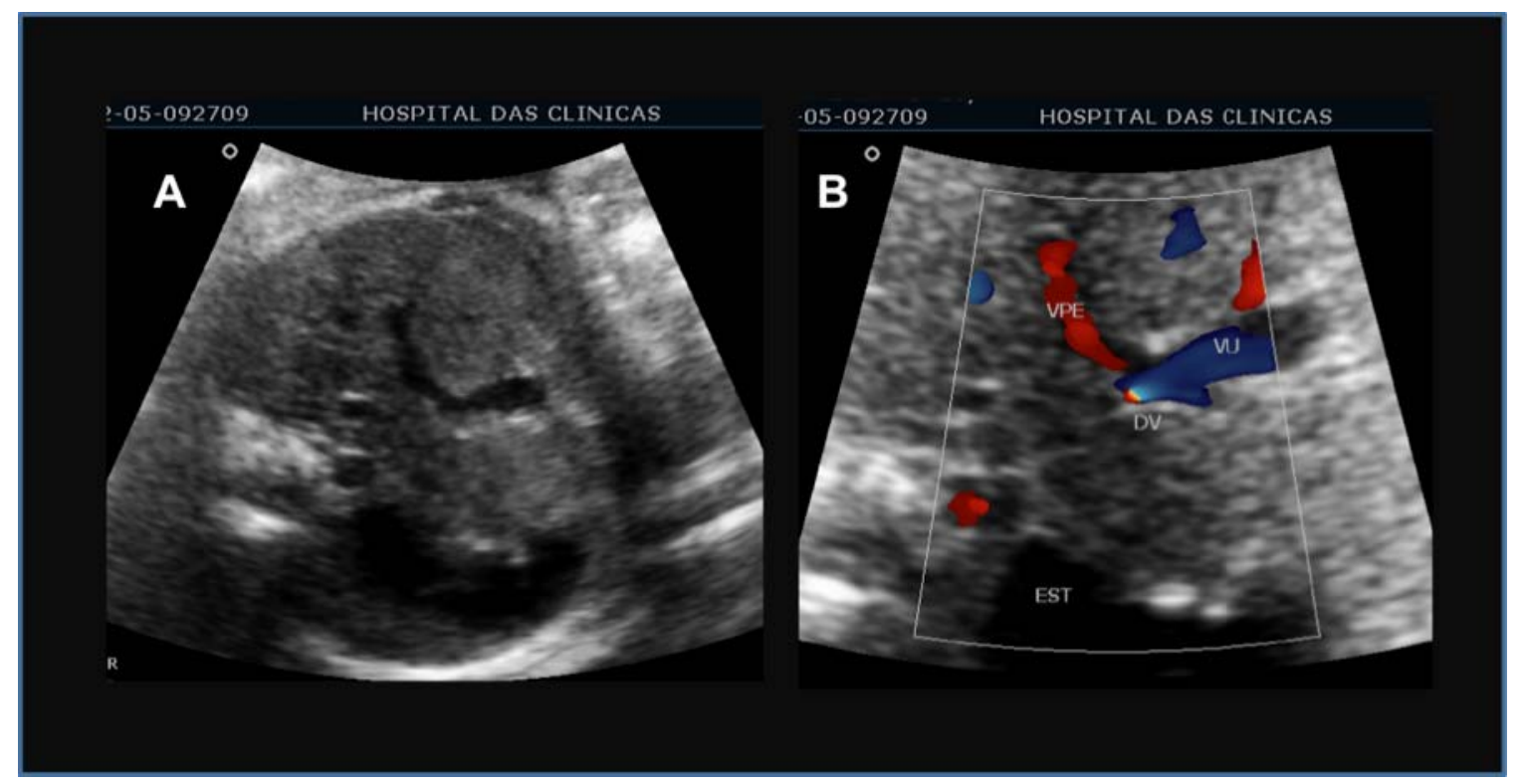

Figura 5: Imagem ultrassonográfica do abdome fetal com (B) e sem (A) mapeamento colorido de fluxo. VPE: veia portal esquerda; VU: veia umbilical; DV: ducto venoso; EST: estômago.

Após a identificação da bifurcação, o mapeamento colorido é desligado, procede-se com a magnificação da imagem e redução do ganho 
para melhor identificação das paredes dos vasos. A VPE corresponde ao trecho em continuação da VU, após a emergência do DV e antes da junção com o tronco portal principal. Nesse local foi mensurado o diâmetro interno (D) do vaso (três medidas), buscando-se as melhores imagens, com insonação perpendicular em relação ao maior eixo do vaso. Nesse mesmo local, com o eixo de insonação ao longo do vaso com o menor ângulo possível e sempre inferior a $20^{\circ}$, o cursor foi alocado no interior da VPE e foram mensuradas as velocidades de fluxo sanguíneo (TAMxV), automaticamente calculadas pelo aparelho de ultrassonografia, por um período de três a cinco segundos ou calculadas como média de três a cinco ciclos cardíacos consecutivos, nos casos com padrão pulsátil do fluxo.

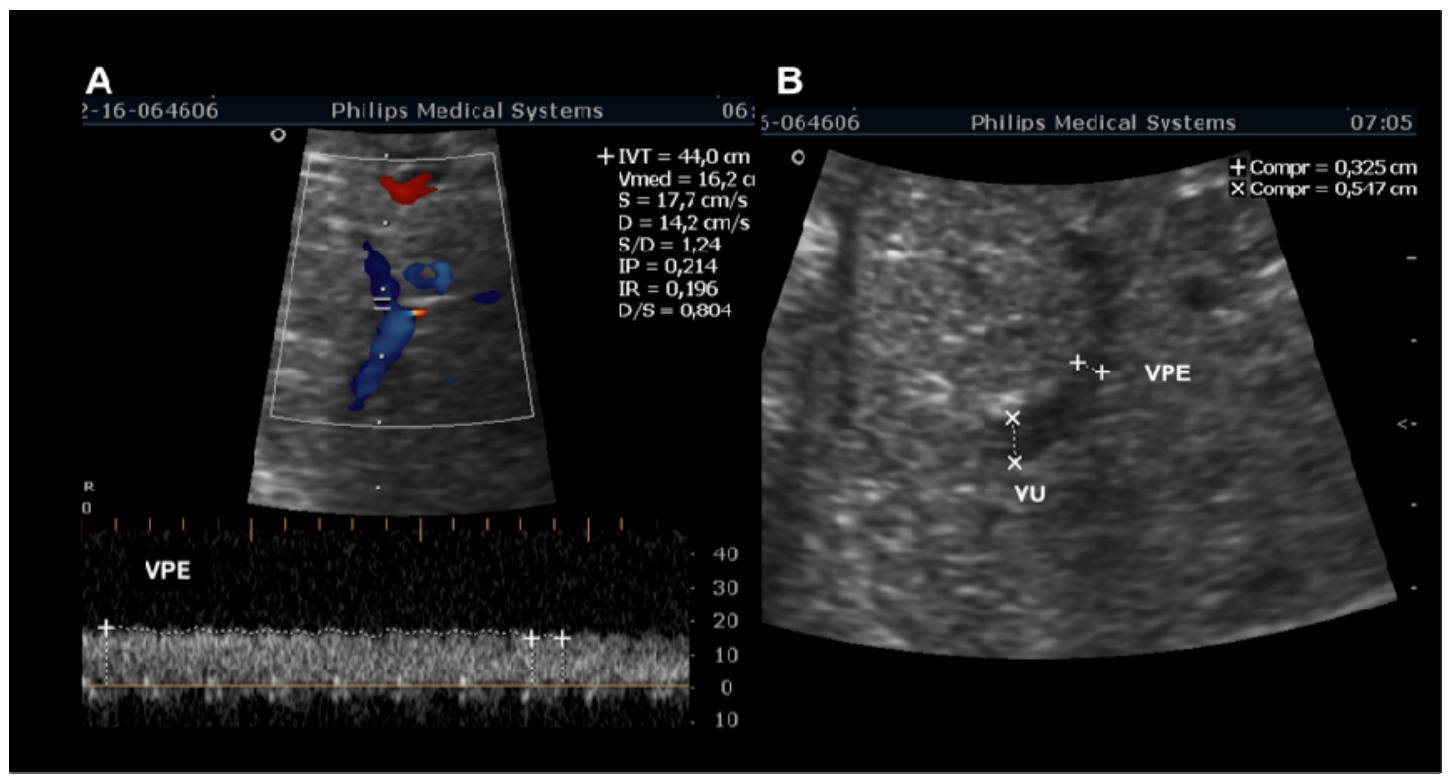

Figura 6: Dopplervelocimetria da veia portal esquerda no abdome fetal com medidas de velocidade $(A)$ e do diâmetro dos vasos (B). VPE: veia portal esquerda; VU: veia umbilical. 
O fluxo sanguíneo $(Q)$ foi calculado pela seguinte fórmula:

$$
\mathbf{Q}=\pi(\mathrm{D} / 2)^{2} \times \mathbf{h} \times \mathrm{TAM} \times \mathbf{V}
$$

onde D é o diâmetro da VPE, h é o coeficiente para o perfil de velocidade do sangue, que no caso da VPE corresponde a 0,5, e o TAMxV foi aquele obtido pela avaliação dopplervelocimétrica.

Para a normalização das medidas obtidas, foi realizado ajuste de acordo com o peso fetal estimado, a partir dos dados obtidos na biometria do feto (diâmetro biparietal, circunferência cefálica, circunferência abdominal e comprimento do fêmur), conforme fórmula de Hadlock et al. (1991) (124).

\subsubsection{Veia umbilical}

A VU fetal, na sua porção intra-abdominal, foi identificada com o auxílio do mapeamento colorido de fluxo, no plano transverso do abdome fetal. Após a identificação desse vaso, o mapeamento colorido é desligado, procede-se com a magnificação da imagem e redução do ganho para melhor identificação das paredes dos vasos. Nesse local foi mensurado o diâmetro interno (D) do vaso (três medidas), com insonação perpendicular em relação ao maior eixo do vaso. Esse parâmetro foi utilizado para o cálculo do volume de fluxo. Nesse mesmo local, mudando-se o eixo de insonação do vaso para obtenção do menor ângulo possível e sempre inferior a $20^{\circ}$, o cursor foi alocado no interior da VU e foram mensuradas as velocidades de fluxo sanguíneo (TAMxV), automaticamente calculadas pelo aparelho de ultrassonografia, por um período de três a cinco segundos ou calculadas 
como média de três a cinco ciclos cardíacos consecutivos, nos casos com padrão pulsátil do fluxo.

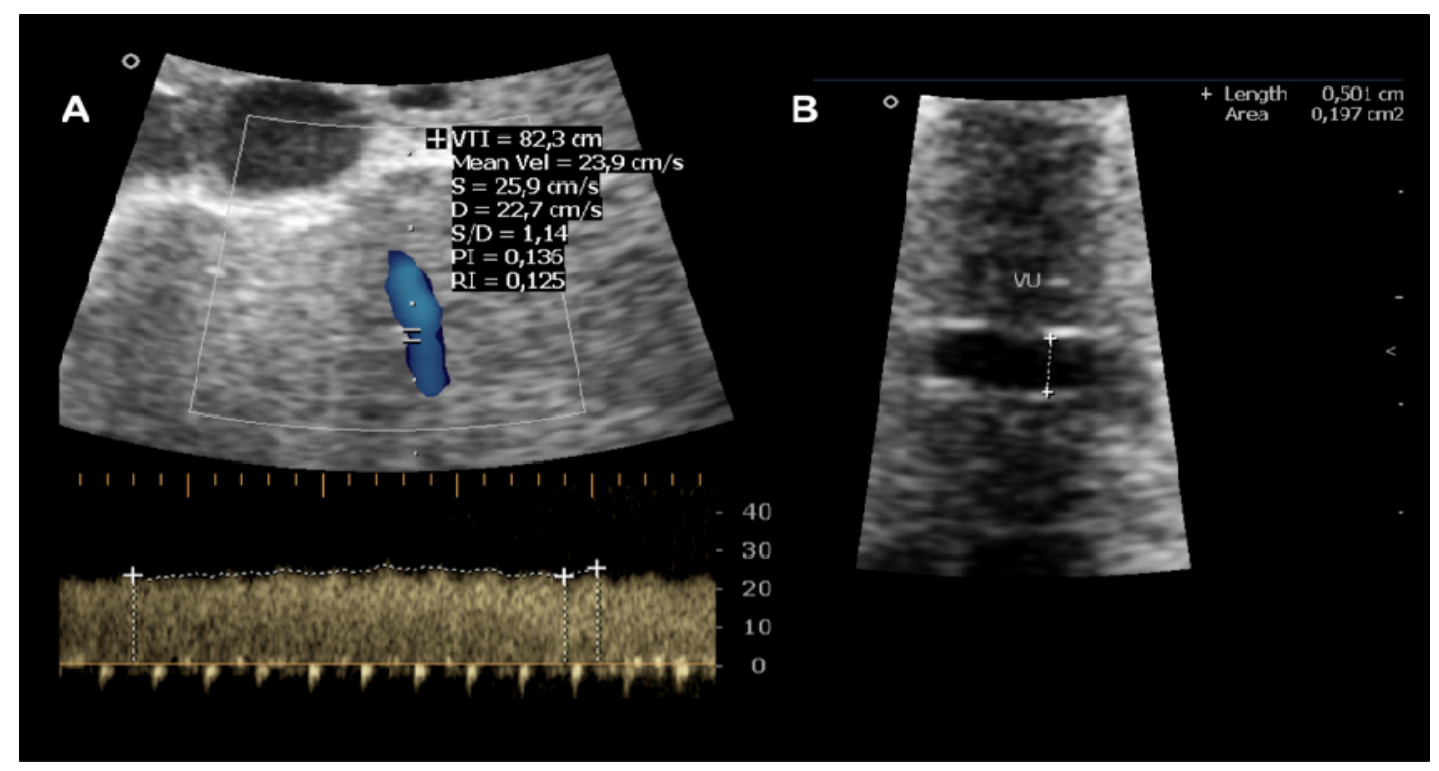

Figura 7: Dopplervelocimetria da veia umbilical no abdome fetal com medidas de velocidade (A) e do diâmetro do vaso (B). VU: Veia umbilical.

O volume de fluxo sanguíneo $(Q)$ foi calculado pela seguinte fórmula:

$$
\mathbf{Q}=\pi(\mathrm{D} / 2) 2 \times \mathrm{h} \times \mathrm{TAM} \times \mathrm{V}
$$

onde $D$ é o diâmetro da veia umbilical, $h$ é o coeficiente para o perfil de velocidade do sangue, que no caso da veia umbilical corresponde a 0,5 , e o TAMxV foi aquele obtido pela avaliação dopplervelocimétrica.

Para a normalização das medidas obtidas, foi realizado ajuste de acordo com o peso fetal estimado, a partir dos dados obtidos na biometria do feto, conforme fórmula de Hadlock et al. (1991) (124).

Os exames de Doppler da VPE e VU foram repetidos nas avaliações seriadas, agendadas de acordo com a gravidade de cada caso conforme a 
rotina assistencial já estabelecida em protocolos clínicos, geralmente a cada três dias, até o dia do parto. Os resultados do Doppler venoso fetal foram comparados com os demais exames de avaliação da vitalidade fetal. Para o presente estudo foi analisada a última avaliação obtida antes do nascimento, ou antes da corticoterapia anteparto.

\subsubsection{Dados do parto e do recém-nascido}

As pacientes arroladas para o presente estudo foram seguidas na Clínica Obstétrica do HCFMUSP até o parto. Os dados referentes ao parto e RN foram obtidos no prontuário da paciente ou por consulta ao livro de partos.

A IG no momento do parto foi calculada com base na data da última menstruação, concordante com a datação por ultrassonografia realizada no primeiro trimestre, ou, quando a data da última menstruação era incerta, o cálculo foi realizado por duas ultrassonografias concordantes efetuadas entre a $12^{\mathrm{a}}$ e a $20^{\mathrm{a}}$ semanas.

O escore de Apgar foi utilizado para a avaliação do RN no momento do nascimento, avaliando-se a frequência cardíaca, esforço respiratório, tônus muscular, irritabilidade reflexa e cor no primeiro, quinto e décimo minutos após o nascimento. Os índices maiores ou iguais a sete foram considerados normais.

$\mathrm{O}$ pH do cordão umbilical foi obtido em exame de gasometria coletado na $A U$ em alça de cordão no momento do parto. Foi caracterizado como acidemia no nascimento os casos que apresentaram valor de $\mathrm{pH}$ inferior a 7,20 . 


\subsubsection{Variáveis estudadas}

Características da população:

- Idade materna (anos)

- Cor (branca / não branca)

- Paridade (nuliparidade ou presença de partos prévios)

- Presença de síndromes hipertensivas (hipertensão arterial sistêmica e/ou doença hipertensiva específica da gestação) (sim/não)

- Presença de diabetes mellitus (sim/não)

- Presença cardiopatias (sim/não)

Avaliação da vitalidade fetal:

- Cardiotocografia anteparto (padrão normal; suspeito ou anormal)

- $\operatorname{PBF}(0 ; 2 ; 4$ : alterado; 6 : suspeito; 8 ou 10: normal)

- $\operatorname{ILA}(\leq 5 ;>5)$

- IP da AU (valores absolutos)

- DZ ou DR da AU (sim/não)

- IP da ACM (valores absolutos)

- Relação cerebroplacentária (valores absolutos)

- escore-zeta da Relação cerebroplacentária

Avaliação da dopplervelocimetria venosa fetal:

Ducto venoso:

- IPV do DV (valores absolutos)

- escore-zeta do IPV do DV 


\section{Dopplervelocimetria da VPE:}

- TAMxV $(\mathrm{cm} / \mathrm{s}$ : valores absolutos e normal / anormal positivo / reverso)

- escore-zeta da TAMxV

- Q (fluxo sanguíneo) (ml/min)

- $\mathrm{Q} / \mathrm{kg}$ (fluxo sanguíneo por $\mathrm{Kg}$ de peso fetal) $(\mathrm{ml} / \mathrm{min} / \mathrm{kg}$ )

- Presença de pulsatilidade (sim/não)

\section{Dopplervelocimetria da VU:}

- TAMxV (cm/s: valores absolutos e normal/anormal)

- escore-zeta da TAMxV

- Q (fluxo sanguíneo) (ml/min)

- $\mathrm{Q} / \mathrm{kg}(\mathrm{ml} / \mathrm{min} / \mathrm{kg})$

- Presença de pulsatilidade (sim/não)

Dados do parto:

- IG no nascimento (semanas)

- Tipo de parto (cesárea/vaginal)

- Peso do RN (g)

- Índices de Apgar <7 no primeiro minuto (sim/não)

- Índices de Apgar $<7$ no quinto minuto (sim/não)

- $\mathrm{pH}$ de $\mathrm{AU}$ no nascimento (valores absolutos)

\subsection{Análise estatística}

O tamanho da amostra foi inicialmente calculado com base no trabalho de Baschat et al. (2004) (6). Considerando-se que em casos de RCF com aumento da resistência placentária, a proporção de acidemia $(\mathrm{pH}<7,20)$ 
quando o Doppler do DV é alterado ou com pulsações da VU é de $42 \%$, para se detectar uma redução para $10 \%$ para um erro do tipo I (alfa) de 0,05 e erro do tipo II (beta) de 0,20 , foi calculado o tamanho amostral de 52 casos.

As variáveis foram analisadas descritivamente, e para as variáveis quantitativas, essa análise foi feita através da observação dos valores mínimos e máximos, do cálculo de medianas, médias e desvios padrão.

Os valores absolutos dos índices dopplervelocimétricos foram convertidos em escore-zeta. Trata-se de parâmetro estatístico que indica quantos desvios padrão o valor observado está em relação à média para cada idade gestacional. Para o cálculo do escore-zeta é necessário aplicar a seguinte fórmula:

$$
\begin{aligned}
& z=(x-\mu) / D P \\
& z: \text { escore-zeta } \\
& x: \text { valor absoluto de uma avaliação } \\
& \mu: \text { média } \\
& \text { DP: desvio padrão }
\end{aligned}
$$

Curvas de normalidade da literatura foram utilizadas para a obtenção das médias e desvios padrão para o cálculo do escore-zeta de cada uma das medidas: IPV do DV (125), TAMxV da VPE (95) e TAMxV da VU (91).

A comparação das médias nos grupos foi realizada utilizando-se o teste $t$ de Student para amostras não-pareadas com distribuição das variáveis demonstrando distribuição normal, ou, quando a distribuição não foi normal, utilizou-se o teste não paramétrico de Mann Whitney U. A comparação entre 
as proporções foi avaliada através do teste qui-quadrado ou teste exato de Fisher.

Foram realizadas análises de correlação entre os parâmetros do Doppler venoso fetal e o pH no nascimento com o cálculo do coeficiente de Spearman (rho).

Para identificação das variáveis independentes associadas à acidemia no nascimento com melhor predição para o evento estudado foi utilizado o modelo de regressão logística, buscando-se o que apresentou melhor detecção de casos comprometidos.

O nível de significância utilizado para os testes foi de $5 \%$.

\subsection{Reprodutibilidade}

\subsubsection{Variação Intraoperador:}

Para avaliar a concordância intraoperador foram utilizadas 30 avaliações. Em cada avaliação foram realizadas três medidas consecutivas de cada parâmetro (diâmetro e TAMxV das VPE e VU). Foram utilizadas correlações intraclasse acompanhadas de gráficos de Bland-Altman para verificação de possíveis padrões (Anexo 3).

Tem-se que, apesar de uma aferiação ficar fora do limite superior, e duas ficarem abaixo do limite inferior, estas não ultrapassam $5 \%$ dos dados. 
Além disso, não se observa nenhum padrão específico para essas aferições intraexaminador.

Para todas as medidas realizadas a concordância está próxima de 1, o que indica reprodutibilidade intraobservador das medidas realizadas (Tabela 1).

Tabela 1 - Medidas de concordância intraexaminador para diâmetro e TAMxV das VPE e VU em fetos com insuficiência placentária HCFMUSP - 2010/2011

\begin{tabular}{|c|c|c|c|}
\hline \multirow[t]{2}{*}{ Medida } & \multirow{2}{*}{$\begin{array}{l}\text { Correlação } \\
\text { intraclasse }\end{array}$} & \multicolumn{2}{|c|}{ IC $95 \%$} \\
\hline & & Inferior & Superior \\
\hline Diâmetro da VPE & 0,9417 & 0,8937 & 0,9703 \\
\hline TAMxV da VPE & 0,963 & 0,9325 & 0,9811 \\
\hline Diâmetro da VU & 0,9494 & 0,9261 & 0,9793 \\
\hline TAMxV da VU & 0,9384 & 0,8876 & 0,9686 \\
\hline
\end{tabular}

\subsubsection{Variação Interoperador}

Para avaliar a concordância interoperador foram utilizadas 45 avaliações realizadas por dois operadores. Cada operador realizou 2 medidas dos seguintes parâmetros: diâmetro e TAMxV das VPE e VU. Foram utilizadas correlações intra-classe acompanhadas de gráficos de Bland-Altman para verificação de possíveis padrões. 
Para todos os parâmetros estudados as diferenças são próximas de zero, e não apresentam padrões específicos para as medidas interexaminadores (Anexo 4).

Para todas as medidas realizadas a concordância está próxima de 1, o que indica reprodutibilidade das medidas realizadas (Tabela 2).

Tabela 2 - Medidas de concordância interexaminadores para diâmetro e TAMxV das VPE e VU em fetos com insuficiência placentária HCFMUSP - 2010/2011

\begin{tabular}{lccc}
\hline Medida & Correlação & \multicolumn{2}{c}{ IC 95\% } \\
\cline { 3 - 4 } & intraclasse & Inferior & Superior \\
\hline Diâmetro da VPE & 0,6725 & 0,4066 & 0,8196 \\
TAMxV da VPE & 0,8248 & 0,6825 & 0,9035 \\
Diâmetro da VU & 0,9217 & 0,8581 & 0,9569 \\
TAMxV da VU & 0,7984 & 0,6348 & 0,8890 \\
\hline $\begin{array}{c}\text { VPE: veia portal esquerda; TAMxV: "time-averaged } \\
\text { umbilical; IC: intervalo de confiança. }\end{array}$ & & \multicolumn{2}{c}{ maximum velocity"; VU: veia } \\
\end{tabular}

\subsection{Caracterização da população}

Foram avaliadas 64 gestantes, sendo que 1 caso foi excluído pela ocorrência de óbito fetal (com 25 semanas), e 5 casos pela não obtenção do resultado do $\mathrm{pH}$ no nascimento ( 3 casos por material insuficiente e 2 casos pela coagulação da amostra). Sendo assim, 58 casos foram classificados 
segundo a presença ou ausência do diagnóstico de acidemia fetal no nascimento, de acordo com o resultado do $\mathrm{pH}$ no sangue da $\mathrm{AU}$, constituindo-se de: 26 casos com acidemia no nascimento ( $\mathrm{pH}<7,20,44,8 \%)$ e 32 casos com $\mathrm{pH}$ normal $(\mathrm{pH} \geq 7,20,55,2 \%)$.

\subsubsection{Caracterização das gestantes}

A comparação dos grupos de acordo com as características maternas está apresentada na Tabela 3. A idade materna variou de 17 a 43 anos, com média de 30,6 anos e desvio padrão (DP) de 6,5 anos. Nesta casuística, houve predomínio de gestantes de cor não branca (30 casos), e 28 pacientes eram de cor branca. Os 58 fetos foram analisados de acordo com a ocorrência ou não de acidemia no nascimento, constituindo-se dois grupos: Grupo I (26 casos) com acidemia e Grupo II (32 casos) sem acidemia. Não houve diferença significante entre os grupos em relação à idade $(P=0,630)$. Quanto à cor, não houve diferença significante entre os grupos $(P=0,616)$ (Tabela 3). Entre estas gestantes, 30 (42\%) eram nulíparas. Não se constatou diferença na paridade dos grupos $(P=0,978)$. Quanto às doenças maternas, não houve associação significativa com a ocorrência da acidemia no nascimento (Tabela 3 ). 
Tabela 3 - Caracterização das gestantes incluídas no Grupo I (26 casos) e Grupo II (32 casos) quanto à idade materna, cor, nuliparidade, presença de doenças de base- HCFMUSP - 2010/2011

\begin{tabular}{|c|c|c|c|c|c|}
\hline \multirow[b]{2}{*}{ Idade materna (anos) } & \multicolumn{2}{|c|}{$\begin{array}{c}\text { Grupo I } \\
\text { pH<7,20 } \\
(n=26)\end{array}$} & \multicolumn{2}{|c|}{$\begin{array}{c}\text { Grupo II } \\
\text { pH } \geq 7,20 \\
(n=32)\end{array}$} & \multirow{2}{*}{$\begin{array}{c}\mathbf{P} \\
0,630^{*}\end{array}$} \\
\hline & 30,4 & $(6,8)$ & 30,9 & $(6,2)$ & \\
\hline Cor branca & 11 & $(42)$ & 17 & (53) & $0,616^{* *}$ \\
\hline Nuliparidade & 14 & (54) & 16 & $(50)$ & $0,978^{* *}$ \\
\hline Hipertensão arterial & 21 & (81) & 21 & (66) & $0,323^{* *}$ \\
\hline Diabetes & 1 & $(3,9)$ & 3 & $(9,4)$ & $0,760^{* * *}$ \\
\hline Cardiopatia materna & 2 & $(7,7)$ & 7 & (22) & $0,263^{* * *}$ \\
\hline
\end{tabular}

Os 58 fetos foram analisados de acordo com a ocorrência ou não de acidemia no nascimento, constituindo-se dois grupos: Grupo I (26 casos) com acidemia e grupo II (32 casos) sem acidemia. 
Resultados 


\subsection{Análise dos testes de vitalidade fetal}

\subsubsection{Cardiotocografia e perfil biofísico fetal}

A distribuição dos casos de acordo com os resultados da cardiotocografia e do PBF está apresentada na Tabela 4. Constatou-se, na análise univariada, associação significativa $(P=0,017)$ entre a cardiotocografia anteparto com padrão suspeito ou anormal e a acidemia no nascimento. A cardiotocografia normal foi observada mais frequentemente no grupo sem acidemia.

Quanto ao resultado do PBF, verificou-se associação significativa $(P=0,0030)$ entre o perfil suspeito (6) ou alterado (0-2-4) e a ocorrência de acidemia. Não houve associação estatisticamente significativa entre o diagnóstico de oligohidrâmnio pelo ILA inferior ou igual a 5,0 cm e a acidemia no nascimento (Tabela 4). 
Tabela 4: Distribuição dos casos de acordo com os resultados da cardiotocografia, perfil biofísico fetal e índice de líquido amniótico nos grupos analisados - HCFMUSP 2010/2011

\begin{tabular}{|c|c|c|c|c|c|}
\hline Cardiotocografi & \multicolumn{2}{|c|}{$\begin{array}{c}\text { Grupo I } \\
\mathrm{pH}<7,20 \\
(\mathrm{n}=26)\end{array}$} & \multicolumn{2}{|c|}{$\begin{array}{c}\text { Grupo II } \\
\mathrm{pH} \geq 7,20 \\
(\mathrm{n}=32)\end{array}$} & $\mathbf{P}$ \\
\hline Normal & 1 & $(4,6)$ & 12 & $(38,7)$ & \\
\hline Suspeita & 17 & $(77,3)$ & 15 & $(48,4)$ & $0,017^{* *}$ \\
\hline Anormal & 4 & $(18,2)$ & 4 & $(12,9)$ & \\
\hline NR & 4 & & 1 & & \\
\hline \multicolumn{6}{|l|}{ PBF } \\
\hline $8-10$ & 16 & $(61,5)$ & 28 & $(87,5)$ & \\
\hline 6 & 7 & $(26,9)$ & 3 & $(9,4)$ & $0,003^{* *}$ \\
\hline $0-2-4$ & 3 & $(11,5)$ & 1 & $(3,1)$ & \\
\hline \multicolumn{6}{|l|}{ ILA } \\
\hline$\leq 5,0 \mathrm{~cm}$ & 6 & $(23,1)$ & 9 & $(28,1)$ & $0,089^{* *}$ \\
\hline
\end{tabular}

NR: não realizada; PBF: perfil biofísico fetal; ILA: índice de liquido amniótico Resultados expressos como $n(\%)$

*4 pacientes sem informação no Grupo I e 1 paciente sem informação no Grupo II

${ }^{* *}$ Teste do qui-quadrado

\subsubsection{Dopplervelocimetria arterial}

A distribuição dos casos de acordo com os resultados da dopplervelocimetria arterial está apresentada na Tabela 5. Os fetos do grupo com acidemia no nascimento apresentaram valor do IP da $A U$ significativamente maior $(P=0,013)$ que o grupo sem acidemia. A proporção de casos com DZ ou DR foi maior no grupo com acidemia no nascimento $(P=0,018)$. Quanto aos resultados do IP da $A C M$ fetal, não houve diferença significativa na comparação das medianas entre os grupos. $\mathrm{Na}$ análise da RCP, constatou-se diferença significativa $(P=0,011)$ entre os grupos 
analisados, com menores valores da RCP nos fetos que apresentaram acidemia no nascimento. O escore-zeta da RCP apresentou diferença estatisticamente significante entre os grupos $(P=0,229)$ (Tabela 5).

Tabela 5: Distribuição dos casos de acordo com os resultados da dopplervelocimetria de artéria umbilical e artéria cerebral média fetal nos grupos analisados - HCFMUSP 2010/2011

\begin{tabular}{lccc}
\hline Dopplervelocimetria & $\begin{array}{c}\text { Grupo I } \\
\text { pH<7,20 } \\
(n=26)\end{array}$ & $\begin{array}{c}\text { Grupo II } \\
p H \geq 7,20 \\
(n=32)\end{array}$ & $P$ \\
\hline
\end{tabular}

Artéria umbilical

$\begin{array}{lccccc}\text { IP } & 2,51 & (1,06 \text { a 8,39) } & 1,75 & (0,75 \text { a } 6,02) & 0,013^{*} \\ \text { Diástole zero ou reversa } & 19 & (73,1) & 11 & (34,4) & 0,008^{* *}\end{array}$

Artéria cerebral média

IP

Relação cerebroplacentária

Escore-zeta da RCP
1,18

$(0,77$ a 1,95$)$

1,20

$(0,73$ a 2,53$)$

$0,579^{*}$

0,45

$(0,14$ a 1,05$)$

0,71

$(0,14$ a 1,55$)$

$0,011^{*}$

$-3,18 \quad(-4,92$ a $-2,12)$

Resultados expressos como n (\%) ou mediana (mínimo; máximo)

IP: índice de pulsatilidade; RCP: relação cerebroplacentária.

${ }^{*}$ Teste não paramétrico de Mann Whitney; ${ }^{* *}$ Teste do qui-quadrado

\subsubsection{Dopplervelocimetria venosa}

\subsubsection{Ducto venoso}

A distribuição dos casos de acordo com os resultados da dopplervelocimetria do DV estão apresentados na Tabela 6. Os valores do IPV foram significativamente $(P=0,009)$ maiores nos fetos que apresentaram acidemia no nascimento quando comparados aos que nasceram sem acidemia. O escore-zeta do IPV do DV foi maior no grupo com acidemia no nascimento $(P=0,008)$. 
Tabela 6: Distribuição dos casos de acordo com os resultados da dopplervelocimetria do ducto venoso fetal nos grupos analisados - HCFMUSP 2010/2011

\begin{tabular}{|c|c|c|c|c|c|}
\hline Ducto venoso & & $\begin{array}{c}\text { Grupo I } \\
\text { pH<7,20 } \\
(n=26)\end{array}$ & & $\begin{array}{c}\text { Grupo II } \\
\text { pH } \geq 7,20 \\
(n=32)\end{array}$ & $\mathbf{P}$ \\
\hline IPV & 1,03 & $(0,38$ a 2,2$)$ & 0,70 & $(0,31$ a 1,62$)$ & $0,009^{*}$ \\
\hline Escore-zeta do IPV & 2,41 & $(-2,22$ a 10,79$)$ & 0,03 & $(-2,81$ a 6,65$)$ & $0,008^{*}$ \\
\hline
\end{tabular}

\subsubsection{Veia Portal Esquerda}

A análise estatística dos parâmetros avaliados na VPE estão apresentados na Tabela 7. Na avaliação de variáveis contínuas, verifica-se pelo apresentado que a TAMxV e o volume de fluxo mostraram associação significativa com a acidemia no nascimento, com valores de $\mathrm{P}$ de 0,003 e 0,023, respectivamente. $\mathrm{Na}$ análise dos casos classificados de forma categórica em relação à velocidade na VPE, a proporção de casos com TAMxV anormal, reduzida de acordo com a curva de normalidade adotada, ou reversa, foi significativamente maior no grupo de fetos que apresentaram acidemia no nascimento $(P<0,001)$. O escore-zeta da TAMxV da VPE foi significantemente maior no grupo sem acidemia $(P=0,003)$. 
Tabela 7: Distribuição dos casos de acordo com os resultados da dopplervelocimetria da veia portal esquerda fetal nos grupos analisados - HCFMUSP 2010/2011

\begin{tabular}{|c|c|c|c|c|c|}
\hline Veia portal esquerda & & $\begin{array}{c}\text { Grupo I } \\
\text { pH<7,20 } \\
(n=26)\end{array}$ & & $\begin{array}{c}\text { Grupo II } \\
\text { pH } \geq 7,20 \\
(n=32)\end{array}$ & $\mathbf{P}$ \\
\hline TAMxV & 4,99 & $(-9,81$ a 8,33$)$ & 8,84 & $(-13,4$ a 17,1$)$ & $0,003^{*}$ \\
\hline \multicolumn{6}{|l|}{ TAMxV, classificação } \\
\hline Normal (>p5) & 0 & $(0)$ & 13 & $(40,6)$ & \\
\hline $\begin{array}{l}\text { Anormal positivo } \\
(\leq \mathrm{p} 5)\end{array}$ & 18 & $(69,2)$ & 11 & $(34,4)$ & $<0,001^{* *}$ \\
\hline Reverso & 8 & $(30,8)$ & 8 & $(25,0)$ & \\
\hline TAMxV, escore-zeta & $-3,57$ & $(-12,18 a-2,21)$ & $-1,99$ & $\begin{array}{c}(-11,97 \text { a } \\
0,95)\end{array}$ & $0,003^{*}$ \\
\hline Fluxo, $\mathrm{mL} / \mathrm{min}$ & 0,007 & $(-0,37$ a 0,38$)$ & 0,15 & $(-0,71$ a 0,70$)$ & $0,0323^{*}$ \\
\hline $\begin{array}{l}\text { Fluxo corrigido, } \\
\mathrm{mL} / \mathrm{Kg} / \mathrm{min}\end{array}$ & 0,10 & $(-0,037$ a 0,28$)$ & 0,16 & $(-0,82$ a 0,53$)$ & $0,044^{*}$ \\
\hline Pulsátil & 14 & $(53,9)$ & 13 & $(40,6)$ & $0,460^{* *}$ \\
\hline
\end{tabular}

\subsubsection{Veia Umbilical}

A análise dos parâmetros avaliados na VU estão apresentados na Tabela 8. O volume de fluxo nesse vaso e o volume corrigido por peso estimado fetal apresentaram valores significativamente menores no grupo com acidemia no nascimento. O escore-zeta da TAMxV da VU foi semelhante entre os dois grupos $(P=0,506)$. 
Tabela 8: Distribuição dos casos de acordo com os resultados da dopplervelocimetria da veia umbilical fetal nos grupos analisados - HCFMUSP 2010/2011

\begin{tabular}{|c|c|c|c|c|c|}
\hline Veia umbilical & & $\begin{array}{c}\text { Grupo I } \\
\text { pH<7,20 } \\
(n=26)\end{array}$ & & $\begin{array}{c}\text { Grupo II } \\
\text { pH } \geq 7,20 \\
(n=32)\end{array}$ & $\mathbf{P}$ \\
\hline TAMxV & 14,90 & $(7,50$ a 22,40$)$ & 15,20 & $(5,67$ a 23,90$)$ & $0,477^{*}$ \\
\hline $\begin{array}{l}\text { TAMxV, escore- } \\
\text { zeta }\end{array}$ & $-1,50$ & $(-2,44$ a $-0,54)$ & $-1,42$ & $(-2,69$ a $-0,32)$ & $0,506^{*}$ \\
\hline Fluxo (mL/min) & 0,64 & $(0,008$ a 2,12$)$ & 0,96 & $(0,13$ a 2,53$)$ & $0,004^{*}$ \\
\hline $\begin{array}{l}\text { Fluxo corrigido, } \\
\mathrm{mL} / \mathrm{Kg} / \mathrm{min}\end{array}$ & 0,60 & $(0,15$ a 1,57$)$ & 0,90 & $(0,26$ a 1,70$)$ & $0,005^{*}$ \\
\hline Pulsátil & 14 & $(53,9)$ & 8 & $(25,0)$ & $0,048^{* *}$ \\
\hline
\end{tabular}

\subsection{Correlação entre a dopplervelocimetria e o pH no nascimento}

Foi realizada análise de correlação entre os valores de $\mathrm{pH}$ no nascimento e os resultados da avaliação da dopplervelocimetria da circulação venosa fetal. Foi constatada correlação significativa (Tabela 9) entre o valor do $\mathrm{pH}$ no nascimento e o Doppler do DV (IPV e escore-zeta), o volume de fluxo na VU e com os parâmetros da VPE. Os respectivos índices de correlação de Spearman estão apresentados na Tabela 9. As equações de regressão estão apresentadas na Tabela 10, com equações demonstrando correlação significativa entre o pH no nascimento e os parâmetros do DV (IPV e escore-zeta) e da VPE (TAMxV e escore-zeta). 
Tabela 9: Correlação entre o pH no nascimento e os parâmetros do Doppler venoso em gestações com insuficiência placentária $(N=58)$ HCFMUSP 2010/2011

\begin{tabular}{|c|c|c|c|}
\hline Doppler venoso & $\begin{array}{c}\text { Coeficiente de } \\
\text { Spearman } \\
\text { (rho) }\end{array}$ & $\mathbf{P}$ & $\begin{array}{c}\text { Intervalo de } \\
\text { confiança de } 95 \% \\
\text { para o rho }\end{array}$ \\
\hline IPV do DV (escore-zeta) & $-0,377$ & 0,004 & $-0,579$ a $-0,131$ \\
\hline TAMxV da VU (escore-zeta) & 0,078 & 0,562 & $-0,184$ a 0,329 \\
\hline $\begin{array}{l}\text { Fluxo/peso na VU } \\
(\mathrm{mL} / \mathrm{min} / \mathrm{kg})\end{array}$ & 0,261 & 0,048 & 0,003 a 0,487 \\
\hline $\begin{array}{l}\text { TAMxV da VPE (escore- } \\
\text { zeta) }\end{array}$ & 0,392 & 0,002 & 0,149 a 0,591 \\
\hline $\begin{array}{l}\text { Fluxo/Kg na VPE } \\
(\mathrm{mL} / \mathrm{min} / \mathrm{kg})\end{array}$ & 0,274 & 0,037 & 0,0172 a 0,497 \\
\hline
\end{tabular}

No Gráfico 1 verifica-se a correlação significativa negativa que foi observada entre o $\mathrm{pH}$ no nascimento e o escore-zeta do IPV do DV (R=$0,38, P=0,004)$.

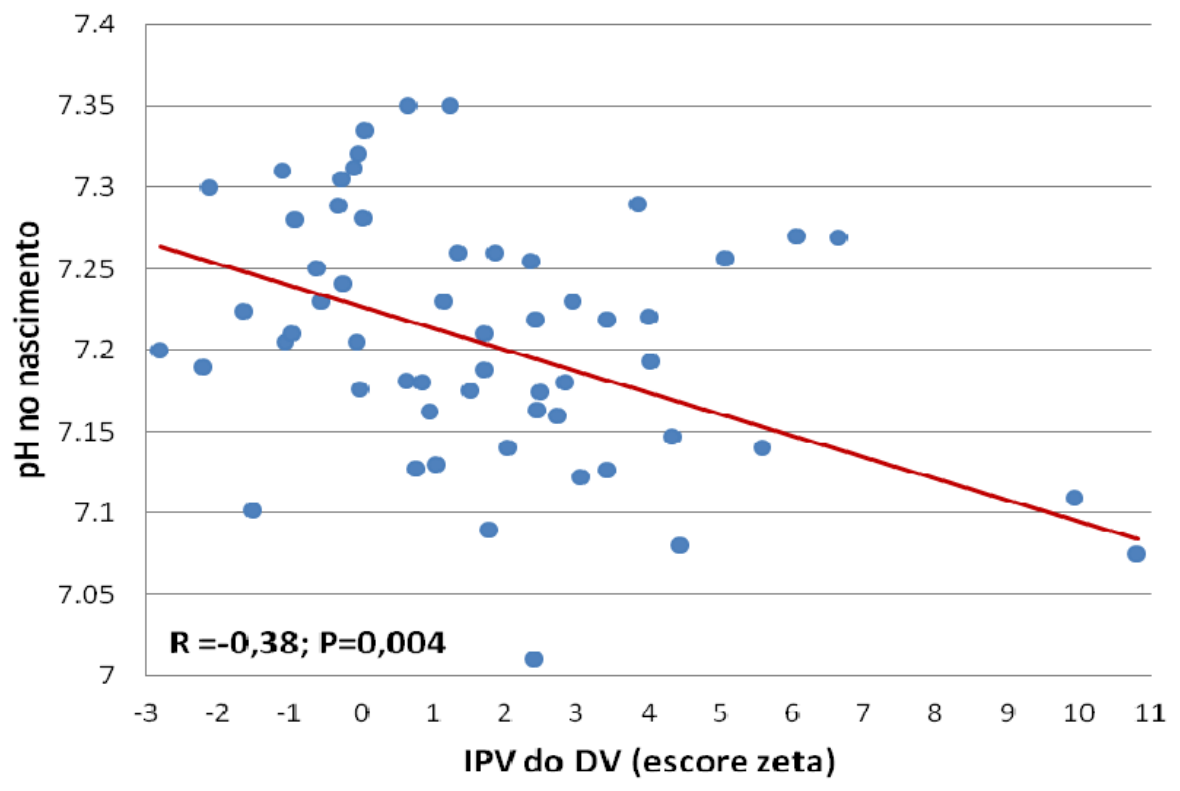

Gráfico 1: Correlação entre os valores do $\mathrm{pH}$ no nascimento e o escore-zeta do índice de pulsatilidade para veias do ducto venoso HCFMUSP 2010/2011 
Verificou-se correlação positiva significativa entre o pH no nascimento e o escore-zeta da TAMxV da VPE $(R=0,39, P=0,002)$, demonstrada no Gráfico 2.

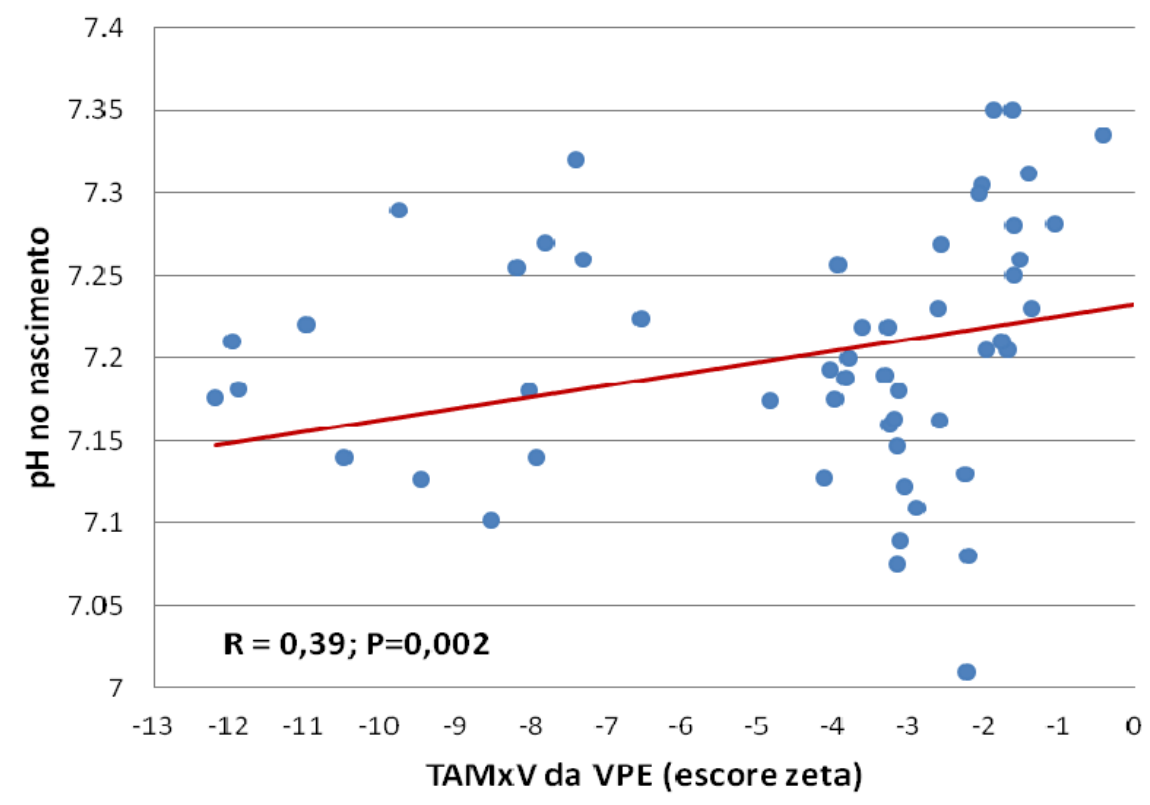

Gráfico 2: Correlação entre os valores do $\mathrm{pH}$ no nascimento e o escore-zeta da TAMxV da veia portal esquerda - HCFMUSP 2010/2011

No Gráfico 3 verifica-se a correlação significativa positiva que foi observada entre $\circ \mathrm{pH}$ no nascimento e $\circ$ Fluxo/peso na VPE $(R=0,27$, $\mathrm{P}=0,037)$. 


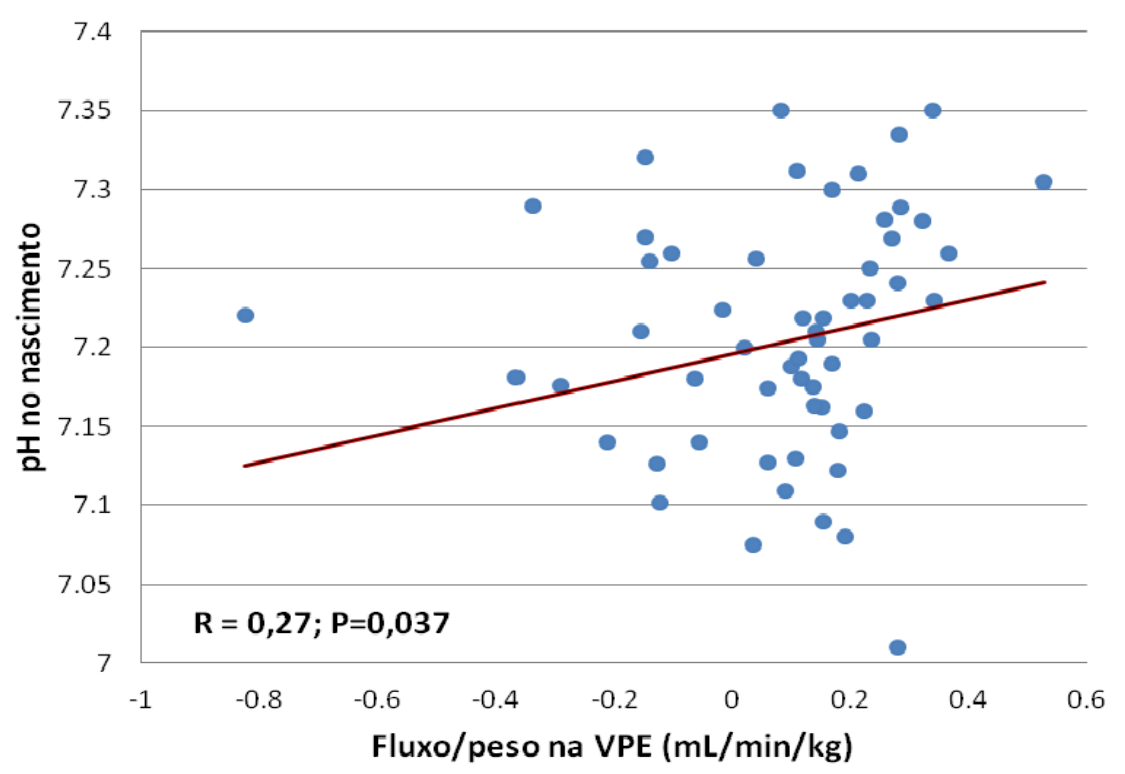

Gráfico 3: Correlação entre os valores do pH no nascimento e o Fluxo/peso na VPE - HCFMUSP 2010/2011

Verificou-se correlação positiva significativa entre o pH no nascimento e o Fluxo/peso na VU ( $R=0,26, P=0,048)$, demonstrada no Gráfico 4.

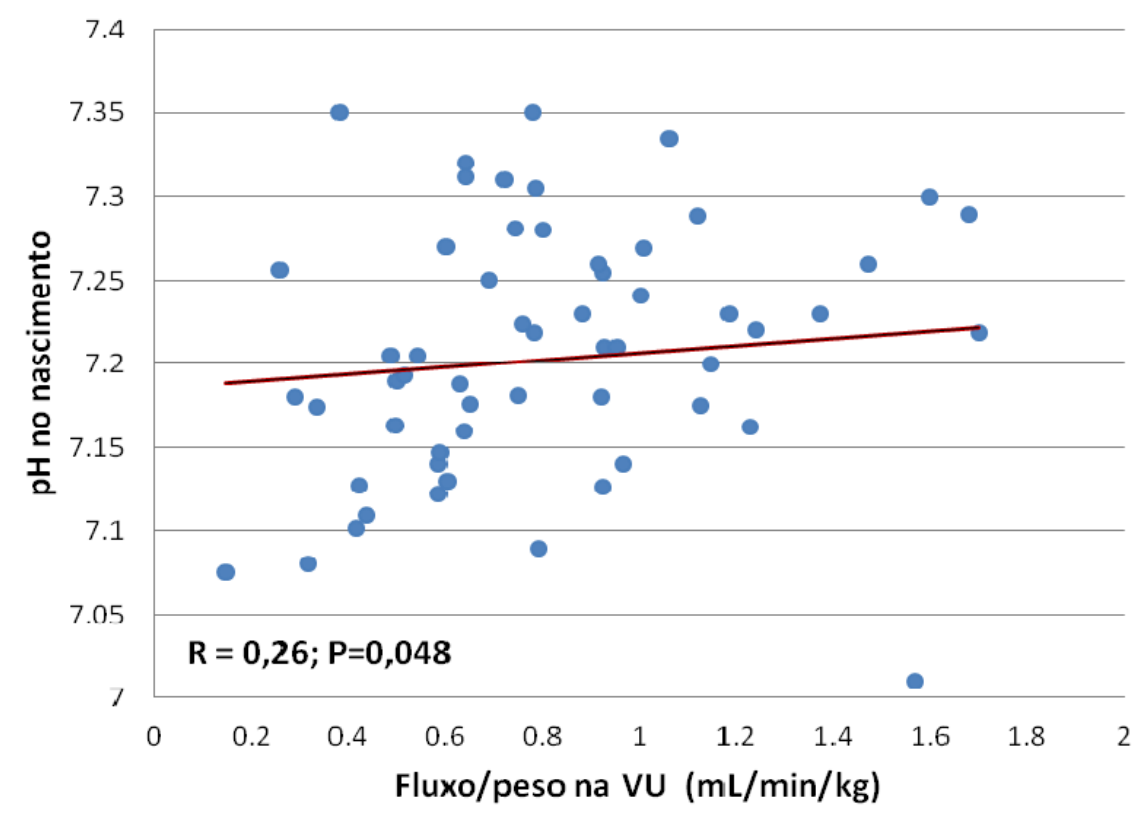

Gráfico 4: Correlação entre os valores do pH no nascimento e o Fluxo/peso na VU - HCFMUSP 2010/2011 


\subsection{Análise multivariada}

As variáveis dopplervelocimétricas foram estudadas para a predição da acidemia no nascimento por meio do modelo de regressão logística. As seguintes variáveis foram incluídas no modelo: RCP (escore-zeta); IPV do DV (escore-zeta), TAMxV da VPE (escore-zeta), classificação da VPE (normal, anormal positivo e reverso) e TAMxV da VU (escore-zeta). Realizando-se a análise, as variáveis independentes que restaram no modelo final foram: TAMxV da VPE (escore-zeta) e fluxo reverso na VPE (Tabela 11). Com o presente modelo, constatou-se que $74,14 \%$ dos casos são corretamente classificados para acidemia no nascimento.

Tabela 10: Variáveis independentes identificadas no modelo de regressão logística múltipla com eliminação retrógrada de fatores associados com a acidemia - HCFMUSP 2010/2011

\begin{tabular}{lccccc}
\hline Variável & OR & IC 95\% & Coeficiente & $\begin{array}{c}\text { Erro } \\
\text { Padrão }\end{array}$ & P \\
\hline $\begin{array}{l}\text { VPE com } \\
\text { fluxo reverso }\end{array}$ & 0,004 & 0,0001 a 0,1543 & $-5,508$ & 1,857 & 0,003 \\
$\begin{array}{l}\text { Escore-zeta } \\
\text { da TAMxV da }\end{array}$ & 0,417 & 0,2453 a 0,7094 & $-0,874$ & 0,271 & 0,001 \\
$\begin{array}{l}\text { VPE } \\
\text { Constante }\end{array}$ & - & - & $-2,452$ & - & -
\end{tabular}

VPE: veia portal esquerda, OR: Odds Ratio; IC: intervalo de confiança

TAMxV: "time-averaged maximum velocity"

\subsection{Dados do parto}

A comparação dos grupos quanto aos dados do parto está apresentada na Tabela 12. A IG na ocasião do parto variou de 26 a 36 
semanas e a média do grupo com acidemia foi significativamente menor.

Todos os partos de ambos grupos foram realizados pela operação cesariana.

Não houve diferença significativa na média do peso do RN na comparação entre os grupos. Também não se observou diferença significativa na proporção de casos com índices de Apgar de $1^{\circ}$ e $5^{\circ}$ minutos inferiores a sete (Tabela 11).

Tabela 11: Dados do parto, resultados perinatais e $\mathrm{pH}$ no nascimento nos grupos analisados - HCFMUSP 2010/2011

\begin{tabular}{|c|c|c|c|c|c|}
\hline & & $\begin{array}{c}\text { Grupo I } \\
\text { pH<7,2 } \\
(n=26)\end{array}$ & & 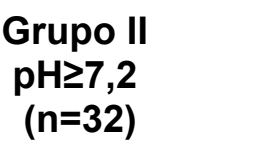 & $\mathbf{P}$ \\
\hline $\begin{array}{l}\text { IG no parto } \\
\text { (semanas) }\end{array}$ & 30,2 & $(2,6)$ & 32,1 & $(3,2)$ & $0,019^{*}$ \\
\hline Peso do RN (g) & 972 & (299) & 1145 & $(473)$ & $0,096^{*}$ \\
\hline Apgar de $1^{\circ} \min <7$ & 13 & $(50)$ & 12 & $(37,5)$ & $0,491^{* *}$ \\
\hline Apgar de $5^{\circ} \min <7$ & 3 & $(11,5)$ & 3 & $(9,4)$ & $>0,99^{* *}$ \\
\hline $\mathrm{pH}$ no nascimento & 7,14 & $(6,85$ a 7,19$)$ & 7,26 & $(7,20$ a 7,35$)$ & $<0,001^{* * *}$ \\
\hline
\end{tabular}


Discussão 
O conhecimento dos mecanismos fisiopatológicos do feto em face da hipoxia serve para subsidiar a propedêutica fetal, objetivando dimensionar a intensidade do comprometimento do concepto. O uso do Doppler no estudo da circulação feto-placentária e dos compartimentos arterial e venoso da circulação fetal possibilita o reconhecimento dos sinais fetais de asfixia crônica e aguda, permitindo o planejamento das condutas apropriadas durante o seguimento da gestação, principalmente daquelas que cursam com a insuficiência ou disfunção placentária.

A necessidade de avaliação minuciosa da vitalidade fetal no seguimento das gestações de alto risco estimulou a efetivação do presente trabalho, com a intenção de trazer novos subsídios na avaliação do perfil hemodinâmico fetal nestes casos.

Numerosos trabalhos, com uso da dopplervelocimetria, evidenciam os sinais de sofrimento fetal antes das alterações da cardiotocografia e tentam demonstrar as vantagens da interrupção da gestação antes do surgimento destas alterações. O Setor de Avaliação da Vitalidade Fetal da Clínica Obstétrica do HCFMUSP incorporou o Doppler venoso como método essencial na avaliação fetal, juntamente com cardiotocografia e o perfil biofísico fetal no seguimento da gestação de alto risco. 
A descompensação hemodinâmica fetal é clinicamente reconhecida pelo padrão anormal da dopplervelocimetria do território venoso. Com a redução no débito cardíaco, a pressão venosa central se eleva, causando, durante a sístole atrial, aumento do fluxo reverso na veia cava inferior ( $\mathrm{VCI})$ e fluxo zero ou reverso no ducto venoso (DV). A progressão dos padrões de fluxos anormais nas veias precordiais reflete, presumivelmente, estágios progressivos da disfunção miocárdica e sua correlação com a gravidade da acidemia (126). A transição entre a adaptação e a descompensação, devido à hipoxemia, é difícil de ser identificada acuradamente. Não existe, na atualidade, intervenção terapêutica efetiva capaz de reverter o curso progressivo da insuficiência placentária, exceto a ultimação da gestação.

Otimizar a assistência e decidir o momento da intervenção é complexo, pois requer a comparação dos riscos da prematuridade contra aqueles da permanência intrauterina: morte e lesão de múltiplos órgãos devido à inadequada perfusão tecidual. Uma conduta razoável é permitir a manutenção da gestação até o ponto anterior à lesão fetal, portanto minimizando tanto os riscos da prematuridade como os da própria lesão orgânica. A questão clínica é saber que ponto seria esse e como o seguimento poderia ser realizado.

Em nosso estudo, tentamos delinear este ponto com o critério de acidemia ao nascimento $(\mathrm{pH}<7,20)$. A análise do sangue do cordão umbilical é considerada o padrão-ouro na avaliação da condição bioquímica fetal/neonatal. A aferição dos parâmetros ácido-básicos no cordão umbilical no nascimento mostrou ser um indicador mais preciso de asfixia intraparto do 
que os escores de Apgar, sendo que essa análise deveria ser rotineira no cuidado obstétrico (127)

O limite inferior da normalidade para o $\mathrm{pH}$, abaixo do qual se considera acidemia ao nascimento, não foi definido com precisão. Observa-se variação de 7,00 a 7,20 (128). O valor clássico do $\mathrm{pH}$ na $\mathrm{AU}<7,20$ foi considerado como alterado. O objetivo desta escolha foi 0 de selecionar mais precocemente todos os fetos com acidemia e não apenas aqueles com acidemia grave $(\mathrm{pH}<7,00)$, nos quais ocorre associação com sequelas neurológicas e, inclusive, morte neonatal.

Baixos valores de Apgar também relacionam-se com maior grau de acidose ao nascimento, verificada pela gasometria da artéria umbilical (129131). Porém, essa relação é evidente apenas quando considerados os valores de $\mathrm{pH}$ ao nascimento inferiores a 7,05 (132). Observe-se que nos casos deste estudo, a frequência de casos com $\mathrm{pH}$ ao nascimento inferior a 7,05 foi muito baixa. Por isso a diferença não significante do índice de Apgar entre os dois grupos.

O primeiro passo para a análise fetal para a decisão de interrupção da gestação nas gestações de alto risco foi a identificação dos casos com insuficiência placentária, ou seja, dos fetos de risco para resultados adversos. Para esse diagnóstico, foi usado o Doppler da $A U$, que reflete a resistência vascular placentária, fortemente correlacionada com a restrição do crescimento fetal e os efeitos multissistêmicos da deficiência de nutrientes e oxigênio. Por isso, é hoje considerado o melhor método para o diagnóstico de insuficiência placentária $(12,131)$. 
O exame da AU, com a identificação de IP anormais, de DZ ou DR já é reconhecido por vários estudos, que demonstram serem estes os casos mais graves, muitas vezes indicando por si só o parto imediato em IG>31 ou 32 semanas (133). Da mesma forma, nosso estudo mostrou relação estatisticamente significativa entre DZ/DR e IP da AU anormal com acidose no nascimento.

A progressão da anormalidade circulatória fetal é representada pelo fenômeno de centralização da circulação fetal. A vasodilatação da ACM é um marcador desta redistribuição circulatória adaptativa. Queda significativa na $\mathrm{pO}_{2}$ fetal está associada a centralização e diminuição do PI da ACM. Em pacientes com formas menos graves de restrição do crescimento fetal, o IP da ACM pode apontar para distúrbios de oxigenação, antes de anormalidades metabólicas como a acidemia fetal $(12,134)$. Alterações isoladas no fluxo sanguíneo cerebral fetal são considerados resposta hemodinâmica precoce, e por este motivo tivemos a falta de relação estatisticamente significante entre as alterações no IP da ACM e o escorezeta da RCP e a acidemia no nascimento.

Anormalidades do Doppler dos vasos cerebrais são, assim, característicos das fases iniciais da hipoxemia fetal. Já a deterioração dos fluxos venosos é uma descoberta posterior, mais comumente associada à acidemia fetal, associando-se com a deterioração do equilíbrio ácido-básico e resultados perinatais adversos (36). Desta forma, o Doppler venoso nos permite definir a gravidade dos resultados perinatais, pois relaciona-se com o grau do comprometimento circulatório do feto $(36,102)$. 
Já é bem conhecido que a fração de sangue é aumentada no DV (aumento do shunt) em casos de RCF como parte da adaptação circulatória à insuficiência placentária $(25,90,108)$. A dopplervelocimetria do DV já é prática consagrada no protocolo de assistência aos casos de insuficiência placentária na Clínica Obstétrica do HCFMUSP.

Essa redistribuição diagnosticada pelas alterações no Doppler do DV é crucial durante mudanças hemodinâmicas agudas na redução da oxigenação fetal.

Já é amplamente conhecido o papel do DV na hipoxia para assegurar o suprimento de oxigênio e glicose aos órgãos vitais. Supõe-se que um aumento no desvio em direção ao DV é importante para a sobrevivência fetal durante situações de stress. Assim, o aumento da pulsatilidade no DV já é um reconhecido marcador de acidose fetal, fato confirmado em nosso estudo, onde tanto a alteração no IPV do DV quanto ao escore-zeta deste índice se mostraram significantemente relacionados com a acidemia no nascimento (6). Progredindo na avaliação hemodinâmica venosa fetal, introduzimos então neste estudo a análise do Doppler da VPE e VU.

A VPE, representando a conexão entre o retorno venoso umbilical e o fluxo portal para o intestino e baço, é considerada um marcador de watershed da circulação fetal. Isto é, um divisor de águas, um local da circulação fetal que tem suas características modificadas de forma importante quando o comprometimento fetal se acentua. Neste sentido, o conhecimento dos padrões de fluxo neste vaso, frente ás alterações de oxigenação fetal, é de suma importância por ser útil para a compreensão das adaptações fetais. Os 
valores de referência das velocidades na VPE, na segunda metade da gestação, já foram estabelecidos por Kessler et al., em 2007 (92).

O aumento do shunt ao DV faz com que diminua o fluxo na VPE, reflexo direto desta redistribuição. Assim, o Doppler da VPE nos promove uma oportunidade de graduar os fenômenos adaptativos e o comprometimento hemodinâmico e metabólico fetal. Representa o potencial para uma melhor avaliação, e também a investigação mais detalhada abordando os mecanismos intrauterino com o assumido efeitos a longo prazo. A direção do fluxo na VPE reflete retorno venoso comprometido demandando um aumento compensatório de sangue vindo da veia portal principal para manutenção das pressões portal e umbilical. Como resultado tem-se a cessação do fluxo venoso umbilical para o braço da VPE, e, em estágio mais avançado de comprometimento, fluxo reverso que promove desvio do sangue esplâcnico para o DV. Nessa fase, caso a função cardíaca ainda permaneça adequada, espera-se que o fluxo reverso seja proeminente, mas, nas situações de descompensação cardíaca, novamente se terá a redução do fluxo nesse vaso, pelo próprio colapso circulatório fetal, com surgimento de pulsações acentuadas e repercussão das alterações no DV.

Neste estudo, a dopplervelocimetria da VPE se mostrou útil para indicar o início de grandes mudanças na circulação fetal antes da descompensação cardiovascular e disfunção cardíaca, ajudando na identificação dos fetos de risco para hipoxemia grave e acidemia. 
Todos os parâmetros contínuos do Doppler da VPE (TAMxV, escorezeta da TAMxV, fluxo e fluxo/kg) se mostraram relacionados com a acidose no nascimento.

Quanto à direção e classificação do fluxo sanguíneo na VPE, o fluxo reverso se mostrou significantemente relacionado à acidemia no nascimento. Normalmente, o fluxo sanguíneo na VPE segue em direção à veia portal principal durante a segunda metade da gravidez. Embora Kessler et al. tenham encontrado dois casos de fluxo reverso na VPE em 160 fetos, sem sinais de comprometimento fetal, para fins práticos, a inversão de fluxo no VPE tem sido considerado inexistente até pouco antes do nascimento (92). A principal preocupação quando o fluxo inverso ocorre no VPE pode ser o efeito deletério para lóbulo direito do fígado e de que a mistura de sangue pobremente oxigenado vindo do sistema portal ao DV, o que reduz o efeito benéfico do mecanismo compensatório de redistribuição. Diferenças locais do fluxo sanguíneo no fígado podem ter consequências para a expressão dos genes e, talvez, consequências metabólicas a longo prazo $(20,135)$.

A pulsatilidade não se mostrou capaz de prever a acidose no nascimento nos casos do presente estudo. Muitos estudos já demonstraram a pulsatilidade na VPE sendo um fenômeno normal em fetos do terceiro trimestre $(26,65)$. Nestes fetos, a causa da pulsatilidade na VPE são variadas, como: transmissão das ondas do DV, movimentos respiratórios fetais, entre outros.

Assim, ficou demonstrado que a apreciação das alterações do Doppler da VPE é exame útil na vigilância de gestações com insuficiência placentária. 
A limitação do presente estudo foi a falta de conhecimento sobre a avaliação longitudinal do doppler da VPE em fetos com acidemia. Além disso, é preciso investigar a relação de anormalidades do fluxo venoso e a magnitude de curto e longo prazo do comprometimento neonatal. A ocorrência de danos fetais significativas que podem predispor o organismo a doenças mais tarde na vida podem ser investigados por estudos prospectivos, que incluam o seguimento infantil.

Desde 1980 sabe-se da diminuição do flluxo na VU em fetos com RCF, e o uso do fluxo na VU tem aplicabilidade clínica desde então $(38,39)$. Fetos com RCF direcionam um reduzido volume sanguineo em direção à placenta, enquanto mantém um output cardíaco normal, implicando em aumento da recirculação de sangue pelo corpo fetal.

A redução da velocidade do sangue na VU é um fenômeno persistente por várias semanas, e não um evento tardio sugestivo de acidose. É importante para diagnóstico precoce de RCF, não para diagnóstico de acidose. Assim, em nosso estudo, a TAMxV na VU não se mostrou relacionado com a acidose no nascimento. A diminuição do fluxo na veia umbilical encontrada no grupo mais comprometido está em acordo com estudos anteriores $(38,50,136)$.

A pulsatilidade na VU fornece uma boa estimativa do grau de acidemia fetal. Na hipoxemia fetal, há estimulação da redistribuição do fluxo sanguíneo arterial para a manutenção da oxigenação normal do cérebro e do miocárdio fetais. Quando esse mecanismo compensatório falha, há insuficiência 
cardíaca fetal pela hipoxia, evidenciada pelo aumento da pulsatilidade na circulação venosa.

Pulsações da VU são consideradas o reflexo final do aumento da pressão venosa central observadas nos estágios finais de comprometimento fetal e, portanto, também mostram uma significativa relação com o status ácido-base fetal. No entanto, pulsações na VU podem ter várias causas, incluindo oligoidrâmnio, alterações da pós-carga placentária, alterações no diâmetro do DV e presença de movimentos respiratórios fetais.

Assim, devemos ter cautela ao avaliar a presença de pulsações na VU, combinando sempre esta avaliação com a análise de outros parâmetros do Doppler fetal.

Apesar desses resultados encorajadores, o fluxo sanguíneo na VU não alcançou resultados promissores em estudos mais antigos, principalmente devido a preocupações quanto à sua reprodutibilidade e pela inacurácia do método. Mais recentemente, pela moderna tecnologia nos aparelhos de ultrassonografia com Doppler, este exame tem sido cada vez apresentado bons resultados, como exemplo, Achayra et al., em 2005, mostraram excelente reprodutibilidade para o exame de Doppler da VU $(14,91)$.

Nosso estudo mostrou bons resultados de reprodutibilidade intra e interoperadores tanto para a análise da VPE quanto da VU. A estimativa de volume de fluxo sanguíneo por ultrassom tem fontes potenciais de erro principalmente relacionados com a medida do diâmetro. Repetir a medição mostrou para reduzir o erro aleatório e foi praticado por nosso estudo. 
A decisão de interrupção da gestação, na presença dos índices de VPE e VU alterados poderia ser aventada pela inegável associação com a acidemia encontrada nesse estudo. No entanto, esses resultados devem ser interpretados com cautela. Deve-se aguardar estudos com casuística maior, bem como compreensão do seu comportamento ao longo da gestação e pesquisas que verifiquem a possibilidade de sua associação com outros resultados perinatais adversos, além da acidemia. 


\section{Conclusões}


O presente estudo, que analisou o Doppler venoso fetal em gestações com insuficiência placentária, permitiu concluir que a acidemia no nascimento $(\mathrm{pH}<7,20)$ está associada de forma independente com o fluxo reverso na VPE e com o escore-zeta da TAMxV da VPE, ambos demonstrando efeito protetor com redução do risco para o evento. 
Anexos 
Anexo 1 - Aprovação do Comitê de Ética para Análise de Pesquisa (CAPPpesq) da Diretoria do Hospital das Clínicas da Faculdade de Medicina da Universidade de São Paulo

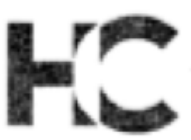

\section{APROVAÇÃO}

A Comissoo de Etica para Ancise de Projetos de Pesquisa . CAPPesa da Diretoria Clínica do Hosplat das Ciricas e da Foculdade de

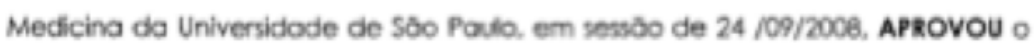
Protocolo de Pesquisa ne 0376/08, infliculodo: Fuxo sANGUíneo NA VEIA PORTAL ESQUERDA DA CIRCULAÇĀo FETAL NA INSUHCIENCIA PLACENTÁRIA apresentodo pelo Deportamento de OBsterkicia t Gintcotocia. inclusive o Termo de Consentimento Lime e Esclarecido.

Cabe oo pesquisodor eloborar a apresentor ò CAPPesq os relatbrios parcials e find sobre a pesquisa (Rescuço do Conseho Nocional de Sojide $n^{*} 196$, do 10/10/1996, incho 0.2 letro "c').

Pesquisador (a) Responsóvel: Rosell Mieko Yomomoto Nomura

Pesquisodor (o) Executanle: Verbênio Nunes Costo

CAPPesq. 25 de Setembro de 2008

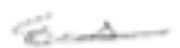

Prot. Dr. Eduardo Massad Presidente do Comissāo de thica para Andilise de Projetos de Pesquisa 


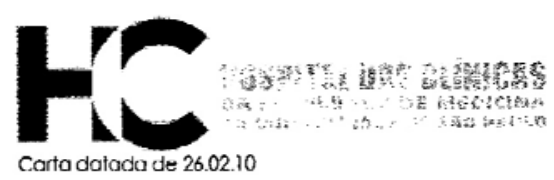

Ao

Departamento de Obstetrícia e Ginecologia

A Comissāo de Ética para Análise de Projetos de Pesquisa - CAPPesq da Diretoria Clínica do Hospital das Clínicas e da Faculdade de Medicina da Universidade de São Paulo, em sessão de 10/03/2010, tomou conhecimento da inclusão da Pesquisadora Executante Cristiane Ortigosa Rocha no Protocolo de Pesquisa $n^{\circ}$ 0376/08, intitulado: "FLUXO SANGÜÍNEO NA VEIA PORTAL ESQUERDA DA CIRCULAÇĀO FETAL NA INSUfICIÊNCIA PLACENTÁRIA", bem Como tomou ciência do Relatório.

Pesquisadora Resporısável: Dra. Roseli Mieko Yamamoto Nomura

Obs.: A Pesquisadora Verbenia Nunes Costa permanecerá como co-autora do estudo.

CAPPesq, 10 de Março de 2010.

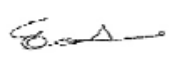

PROF. DR. EDUARDO MASSAD

Presidente da Comissão de Ética para Análise de Projetos de Pesquisa

\footnotetext{
Comissôn de Ética para Análise de Projetos de Pesquisa
Diretoria Clínica do Hospitel das Clínicas da Faculdade de Medicinn da Universidade de Sz̃o Paulo Clínica do Hospitol das Clínicas da Faculdade de Medicinn da Universidade de
Rua Ovídio Pres de Campos. 22.5. $5^{\circ}$ andar - CEP 05430 010 - São Paulo - SP

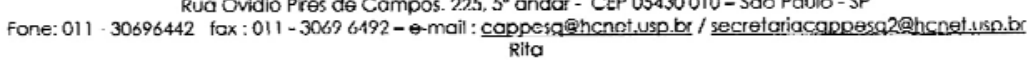


Anexo 2 - Termo de Consentimento Livre e Esclarecido

\author{
HOSPITAL DAS CLÍNICAS DA FACULDADE DE MEDICINA DA \\ UNIVERSIDADE DE SÃO PAULO-HCFMUSP
}

TERMO DE CONSENTIMENTO LIVRE E ESCLARECIDO

\title{
DADOS DE IDENTIFICAÇÃO DO SUJEITO DA PESQUISA OU RESPONSÁVEL LEGAL
}

1. NOME:

DOC. DE IDENTIDADE No :

DATA NASCIMENTO:

$. / \ldots \ldots . . . . . . .$.

SEXO : $\quad M \square F \square$

ENDEREÇO

APTO:

BAIRRO:

$\mathrm{N}^{\circ}$

CEP:

TELEFONE: DDD (........)

2.RESPONSÁVEL LEGAL:

NATUREZA (grau de parentesco, tutor, curador etc.)

DOC. DE IDENTIDADE No :

DATA NASCIMENTO:

................

SEXO : $\quad M \square \quad F \square$

ENDEREÇO

APTO:

BAIRRO:

$\mathrm{N}^{\circ}$

CEP:

TELEFONE: DDD $(\ldots \ldots \ldots)$

CIDADE.

\section{DADOS SOBRE A PESQUISA}

1. TÍTULO DO PROTOCOLO DE PESQUISA: FLUXO SANGUÍNEO NA VEIA PORTAL ESQUERDA DA CIRCULAÇÃO FETAL NA INSUFICIÊNCIA

PLACENTÁRIA

PESQUISADOR :ROSELI MIEKO YAMAMOTO NOMURA

CARGO/FUNÇÃO: MÉDICA.

INSCRIÇÃO CONSELHO REGIONAL N CRM-SP 59.590

UNIDADE DO HCFMUSP: DIVISÃO DE CLÍNICA OBSTÉTRICA

2. AVALIAÇÃO DO RISCO DA PESQUISA:

RISCO MÍNIMO X RISCO MÉDIO $\quad$ RISCO BAIXO $\quad$ RISCO MAIOR $\square$

3.DURAÇÃO DA PESQUISA : 2 ANOS

\section{INFORMAÇÕES SOBRE A PESQUISA}

1 - O objetivo deste estudo é avaliar o fluxo de sangue nas veias do fígado do feto, que pode estar alterado nos casos em que existem problemas no crescimento fetal, e estamos comparando com casos cujo feto tem crescimento normal;

2 - A avaliação da circulação do fígado fetal é feita pelo exame de Doppler, que é realizado durante o exame de ultrassonografia. Por este exame podemos avaliar a circulação do feto, e isso é rotineiramente realizado nos fetos com problemas de crescimento;

3 - No exame de Doppler obstétrico, é rotina a avaliação da circulação da placenta, pela análise do fluxo no cordão umbilical, bem como a avaliação da circulação cerebral do feto, para verificar se existe algum mecanismo de compensação na circulação. São todos exames 
feitos pela ultrassonografia;

4 - A realização desses exames pode demorar cerca de 20 minutos, e o Doppler das veias do fígado fetal irá acrescentar cerca de 10 minutos no tempo que geralmente se demora para fazer a avaliação habitual;

5 - Como benefício caso você concorde em participar, temos que anormalidades na circulação do fígado podem ser detectadas e isso poderá ensejar investigação mais detalhada após o nascimento;

6 - Como procedimentos alternativos, você pode optar em não participar da pesquisa, e faremos os exames que são necessários para o acompanhamento do seu caso;

7 - A qualquer momento você tem acesso garantido aos profissionais responsáveis pela pesquisa para esclarecimento de eventuais dúvidas. O principal investigador é o Dra Roseli Nomura, que pode ser encontrada na Clínica Obstétrica, $10^{\circ}$ andar do Instituto Central do Hospital das Clínicas, na Av Enéas de Carvalho Aguiar no 255, Telefone(s) 30696209, 99373001. Se você tiver alguma consideração ou dúvida sobre a ética da pesquisa, entre em contato com o Comitê de Ética em Pesquisa (CEP) - Rua Ovídio Pires de Campos, 225 - $5^{\circ}$ andar - tel: 3069-6442 ramais 16, 17, 18 ou 20, FAX: 3069-6442 ramal 26 - E-mail: cappesq@hcnet.usp.br

8 - Você pode revogar este consentimento a qualquer momento e deixar de participar do estudo, sem qualquer prejuízo ao tratamento que lhe é oferecido na Instituição;

09 - Todas as informações obtidas serão mantidas em sigilo, seu nome não será divulgado em nenhuma publicação, e os dados serão utilizados exclusivamente para os fins desta pesquisa;

10 - Você poderá se manter atualizado sobre os resultados parciais desta pesquisa, podendo questionar a qualquer momento sobre as informações obtidas;

11 - Não há despesas pessoais para o participante desta pesquisa, incluindo exames e consultas. Também não há compensação financeira relacionada à sua participação;

12 - Em caso de dano pessoal, diretamente causado pelos procedimentos propostos nesta pesquisa (nexo causal comprovado), você tem direito a tratamento médico na Instituição, bem como às indenizações estabelecidas pela legislação brasileira.

Acredito ter sido suficientemente informado a respeito das informações que li ou que foram lidas para mim, descrevendo o estudo "FLUXO SANGUÍNEO NA VEIA PORTAL

ESQUERDA DA CIRCULAÇÃO FETAL NA INSUFICIÊNCIA PLACENTÁRIA"

Eu discuti com o com os pesquisadores sobre a minha decisão em participar nesse estudo. Ficaram claros para mim quais são os propósitos do estudo, os procedimentos a serem realizados, seus desconfortos e riscos, as garantias de confidencialidade e de esclarecimentos permanentes. Ficou claro também que minha participação é isenta de despesas e que tenho garantia do acesso a tratamento hospitalar quando necessário. Concordo voluntariamente em participar deste estudo e poderei retirar o meu consentimento a qualquer momento, antes ou durante o mesmo, sem penalidades ou prejuízo ou perda de qualquer benefício que eu possa ter adquirido, ou no meu atendimento neste Serviço.

Assinatura do paciente/representante legal

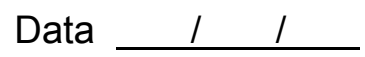

Assinatura da testemunha

Data /

para casos de pacientes menores de 18 anos, analfabetos, semi-analfabetos ou portadores de deficiência auditiva ou visual.

Declaro que obtive de forma apropriada e voluntária o Consentimento Livre e Esclarecido deste paciente ou representante legal para a participação neste estudo.

Assinatura do responsável pelo estudo Data 11 
Anexo 3: Gráfico - Reprodutibilidade (Análise Intraobservador):

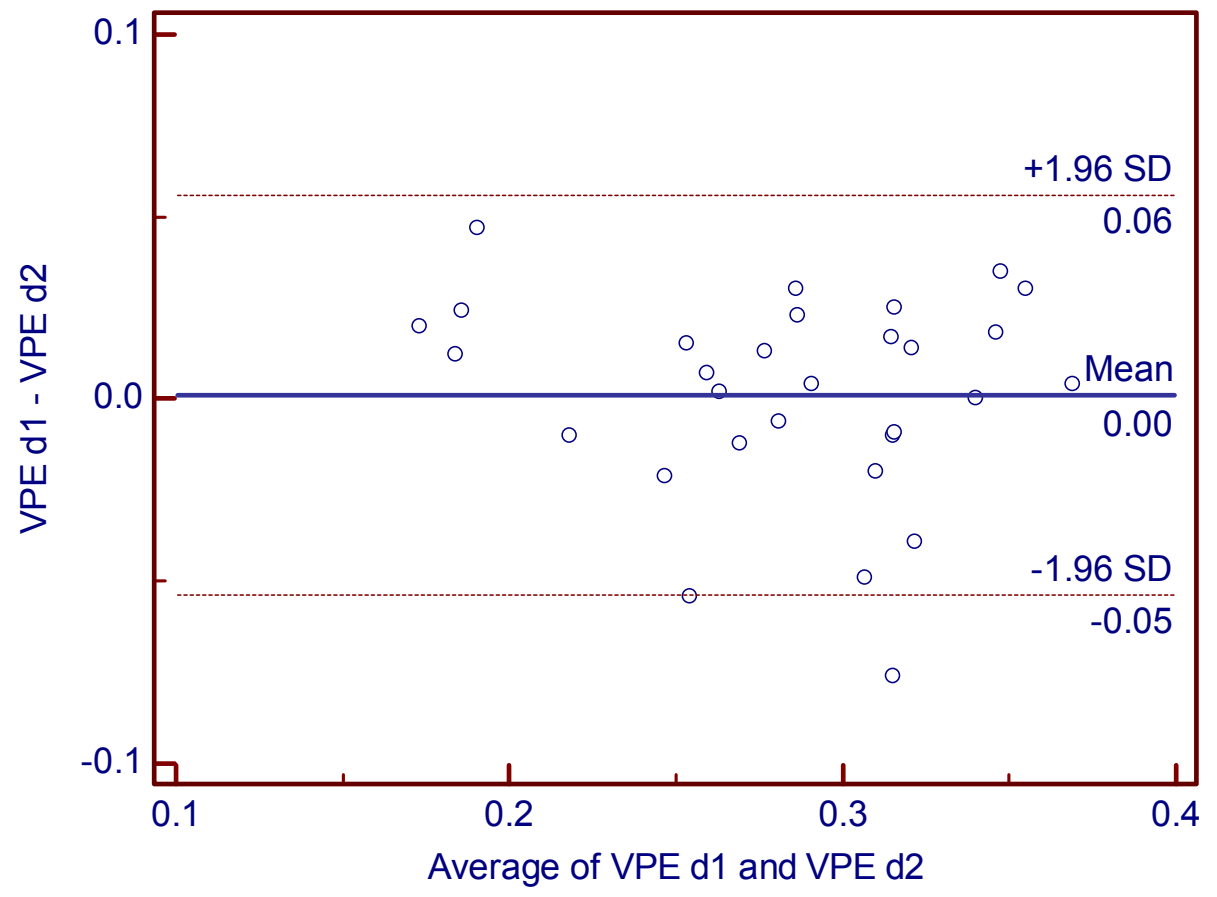


Anexo 4: Gráficos - Reprodutibilidade (Análise Interobservador):
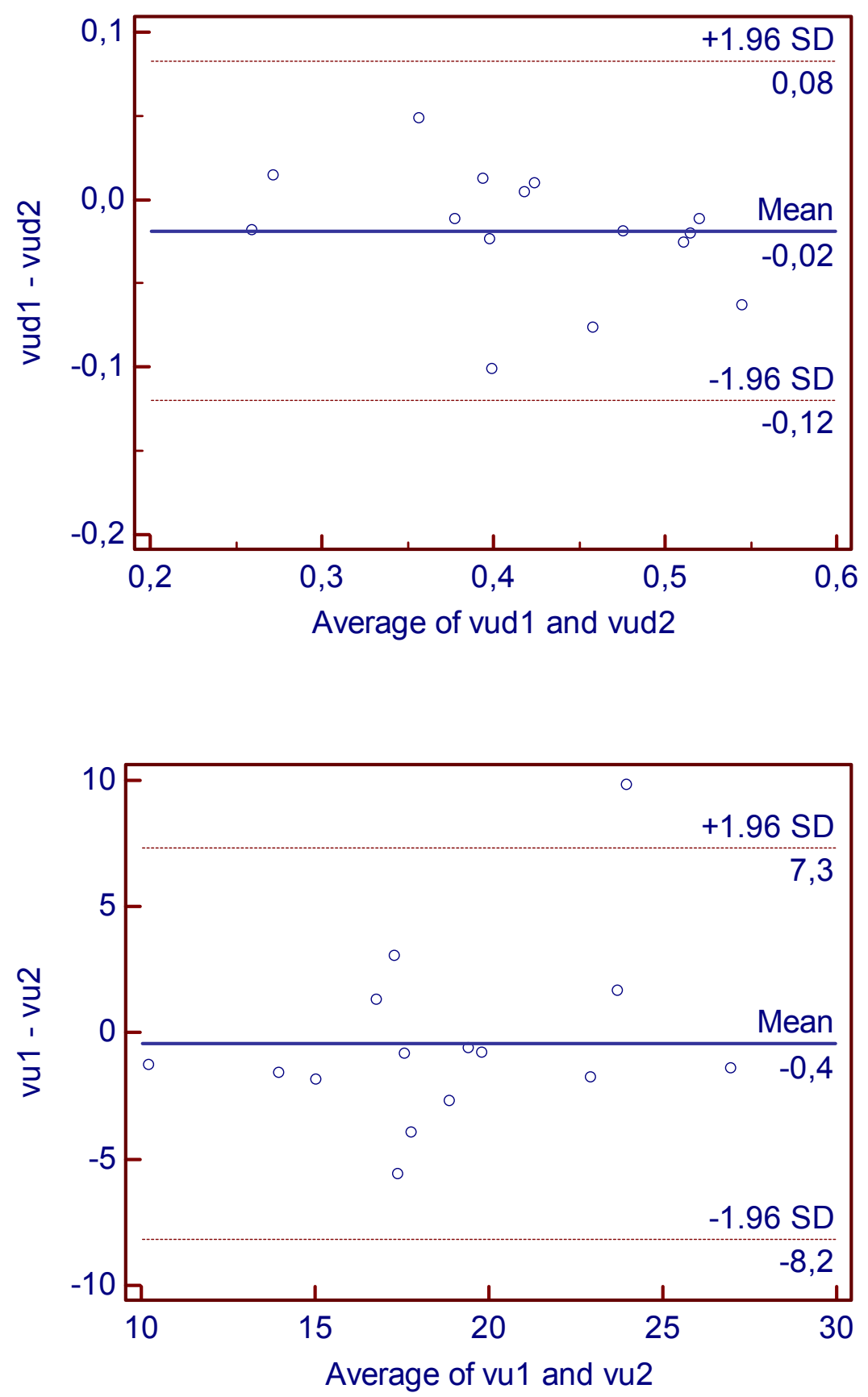

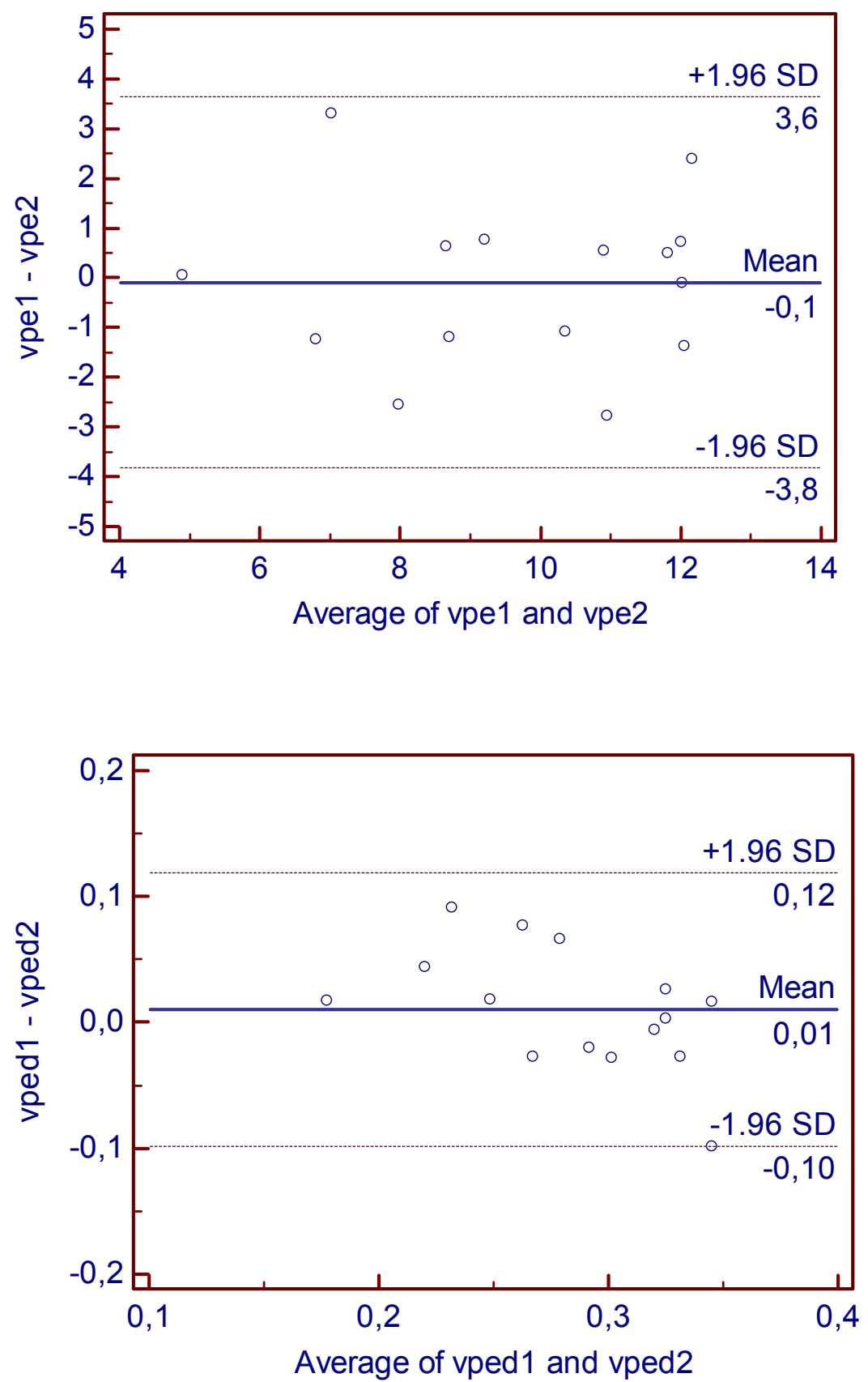
Referências Bibliográficas 
1. Bilardo CM, Nicolaides KH, Campbell S. Doppler measurements of fetal and uteroplacental circulations - Relationship with umbilical venous-blood gases measured at cordocentesis. Am J Obst Gynecol. 1990;162(1):115-20.

2. Karsdorp VHM, Vanvugt JMG, Vangeijn HP, Kostense PJ, Arduini D, Montenegro $\mathrm{N}$, et al. Clinical significance of absent or reversed end-diastolic velocity wave-forms in umbilical artery. Lancet. 1994;344(8938):1664-8.

3. Wladimiroff JW, Vonderwijngaard J, Degani S, Noordam MJ, Voneyck J, Tonge HM. Cerebral and umbilical arterial blood-flow velocity wave-forms in normal and growth-retarded pretnancies. Obstet Gynecol. 1987;69(5):705-9.

4. Tyrrell S, Obaid AH, Lilford RJ. Umbilical artery doppler velocimetry as a predictor of fetal hypoxia and acidosis at birth. Obstet Gynecol. 1989;74(3):3327.

5. Andrade J, Miyadahira S, Yamamoto R, Francisco R, Zugaib M. Estudo da hemodinâmica feto-placentária em gestações de alto risco e o resultado do pH do cordão umbilical ao nascimento. Rev Br Ginecol Obstet. 1997;19: 51.

6. Baschat AA, Guclu S, Kush ML, Gembruch U, Weiner CP, Harman CR. Venous Doppler in the prediction of acid-base status of growth-restricted fetuses with elevated placental blood flow resistance. Am J Obstet Gynecol. 2004;191(1):277-84.

7. Kessler J, Rasmussen S, Kiserud T. The fetal portal vein: normal blood flow development during the second half of human pregnancy. Ultrasound Obstet Gynecol. 2007;30(1):52-60.

8. Baschat AA, Gembruch U, Reiss I, Gortner L, Weiner CP, Harman CR. Relationship between arterial and venous Doppler and perinatal outcome in fetal growth restriction. Ultrasound Obstet Gynecol. 2000;16(5):407-13.

9. Di Naro E, Raio L, Ghezzi F, Franchi M, Romano F, D'Addario V. Longitudinal umbilical vein blood flow changes in normal and growth-retarded fetuses. Acta Obstet Gynecol Scand. 2002;81(6):527-33.

10. Carvalho FHC, Moron AF, Mattar R, Murta CGV, Santana RM, Barbosa MM, et al. Venous-arterial Doppler ratios in the prediction of acidemia at birth in pregnancies with placental insufficiency. Fetal Diagn Ther. 2006;21(5):418-23.

11. Baschat AA. Ductus Venosus Doppler for Fetal Surveillance in High-risk Pregnancies. Clin Obstet Gynecol. 2010;53(4):858-68.

12. Turan OM, Turan S, Gungor S, Berg C, Moyano D, Gembruch U, et al. Progression of Doppler abnormalities in intrauterine growth restriction. Ultrasound Obstet Gynecol. 2008;32(2):160-7.

13. Baschat AA. Venous Doppler Evaluation of the Growth-Restricted Fetus. Clinics Perinatol. 2011;38(1):103-+. 
14. Haugen G, Kiserud T, Godfrey K, Crozier S, Hanson M. Portal and umbilical venous blood supply to the liver in the human fetus near term. Ultrasound Obstet Gynecol. 2004;24(6):599-605.

15. Chinn DH, Filly RA, Callen PW. Ultrasonic evaluation of fetal umbilical and hepatic vascular anatomy. Radiology. 1982;144(1):153-7.

16. Edelstone DI, Rudolph AM, Heymann MA. Effects of hypoxemia and decreasing umbilical flow on liver and ductus venosus blood flows in fetal lambs. Am J Physiol. 1980;238(5):H656-H63.

17. Rudolph AM. Hepatic and ductus venosus blood flows during fetal life. Hepatology. 1983;3(2):254-8.

18. Schmidt KG, Silverman NH, Rudolph AM. Assessment of flow events at the ductus venosus inferior vena cava junction and at the foramen ovale in fetal sheep by use of multimodal ultrasound. Circulation. 1996;93(4):826-33.

19. Rudolph AM, Heymann MA. Circulation of fetus in utero - methods for studying distribution of blood flow cardiac output and organ blood flow. Circulation Res. 1967;21(2):163-\&.

20. Drew JH, Guaran RL, Grauer S, Hobbs JB. Cord whole-blood hyperviscosity - measurement, definition, incidence and clinical features. J Paediatr Child Health. 1991;27(6):363-5.

21. Jouppila P, Kirkinen P, Puukka R. Correlation between umbilical vein blood-flow and umbilical blood-viscosity in normal and complicated pregnancies. Arch Gynecol. 1986;237(4):191-7.

22. Morrow RJ, Adamson SL, Bull SB, Ritchie JWK. Acute hypoxemia does not affect the umbilical artery flow velocity wave-form in fetal sheep. Obstet Gynecol. 1990;75(4):590-3.

23. Devoe LD, Gardner P, Dear C, Faircloth D. The significance of increasing umbilical artery systolic-diastolic ratios in $3^{\text {rd }}$-trimester pretnancy. Obstet Gynecol. 1992;80(4):684-92.

24. Kiserud T, Ebbing C, Kessler J, Rasmussen S. Fetal cardiac output, distribution to the placenta and impact of placental compromise. Ultrasound Obstet Gynecol. 2006;28(2):126-36.

25. Kiserud T, Kessler J, Ebbing C, Rasmussen S. Ductus venosus shunting in growth-restricted fetuses and the effect of umbilical circulatory compromise. Ultrasound Obstet Gynecol. 2006;28(2):143-9.

26. Vansplunder IP, Huisman TWA, Stijnen T, Wladimiroff JW. Presence of pulsations and reproducibility of wave-form recording in the umbilical and left portal-vein in normal pregnancies. Ultrasound Obstet Gynecol. 1994;4(1):49-53.

27. Kilavuz O, Vetter $\mathrm{K}$, Kiserud $\mathrm{T}$, Vetter $\mathrm{P}$. The left portal vein is the watershed of the fetal venous system. J Perinat Med. 2003;31(2):184-7.

28. Boehm G, Muller DM, Teichmann B, Krumbiegel P. Influence of intrauterine growth-retardation on parameters of liver function in low-birthweight infants. Eur J Pediatr. 1990;149(6):396-8.

29. Jones JN, Gercel-Taylor C, Taylor DD. Altered cord serum lipid levels associated with small for gestational age infants. Obstet Gynecol. 1999;93(4):527-31.

30. Baserga MC, Sola A. Intrauterine Growth Restriction Impacts Tolerance to Total Parenteral Nutrition in Extremely Low Birth Weight Infants. J Perinatol. 2004;24:476-481. 
31. Zambrano E, El-Hennawy M, Ehrenkranz RA, Zelterman D, Reyes-Múgica M. Total parenteral nutrition induced liver pathology: an autopsy series of 24 newborn cases. Pediatr Dev Pathol. 2004; 7(5):425-32.

32. Reynolds S. Hemodynamic characteristics of the fetal circulation. Am J Obstet Gynecol1964. p. 69.

33. Kiserud T, Kilavuz O, Hellevik LR. Venous pulsation in the fetal left portal branch: the effect of pulse and flow direction. Ultrasound Obstet Gynecol. 2003;21(4):359-64.

34. Bristow J, Rudolph AM, Itskovitz J, Barnes R. Hepatic oxygen and glucose metabolism in the fetal lamb. J Clin Invest1982. p. 1047-61.

35. Kiserud T, Eiknes SH, Blaas HG, Hellevik LR. Foramen ovale - an ultrasonographic study of its relation to the inferior vena-cava, ductus venosus and hepatic veins. Ultrasound Obstet Gynecol. 1992;2(6):389-96.

36. Hecher K, Campbell S, Doyle P, Harrington K, Nicolaides K. Assessment of fetal compromise by Doppler ultrasound investigation of the fetal circulation arterial, intracardiac, and venous-blood flow velocity studies. Circulation. 1995;91(1):129-38.

37. Ozyuncu O, Saygan-Karamursel B, Armangil D, Onderoglu LS, Yigit S, Velipasaoglu $\mathrm{M}$, et al. Fetal arterial and venous Doppler in growth restricted fetuses for the prediction of perinatal complications. Turk J Pediatr. 2010;52(4):384-92.

38. Gill RW, Kossoff G, Warren PS, Garrett WJ. Umbilical venous flow in normal and complicated pregnancy. Ultrasound Med Biol. 1984;10(3):349-63.

39. Jouppila P, Kirkinen P. Umbilical vein blood-flow as an indicator of fetal hypoxia. Br J Obstet Gynaecol. 1984;91(2):107-10.

40. Kiserud T, Eiknes SH, Blaas HGK, Hellevik LR. Ultrasonographic velocimetry of the fetal ductus venosus. Lancet. 1991;338(8780):1412-4.

41. Edelstone DI, Rudolph AM. Preferential streaming of ductus venosus blood to the brain and heart in fetal lambs. Am J Physiol. 1979;237(6):H724-H9.

42. Hellevik LR, Kiserud T, Irgens F, Stergiopulos N, Hanson M. Mechanical properties of the fetal ductus venosus and umbilical vein. Heart and Vessels. 1998;13(4):175-80.

43. Kiserud T, Saito T, Ozaki T, Rasmussen S, Hanson MA. Validation of diameter measurements by ultrasound: intraobserver and interobserver variations assessed in vitro and in fetal sheep. Ultrasound Obstet Gynecol. 1999;13(1):52-7.

44. Chacko AW, Reynolds SRM. Embryonic development in the human of the sphincter of the ductus venosus. Anatom Record. 1953;115(2):151-73.

45. Paulick RP, Meyers RL, Rudolph CD, Rudolph AM. Umbilical and hepatic venous responses to circulating vasoconstrictive hormones in fetal lamb. Am J Physiol. 1991;260(4):H1205-H13.

46. Tchirikov M, Schroder HJ, Hecher K. Ductus venosus shunting in the fetal venous circulation: regulatory mechanisms, diagnostic methods and medical importance. Ultrasound Obstet Gynecol. 2006;27(4):452-61.

47. Kiserud T, Rasmussen S, Skulstad S. Blood flow and the degree of shunting through the ductus venosus in the human fetus. Am J Obstet Gynecol. 2000;182(1):147-53. 
48. Rudolph AM, Heymann MA, Teramo KAW, et al . Studies on the circulation on the previable human fetus. Pediatr Res1971; 5: 452-65.

49. Skulstad SM, Kiserud T, Rasmussen S. The effect of vascular constriction on umbilical venous pulsation. Ultrasound Obstet Gynecol. 2004;23(2):126-30.

50. Boito S, Struijk PC, Ursem NTC, Stijnen T, Wladimiroff JW. Umbilical venous volume flow in the normally developing and growth-restricted human fetus. Ultrasound Obstet Gynecol. 2002;19(4):344-9.

51. Rizzo G, Arduini D, Romanini C. Umbilical vein pulsations - a physiological finding in early gestation. Am J Obstet Gynecol. 1992;167(3):675-7.

52. Kiserud T, Hellevik LR, Eiknes SH, Angelsen BAJ, Blaas HG. Estimation of the pressure-gradient across the fetal ductus venosus based on doppler velocimetry. Ultrasound Med Biol. 1994;20(3):225-32.

53. Mavrides E, Moscoso G, Carvalho JS, Campbell S, Thilaganathan B. The anatomy of the umbilical, portal and hepatic venous systems in the human fetus at 14-19 weeks of gestation. Ultrasound Obstetr Gynecol. 2001;18(6):598-604.

54. Bellotti M, Pennati G, Pardi G, Fumero R. Dilatation of the ductus venosus in human fetuses: ultrasonographic evidence and mathematical modeling. Am J Physiol. 1998;275(5):H1759-H67.

55. Hecher K, Snijders R, Campbell S, Nicolaides K. Fetal venous, intracardiac, and arterial blood-flow measurements in intrauterine growth-retardation relationship with fetal blood-gases. Am J Obstet Gynecol. 1995;173(1):10-5.

56. Gill RW, Trudinger BJ, Garrett WJ, Kossoff G, Warren PS. Fetal umbilical venous flow measured in utero by pulsed doppler and b-mode ultrasound.1. Normal pregnancies. Am J Obstet Gynecol. 1981;139(6):720-5.

57. Bellotti M, Pennati G, De Gasperi C, Battaglia FC, Ferrazzi E. Role of ductus venosus in distribution of umbilical blood flow in human fetuses during second half of pregnancy. Am J Physiol. 2000;279(3):H1256-H63.

58. Behrman RE, Lees MH, Peterson EN, Delannoy CW, Seeds AE. Distribution of circulation in normal and asphyxiated fetal primate. Am J Obstet Gynecol. 1970;108(6):956-69.

59. Itskovitz J, Lagamma EF, Rudolph AM. Effects of cord compression on fetal blood-flow distribution and 02 delivery. Am J Physiol. 1987;252(1):H100-H9.

60. Meyers RL, Paulick RP, Rudolph CD, Rudolph AM. Cardiovascularfesponses to acute, severe hemorrhage in fetal sheep. J Develop Physiol. 1991;15(4):189-97.

61. Paulick RP, Meyers RL, Rudolph CD, Rudolph AM. Venous and hepatic vascular-responses to indomethacin and prostaglandin-E1 in the fetal lamb. Am J Obstet Gynecol. 1990;163(4):1357-63.

62. Bellotti M, Pennati G, De Casperi C, Rognoni G, Bozzo M, Zucca I, et al. Awave reduction is related to dilatation of ductus venosus in IUGR human fetuses. Am J Obstet Gynecol. 2001;185(6):663.

63. Collardeau-Frachon S, Scoazec JY. Vascular development and differentiation during human liver organogenesis. Anat Record-Adv Integr Anat Evolut Biol. 2008;291(6):614-27.

64. Edelstone DI, Rudolph AM, Heymann MA. Liver and ductus venosus blood flows in fetal lambs in utero. Circulation Res. 1978;42(3):426-33.

65. Mari G, Uerpairojkit B, Copel JA. Abdominal venous system in the normal fetus. Obstet Gynecol. 1995;86(5):729-33. 
66. Rizzo G, Arduini D, Romanini C. Inferior vena-cava flow velocity waveforms in appropriate-for-gestational-age and small-for-gestational-age fetus. Am J Obstet Gynecol. 1992;166(4):1271-80.

67. Reed KL, Appleton CP, Anderson CF, Shenker L, Sahn DJ. Doppler studies of vena-cava flows in human fetuses - insights into normal and abnormal cardiac physiology. Circulation. 1990;81(2):498-505.

68. Huisman TWA, Stewart PA, Wladimiroff JW, Stijnen T. Flow velocity waveforms in the dutus venosus, umbilical vein and inferior vena-cava in normal human fetuses at 12-15 weeks of gestation. Ultrasound Med Biol. 1993;19(6):441-5.

69. Huisman TWA, Stewart PA, Wladimiroff JW. Flow velocity wave-forms in the fetal inferior vena-cava during the $2^{\text {nd }}$-half of normal pregnancy. Ultrasound Med Biol. 1991;17(7):679-82.

70. Gudmundsson S, Huhta JC, Wood DC, Tulzer G, Cohen AW, Weiner S. Venous Doppler ultrasonography in the fetus with nonimmune hydrops. Am J Obstet Gynecol. 1991;164(1):33-7.

71. Okura I, Miyagi Y, Tada K, Masaoka H, Akamatsu N, Kudo T. The relationship between Doppler indices from inferior vena cava and hepatic veins in normal human fetuses. Acta Med Okayama. 2003;57(2):77-82.

72. Peeters LLH, Sheldon RE, Jones MD, Makowski EL, Meschia G. Blood-flow to fetal organs as a function of arterial oxygen content. Am J Obstet Gynecol. 1979;135(5):637-46.

73. Arbeille P, Maulik D, Fignon A, Stale H, Berson M, Bodard S, et al. Assessment of the fetal pot changes gy cerebral and umbilical doppler on lamb fetuses during acute hypoxia. Ultrasound Med Biol. 1995;21(7):861-70.

74. Vanhuisseling H, Muijsers G, Dehaan J, Hasaart THM. Fetal hypertension induced by norepinephrine infusion and umbilical artery flow velocity waveforms in fetal sheep. Am J Obstet Gynecol. 1991;165(2):450-5.

75. Tchirikov M, Kertschanska S, Sturenberg HJ, Schroder HJ. Liver blood perfusion as a possible instrument for fetal growth regulation. Placenta. 2002;23:S153-S8.

76. Tchirikov M, Kertschanska S, Schroder HJ. Obstruction of ductus venosus stimulates cell proliferation in organs of fetal sheep. Placenta. 2001;22(1):24-31.

77. Gill RW. Pulsed Doppler with B-mode imaging for quantitative blood flow measurement. Ultrasound Med Biol. 1979;5(3):223-35.

78. Barbera A, Galan HL, Ferrazzi E, Rigano S, Jozwik M, Battaglia FC, et al. Relationship of umbilical vein blood flow to growth parameters in the human fetus. Am J Obstet Gynecol. 1999;181(1):174-9.

79. Gerson AG, Wallace DM, Stiller RJ, Paul D, Weiner S, Bolognese RJ. Doppler evaluation of umbilical venous and afterial blood-flow in the $2^{\text {nd }}$ trimester and 3re trimester of normal pregnancy. Obstet Gynecol. 1987;70(4):622-6.

80. Sutton MS, Theard MA, Bhatia SJS, Plappert T, Saltzman DH, Doubilet P. Changes in placental blood-flow in the normal human fetus with gestational-age. Pediatr Res. 1990;28(4):383-7.

81. Lees C, Albaiges G, Deane C, Parra M, Nicolaides KH. Assessment of umbilical arterial and venous flow using color Doppler. Ultrasound Obstet Gynecol. 1999;14(4):250-5. 
82. Pennati G, Redaelli A, Bellotti M, Ferrazzi E. Computational analysis of the ductus venosus fluid dynamics based on Doppler measurements. Ultrasound Med Biol. 1996;22(8):1017-29.

83. Thompson RS, Trudinger BJ. Doppler wave-form pulsatility index and resistance, pressure and flow in the umbilical placental circulation - an investigation using a mathematical-model. Ultrasound Med Biol. 1990;16(5):449-58.

84. Costa A, Costantino ML, Fumero R. Oxygen-exchange mechanisms in the human placenta - mathematical-modeling and simulation. J Biomed Eng. 1992;14(5):385-9.

85. Guettouche A, Challier JC, Ito Y, Papapanayotou C, Cherruault Y, Azancotbenisty A. Mathematical-modeling of the human fetal arterial bloodcirculation. Int J Biomed Comput. 1992;31(2):127-39.

86. Huikeshoven F, Coleman TG, Jongsma HW. Mathematical-model of the cardiovascular system - the uncontrolled case. Am J Physiol. 1980;239(3):R317R25.

87. Pennati G, Bellotti M, Fumero R. Mathematical modelling of the human foetal cardiovascular system based on Doppler ultrasound data. Med Eng Physics. 1997;19(4):327-35.

88. Pennati G, Fumero R. Scaling approach to study the changes through the gestation of human fetal cardiac and circulatory behaviors. Ann Biomed Eng. 2000;28(4):442-52.

89. Pennati G, Corno C, Costantino ML, Bellotti M. Umbilical flow distribution to the liver and the ductus venosus in human fetuses during gestation: an anatomy-based mathematical modeling. Med Eng Physics. 2003;25(3):229-38.

90. Bellotti M, Pennati G, De Gasperi C, Bozzo M, Battaglia FC, Ferrazzi E. Simultaneous measurements of umbilical venous fetal hepatic, and ductus venosus,blood flow in growth-restricted human fetuses. Am J Obstet Gynecol. 2004;190(5):1347-58.

91. Acharya G, Wilsgaard T, Berntsen GKR, Maltau JM, Kiserud T. Reference ranges for umbilical vein blood flow in the second half of pregnancy based on longitudinal data. Prenat Diagn. 2005;25(2):99-111.

92. Kessler J, Rasmussen S, Kiserud T. The left portal vein as an indicator of watershed in the fetal circulation: development during the second half of pregnancy and a suggested method of evaluation. Ultrasound Obstet Gynecol. 2007;30(5):757-64.

93. Haugen G, Kiserud T, Godfrey K, Shore S, Hanson M. Distribution of umbilical and portal blood flow to the fetal liver at 36 weeks of the normal human pregnancy. Pediatr Res. 2003;53(6):14A-A.

94. Kiserud T. Hemodynamics of the ductus venosus. Eur J Obstet Gynecol Reprod Biol. 1999;84(2):139-47.

95. Kessler J, Rasmussen S, Kiserud T. The left portal vein as an indicator of watershed in the fetal circulation: development during the second half of pregnancy and a suggested method of evaluation. Ultrasound Obstet Gynecol. 2007;30:757-64.

96. Link G, Clark KE, Lang U. Umbilical blood flow during pregnancy: evidence for decreasing placental perfusion. Am J Obstet Gynecol. 2007;196(5)489 e1-7. 
97. Kessler J, Rasmussen S, Godfrey K, Hanson M, Kiserud T. Longitudinal study of umbilical and portal venous blood flow to the fetal liver: Low pregnancy weight gain is associated with preferential supply to the fetal left liver lobe. Pediatr Res. 2008;63(3):315-20.

98. Ferrazzi E. Measurement of venous blood flow in the human fetus: a dream comes true, but now for some standardization. Ultrasound Obstet Gynecol. 2001;18(1):1-4.

99. Rigano S, Bozzo M, Ferrazzi E, Bellotti M, Battaglia FC, Galan HL. Early and persistent reduction in umbilical vein blood flow in the growth-restricted fetus: A longitudinal study. Am J Obstet Gynecol. 2001;185(4):834-8.

100. Laurin J, Marsal K, Persson PH, Lingman G. Ultrasound measurement of fetal blood-flow in predicting fetal outcome. $\mathrm{Br} \mathrm{J}$ Obstet Gynaecol. 1987;94(10):940-8.

101. Ferrazzi E, Rigano S, Bozzo M, Bellotti M, Giovannini N, Galan H, et al. Umbilical vein blood flow in growth-restricted fetuses. Ultrasound Obstet Gynecol. 2000;16(5):432-8.

102. Hofstaetter C, Gudmundsson S, Hansmann M. Venous Doppler velocimetry in the surveillance of severely compromised fetuses. Ultrasound Obstet Gynecol. 2002;20(3):233-9.

103. Cloez JL, Schmidt KG, Birk E, Silverman NH. Determination of pulmonary to systemic blood-flow ratio in children by a simplified doppler echocardiographic method. J Am Coll Cardiol. 1988;11(4):825-30.

104. Valdescruz LM, Horowitz S, Mesel E, Sahn DJ, Fisher DC, Larson D. A pulsed doppler echocardiographic method for calculating pulmonary and systemic blood-flow in atrial level shunts - validation studies in animals and initial human experience. Circulation. 1984;69(1):80-6.

105. Meijboom EJ, Horowitz S, Valdescruz LM, Sahn DJ, Larson DF, Lima CO. A doppler echocardiographic method for calculating volume flow across the tricuspid valve - correlative laboratory and clinical studies. Circulation. 1985;71(3):551-6.

106. Lingman G, Marsal K. Fetal central blood-circulation in the $3^{\mathrm{RD}}$ trimester of normal pregnancy - a longifudinal study. 1. Aortic and umbilical blood-flow. Early Hum Develop. 1986;13(2):137-50.

107. Weissman A, Jakobi P, Bronshtein M, Goldstein I. Sonographic measurements of the umbilical-cord and vessels during normal pregnancies. J Ultrasound Med. 1994;13(1):11-4.

108. Kessler J, Rasmussen S, Godfrey K, Hanson M, Kiserud T. Fetal Growth Restriction Is Associated With Prioritization of Umbilical Blood Flow to the Left Hepatic Lobe at the Expense of the Right Lobe. Pediatr Res. 2009;66(1):113-7.

109. Tchirikov M, Strohner M, Forster D, Huneke B. A combination of umbilical artery PI and normalized blood flow volume in the umbilical vein: Venousarterial index for the prediction of fetal outcome. Eur J Obstet Gynecol Reprod Biol. 2009;142(2):129-33.

110. d'Ancona RL, Rahman F, Ozcan T, Copel JA, Mari G. The effect of intravascular blood transfusion on the flow velocity waveform of the portal venous system of the anemic fetus. Ultrasound Obstet Gynecol. 1997;10(5):3337. 
111. Gudmundsson S, Gunnarsson GO, Hokegard KH, Ingemarsson J, Kjellmer I. Venous Doppler velocimetry in relationship to central venous pressure and heart rate during hypoxia in the ovine fetus. J Perinat Med. 1999;27(2):81-90.

112. Hasaart THM, Dehaan J. Phasic blood-flow patterns in the commom umbilical vein of fetal sheep during umbilical-cord occlusion and the influence of autonomic nervous system blockade. J Perinat Med. 1986;14(1):19-26.

113. Reed KL, Chaffin DG, Anderson CF, Newman AT. Umbilical venous velocity pulsations are related to atrial contraction pressure waveforms in fetal lambs. Obstet Gynecol. 1997;89(6):953-6.

114. Reuss ML, Rudolph AM, Dae MW. Phasic blood-flow patterns in the superior and inferior venae cavae and umbilical vein of fetal sheep. Am J Obstet Gynecol. 1983;145(1):70-8.

115. Hellevik LR, Stergiopulos N, Kiserud T, Rabben SI, Eik-Nes SH, Irgens F. A mathematical model of umbilical venous pulsation. J Biomech. 2000;33(9):112330 .

116. Rasmussen K. Precision and accuracy of doppler flow measurements invitro and invivo study of the applicability of the method in human fetuses. Scand J Clin Labor Invest. 1987;47(4):311-8.

117. Figueras F, Fernandez S, Hernandez-Andrade E, Gratacos E. Umbilical venous blood flow measurement: accuracy and reproducibility. Ultrasound Obstet Gynecol. 2008;32(4):587-91.

118. Fernandez S, Figueras F, Gomez O, Martinez JM, Eixarch E, Comas M, et al. Intra- and interobserver reliability of umbilical vein blood flow. Prenat Diagn. 2008;28(11):999-1003.

119. Burns PN. Measuring volume flow with doppler ultrasound - an old nut. Ultrasound Obstet Gynecol. 1992;2(4):238-41.

120. Phelan JP, Smith CV, Broussard P, Small M. Amniotic fluid volume assessment with the 4-quadrant technique at 36-42 weeks gestation. J Reprod Med. 1987;32(7):540-2.

121. Arduini D, Rizzo G. Normal values of pulsatility index from fetal vessels - a cross sectional study on 1556 healthy fetuses. J Perinat Med. 1990;18(3):165-72.

122. Baschat AA, Gembruch U. The cerebroplacental Doppler ratio revisited. Ultrasound Obstet Gynecol. 2003;21(2):124-7.

123. Hecher K, Campbell S, Snijders R, Nicolaides K. Reference ranges for fetal venous and atrioventricular blood-flow parameters. Ultrasound Obstet Gynecol. 1994;4(5):381-90.

124. Hadlock FP, Harrist RB, Martinezpoyer J. Inutero analysis of fetal growth a sonographic weight standard. Radiology. 1991;181(1):129-33.

125. Baschat AA. Relationship between placental blood flow resistance and precordial venous Doppler indices. Ultrasound Obstet Gynecol. 2003;22(6):5616.

126. Ferrazzi E, Bozzo M, Rigano S, Bellotti M, Morabito A, Pardi G, et al. Temporal sequence of abnormal Doppler changes in the peripheral and central circulatory systems of the severely growth-restricted fetus. Ultrasound Obstet Gynecol. 2002;19(2):140-6.

127. Low JA, Lindsay BG, Derrick EJ. Threshold of metabolic acidosis associated with newborn complications. Am J Obstet Gynecol. 1997;177(6):1391-4. 
128. ACOG Committe Opinion no 348, november 2006: Umbilical cord blood gas and acid-base analysis.: Obstet Gynecol; 2006. p. 1319.

129. Socol ML, Garcia PM, Riter S. Depressed Apgar scores, acid-base status, and neurologic outcome. Am J Obstet Gynecol. 1994;170(4):991-9.

130. Victory R, Penava D, da Silva O, Natale R, Richardson B. Umbilical cord pH and base excess values in relation to neonatal morbidity for infants delivered preterm. Am J Obstet Gynecol. 2003;189(3):803-7.

131. Francisco RPV, Miyadahira S, Zugaib M. Predicting $\mathrm{pH}$ at birth in absent or reversed end-diastolic velocity in the umbilical arteries. Obstet Gynecol. 2006;107(5):1042-8.

132. Ingemarsson I, Herbst A, ThorngrenJerneck K. Long term outcome after umbilical artery acidaemia at term birth: influence of gender and duration of fetal heart rate abnormalities. Br J Obstet Gynaecol. 1997;104(10):1123-7.

133. Marsal K. Obstetric management of intrauterine growth restriction. Best Prac Res Clin Obstet Gynaecol. 2009;23(6):857-70.

134. Andrade J, Miyadahira S, Yamamoto R, Francisco R, Zugaib M. Dopplervelocimetria dos Compartimentos Arterial e Venoso da Circulação Fetal e Umbilical emGestação de Alto-Risco. Análise dos Resultados Perinatais. Rev Br Ginecol Obstet 2002. p. 153-60.

135. Weiner CP, Williamson RA. Evaluation of severe growth-retardation using cordocentesis - hematologic and metabolic alterations by etiology. Obstet Gynecol. 1989;73(2):225-9.

136. Ebbing C, Rasmussen S, Godfrey KM, Hanson MA, Kiserud T. Redistribution pattern of fetal liver circulation in intrauterine growth restriction. Acta Obstet Gynecol Scand. 2009;88(10):1118-23. 